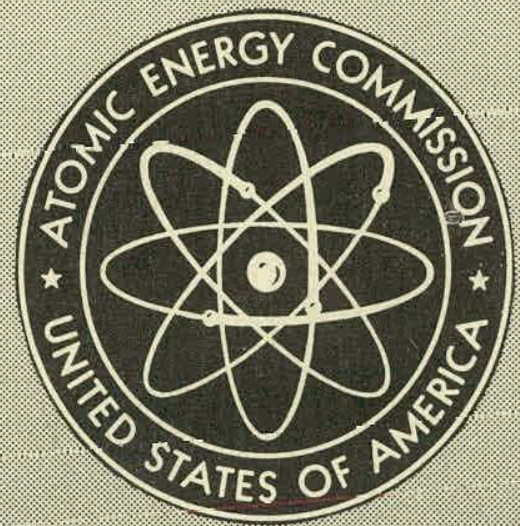

UCD-34-P-80-5

RADIATION TECHNOLOGY IN CONJUNCTION WITH POSTHARVEST PROCEDURES AS A MEANS OF EXTENDING THE SHELF LIFE OF FRUITS AND VEGETABLES

Period Covered: February 1, 1966 - January 30, 1967

By
E. C. Maxie
N. F. Sommer
D. S. Brown

April 1968

[DTIE Issuance Date]

Department of Pomology University of California

Davis, California 


\section{DISCLAIMER}

This report was prepared as an account of work sponsored by an agency of the United States Government. Neither the United States Government nor any agency Thereof, nor any of their employees, makes any warranty, express or implied, or assumes any legal liability or responsibility for the accuracy, completeness, or usefulness of any information, apparatus, product, or process disclosed, or represents that its use would not infringe privately owned rights. Reference herein to any specific commercial product, process, or service by trade name, trademark, manufacturer, or otherwise does not necessarily constitute or imply its endorsement, recommendation, or favoring by the United States Government or any agency thereof. The views and opinions of authors expressed herein do not necessarily state or reflect those of the United States Government or any agency thereof. 


\section{DISCLAIMER}

Portions of this document may be illegible in electronic image products. Images are produced from the best available original document. 


\section{LEGAL NOTICE}

This report was prepared as an account of Government sponsored work. Neither the Untted States, nor the Commission, nor any person acting on behalf of the Commisaion:

A. Makes any warranty or representation, expressed or implied, with respect to the accuracy, completeness, or usefulness of the information contained in this report, or that the use of any information, apparatus, method, or process disclosed in this report may not infringe privately owned rights; or

B. Assumes any liabilities with respect to the use of, or for damages resulting from the use of any information, apparatus, method, or process disclosed in thls report.

As used in the above. "person acting on behalf of the Commission" Includes any employee or contractor of the Commission, or employee of such contractor, to the extent that such employee or contractor of the Commission, or employee of such contractor prepares. disseminates, or provides access to, any information pursuant to hls employment or contract with the Commission, or his employment with such contractor.

This report has been reproduced directly from the best available copy.

Printed in USA. Price $\$ 3.00$. Available from the Clearinghouse for Federal Scientific and Technical Information, National Bureau of Standards, U. S. Department of Commerce, Springfield, Virginia 22151. 


\title{
RADIATION TECHNOLOGY IN CONJUNCTION WITH POSTHARVEST PROCEDURES AS A MEANS OF EXTENDING THE SHELF LIFE OF FRUITS AND VEGETABLES
}

Prepared By

E. C. Maxie, N. F. Sommer, and D. S. Brown

$$
\begin{aligned}
& \text { For } \\
& \text { Division of Isotopes Development } \\
& \text { U.S. Atomic Energy Commission }
\end{aligned}
$$

\author{
Contract No. AT(11-1)-34 \\ Project Agreement No. 80 \\ (California Agricultural Experiment \\ Station Project No. 639) \\ February 1, 1966 - January 30, 1967 \\ Department of Pomology, University of \\ California, Davis, California
}




\section{CONTENTS}

Pages

Summary ...... . . . . . . . . . . . . .

Effert Uf Mechanical Injury And Gamma Irradiation On Ripening of Banana Fruits . . . . . . . . . . .

Introduction ................... 1

Materials and Methods ............. 3

Results ..................... . . . . . . . . 5

Discussion .................. 20

Summary . . . . . . . . . . . ....

Literature cited ............... 24

Effect of Gamma Irradiation On Ascorbic-Acid Content of Strawberry Fruits .................. 30

I. Experiment No. I ............. 30

Air Test Shipment of Irradiated Strawberries . . . . . 34

Kesults ..................... . . . . 36

Discussion and Conclusions . . . . . . . . . 39

Effect of Heat And Irradiation Alone And In Combination On Color Changes In Peaches And Nectarines . . . . .

1. Gardner Colorimeter Readings on the Flesh of Peaches and Nectarines Treated to 0 and 100 Krad . . . . . . . . . . . . . . . . .

II. Skin Color Readings on One Variety of Peaches Heat and Irradiation Treated . . . . . . :

Summary . . . . . . . . . . . . . .

Cffect of Gamma Radiation On Mushrooms . . . . . . 56

1. Growth Measurements . . . . . . . . . 56

Il. Sensory livaluation . . . . . . . ... . 59

1II. Iiffect of Irradiation on the Ascorbic-Acid Content of Mushrooms . . . . . . . . . . 
Effect of Gamma Irradiation On Postharvest Behavior of

The Cantaloupe .................. . . . 65

Abstract .................. . . 65

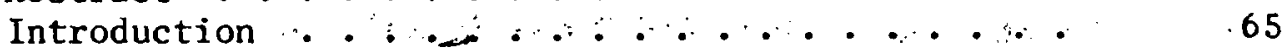

Materials and Methods .......................... 66

Results .................. . . . . . 71

Conclusions . . . . . . . . . . . . 89

Sumnary . . . . . . . . . . . ...... . 89

Literature Cited . . . . . . . . . . . 91

Effects of Gamma Irradiation On Postharvest Behavior of

Honeydew Melons . . . . . . . . . . . . . 92

Abstract .................... . . . . . 92

Introduction ................. 92

Materials and Methods . . . . . . . . . . . 92

Results..................... 96

Discussion and Conclusions . . . . . . . . . 98

Summary . . . . . . . . : . . . . . . 103

Effect of Gamma Irradiation On The Susceptibility of

Tomato Fruits To Transit Injury . . . . . . . . . . .. 104

Abstract ................... . . . . 104

Introduction ................. . . 104

Materials and Methods............... 105

Results.................... 111

Discussion and Conclusions . . . . . . . . . 121

Summary ................... . . . . . . 122

Ljterature Cited . . . . . . . . . . . . . . 129

The Mobile Gama Irradiator (MGI) . . . . . . . . . 124

Introduction . . . . . . . . . . . . . . 124

Design Chäracteristics... . . . . . . . . 124

Measurement of Ras

Irradiator . . . . . . . . . . . . . . . . . 135

Introduction ................... 135

Materials and y ans . . . . . . . . . . . 135

Results . . . . . . . . . . . . . . . . 151

Discussion . . . . . . . . . . . . . . . 152

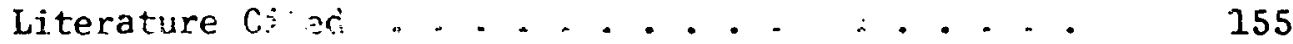


Gamma Radiation And Heat For Therapeutic Treatment of . Fruits And Vegetables For Postharvest Diseases . . .

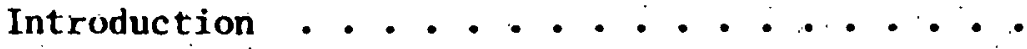

Etiology of Postharvest Diseases . . . . . .

Postharvest Treatments . . . . . . . . .

Summary and Conclusions . . . . . . . . . .

161

Literature Cited

167

168 


\section{SUMMARY}

Mechanical injury stimulates ripening in banana fruits by stimulating the production of the ripening hormone, ethylene gas $\left(\mathrm{C}_{2} \mathrm{H}_{4}\right)$ by wounded tissues.: Gamma irradiation at doses of 35-50 kilorad (Krad) offsets the ripening stimulus of wounded tissues, apparently by reducing the sensitivity of the bananas to the ripening action of the gas.

'Shasta' strawberry fruits subjected to $200 \mathrm{Krad}$ of gamma rays in the Mobjle Gamma Irradiator (MGI) showed considerably less rot ( 8.9 vs. $37.1 \%$ in simulated marketing) following air shipment from San Francisco, California, to New York, New York.

Measurements of tlesh color in irradiated 'Elberta' peaches using the Gardner Automatic Color Difference Meter confirmed earlier results jndicating an increased amount of red pigments in the irradiated fruits. Heat treatments in combination with irradiation did not adversely affect pigment development.

Irradiation to $100 \mathrm{Krad}$ substantially reduced cap opening and stem growth in brown mushrooms subsequently stored at $41^{\circ}$. and $68^{\circ} \mathrm{F}$. No benefit was found if a storage temperature of $32^{\circ} \mathrm{F}$ was employed. Doses of $1.00 \mathrm{Krad}$ did not significantly affect aroma and llavor or the ascorbic-acid content of mushrooms.

Quality, ripeness, per cent soluble solids, flesh color, and flavor of cantaloupes is not adversely affected by gamma rays at doses below $400 \mathrm{krad}$. The flesh of cantaloupes is markedly sottened by irradiation, but the differences between irradiated and unirradiated fruits disappears as the fruit ripens. There is a substantial loss in ascorbic acid in irradiated cantaloupes, apparently directly related to duse.

Honeydew melons respond similarly to gamma irradiation as does cantaloupes in most respects. However, this fruit can tolerate doses as high as $800 \mathrm{Krad}$ with an adverse effect on tlavor. This apparent 
advantage is offset by an extreme sensitivity of the textural components of the fruit to irradiation.

Gamma irradiation to 300 and $400 \mathrm{Krad}$ increases the susceptibility of tomato truits to transit injury. This adverse effect can be markedly reduced by packaging the fruits in a manner that precludes movement. within the package.

The Mobile Gamma Irradiator is now functional. This unit can process 600 pounds of strawberries and peaches and 700 pounds of tomatues per hour. For germination-inhibiting doses of potatoes and onions; the capacity is 3,600-5,600 pounds per hour depending on varietal dose requirements. The dose variation within product packages seems acceptable to the objectives of the unit.

There is a marked synergistic interaction between heat and gamma irradiation which increases the fungicidal effectiveness of irradiation without noticeable added host damage. This offers the promise of feasibility of irradiation as a technology for several commodities previously considered too sensitive to the treatment. 


\section{EFFECT OF MECHANICAL INJURY AND GAMMA IRRADIATION \\ ON RIPENING OF BANANA FRUITS*}

Babiker M. Hassan and E. C. Maxie

\section{INTRODUCTION}

The banana (Musa sapientum L.) is one of the world's most popular fruits, with a crop value (52) of about $\$ 500,000,000$ per year. Eighty'five per cent of the crop is produced in South America and the principal imarkets are Europe and the United States.

Banana fruits are subject to chilling injury (5) and are thus shipped at temperatures between $56^{\circ}$ and $58^{\circ} \mathrm{F}(7)$. This temperature is only $4-6^{\circ} \mathrm{F}$ below the optimum ripening temperature for bananas. Therefore, ripening losses of from $20-25 \%$ often occur during sea voyages which may take up to 16 days (53). During and after transit of bananas, one hand, or one or more fingers in a hand, may start ripening prematurely. The others remain unripe even though they are in close contact with the ripening fruit. Thorough examinations revealed that the prematurely ripening fruits usually had mechanical injuries such as scratches," bruises, split tips, etc. Bananas shipped to England and given complete protection from mechanical injury were received in far better condition than were control fruits in the same cargo (53).

According to Hansen (27), ripening in climacteric-type fruits begins with the onset of the rapid increase in respiratory activity. An increased rate of respíration due to mechanical deformation has been noticed with leaves (6), sweet potatoes $(30)$, potato tuber $(20,29)$, cherries (34), and citrus fruits (18). Mechanical injury accelerated the climacteric and ripening process of apples (49) and shaking and peeling of avocado fruits hastened the onset of the respiratory rise ( 8 ). Partial destruction of the epidemis in papaya fruits caused an increase

* A purtion of this paper was presented in the 1965-1966 report and is repeated here for completeness. 
in the rate of respiration (55). Marks and Varner (33) reported that bruising injury retarded normal ripening of tomato, but these workers used fruits whose physiological state was poorly defined.

Considering banana fruits, 'Cavendish' banana is reported to have an inferior keeping quality (55) because of their susceptibility to. bruising, whlle 'Giant Governor,' a mutant of the 'Cavendish,' gave better results (54) owing to its toughness of skin. In a preliminary study with 'Valery' bananas, Maxie et al. (39) reported that mechanical injury stimulated ripening。

The banana is a climacteric fruit (9) and evolves ethylene during ripening (43). Some workers believe that ethylene is a by-product of ripening metabolism $(\$, I I)$ rather than an autostimulant which induces the climacteric and ripening. However, in several fruits a great increase in both internal and evolved ethylene $(12,13,32)$ coincides with, or imediately precedes the climacteric rise. Burg and Burg (15) concluded that ethylene production triggers ripening. Ethylene induces ripening of fruits (19) such as pears (24, 25, 28), peaches (23), tomato (44), and banana $(53,57)$. Burg and Burg (13) showed by direct measurements that an incernal accumulation of a stimulatory concentration of ethylene preceded the onset of the climacteric in banana.

Williamson (56) showed an increased evolution of ethylene by injured plants. Although the orange has been reported not to produce ethylene $(9,10)$, cut oranges (21) produced a detectable amount of ethylene. Sub-cellular fractions from tomatoes subjected to sonication $(45,46,50)$ produced ethylene. Cutring apples stimulated the production of ethylene (4l). In pears (31) mechanical injury stimulated the production of volatiles usually produced by ethylene-treated fruit.

The use of ionizing radiation for the preservation of fruits and vegetables is still considered experimental, though promising results have been reported (22) for some fruits and vegetables. According to Salunkhe (47) gamma irradiation inhibited ripening of tomatoes and apricots. Abdel-Kader et al. $(1,2)$ confirmed Salunkhe's results for 
tomatoes. Similar results were reported for 'Bartlett' pears (38) and papayas (40). According to Teas et al. (5l), $25 \mathrm{Krad}$ of gamma rays markedly inhibited ripening of 'Gros Michel' bananas. Amezquita (3) obtained similar results with 'Gros Michel,' using doses between 10 and $50 \mathrm{Krad}$. For 'Valery' bananas Maxie et al. (39) reported inhibition of ripening with 35 Krad of gamma rays.

The effect of gamma irradiation on ethylene production by fruits and vegetables has been investigated by several workers. With lemon fruits $(35,36)$ and peaches (37), gamma irradiation stimulates ethylene production. With 'Bartlett' pears, Bussel (16) reported a stimulation of ethylene production. However, Maxie et al. (38) showed that the stimulation was only for one or two days immediately following irradiation and the net result was a reduction of the fruit's capacity to produce ethylene. Inhibition of ethylene production by gamma irradiation was also reported for apples (48), and tomatoes (1). Amezquita et al. (4), working with 'Gros Michel' bananas reported a delay in ethylene production by irradiated fruits to 10 and 19 days for those given doses of 10 and $20 \mathrm{Krad}$ of gamna rays respectively.

The possible induction of ripening in fruits by mechanical injury during harvesting, packing and shipping has been considered (42), but generally the emphasis has been on appearance and susceptibility to decay. It is clear that additional research is needed on the effects of mechanical injury on ripening of fruits.

The objectives of this research were to determine:

1) if mechanical injury causes bananas to ripen prematurely.

2) if ethylene production is stimulated by mechanical injury.

$3)$ what type of injury causes the greatest effect.

4) if gamma irradiation can inhibit early ripening and/or ethylene stimulation caused by mechanical injury.

\section{MATERIALS AND METHODS}

The bananas used in this study were obtained from the United Fruit 
Company Wharf in San Francisco immediately after they were unloaded from the ship. Fruits were carefully selected for freedom from defects and uniformity of green color. To get the most uniform results (57), fingers from the same hand were divided into sub-samples for the various treatments.

Fingers were cut from the hand and the cut surfaces dusted with sulfanilamide powder to control decay. Individual fingers were used, with 4-6 replicates per treatment. Fruits differed greatly in size between experiments but for each individual experiment replicate fruits were uniform.

Each finger was sealed in a half-gallon jar fitted with a rubber plate-disk cover containing air inlet and outlet tubes. Aeration was continuous at a rate of $50-60 \mathrm{ml} /$ minute at $68^{\circ} \mathrm{F}$ and a saturated relative humidity. Respiratory rates were measured by the method of Claypool and Keefer (17). The rates of ethylene production were measured by gas chromatography as described by Maxie et al. $(36,38)$.

To study the effect of mechanical injury on the ripening of fruits, two types of injury were inflicted. In the first, either the flower end or the stem end of a finger was crushed in a vise to just split the tissues. In the second, one face of either the stem or flower end of the finger was scraped with stainless steel gauze to remove the epidermis from an area of about $1 / 10$ of the total surface of the fruit. An uninjured group was used as controls in each replicate.

For studying the effect of gamma irradiation on the ripening of fruits, one group of fingers was given a dose of $35 \mathrm{Krad}$ of gamma rays in the case of 'Valery' and $50 \mathrm{Krad}$ in case of 'Gros Michel' employing the Mark II Food Irradiator of the Department of Pomology, University of California, Davis. The companion group was not irradiated.

To investigate the effect of mechanical injury on previously irradiated fruits, 'Gros Michel' bananas were used. Fruits were given a dose of $50 \mathrm{Krad}$ of gamma rays one day before they were injured, as described above. Injured fingers which were not irradiated, irradiated 
but not injured, and unirradiated uninjured fingers were used in each replicate.

To test the immediate effect of mechanical injury on ethylene pruduction by banana fruits, 1 inch pieces were cut trom the flower end of fingers. All the exposed cut surfaces were dusted with sulfanilamide powder. Sixty pieces were placed in each of 6 halfgallon jars." The ethylene production was measured, then the tip end of the pieces in 3 jars were crushed in a vise. Those in the other. 3 .jars were left as controls. Ethylene production was determined at short intervals on the first day and twice a day thereafter.

\section{RESULTS}

The rise and fall in rate of ethylene production by a single ripening banana fruit is so rapid that it is doubtful that the peak values shown in this paper are the true peaks. More likely, they represent values a few hours before or after the actual peak. The number of individual fruits within samples and the number of samples used in this study made it impractical to make determinations frequently enough to precisely define the peak in ethylene production.

Figure 1. shows the effect of crushing either the flower end or the stem end on the respiratory rates of unirradiated "Valery' banana fruits. Injured fruits started their respiratory rise 7-9 days earlier than uninjured truits. The rate of respiration increased slightly immediately following injury, but soon declined to a rate near that of control frujts until the onset of climacteric. Both the injured and uninjured fruits passed through typical, respiratory climacterics.

Eigure 2 shows that ethylene production began just prior to, or simultaneously with, the onset of the respiratory climacteric, and reached a peak within $24-48$ hours. The injured fruits began to produce measurable amounts of ethylene o-7 days earlier than uninjured fruits: 


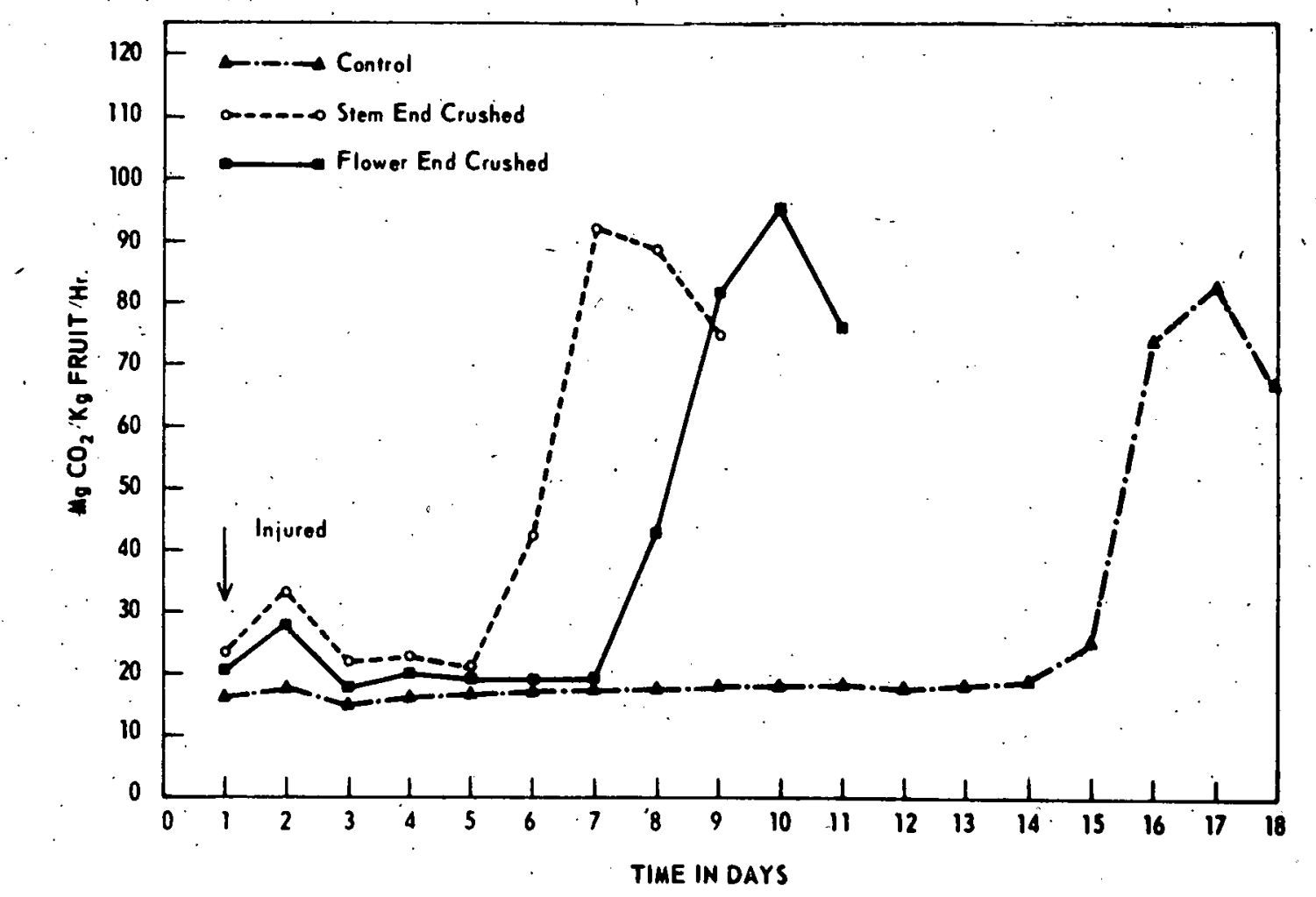

Fig. 1. Effect of crushing injury on the respiratory rates of unirradiated individual preclimacteric 'Valery' bananas. 


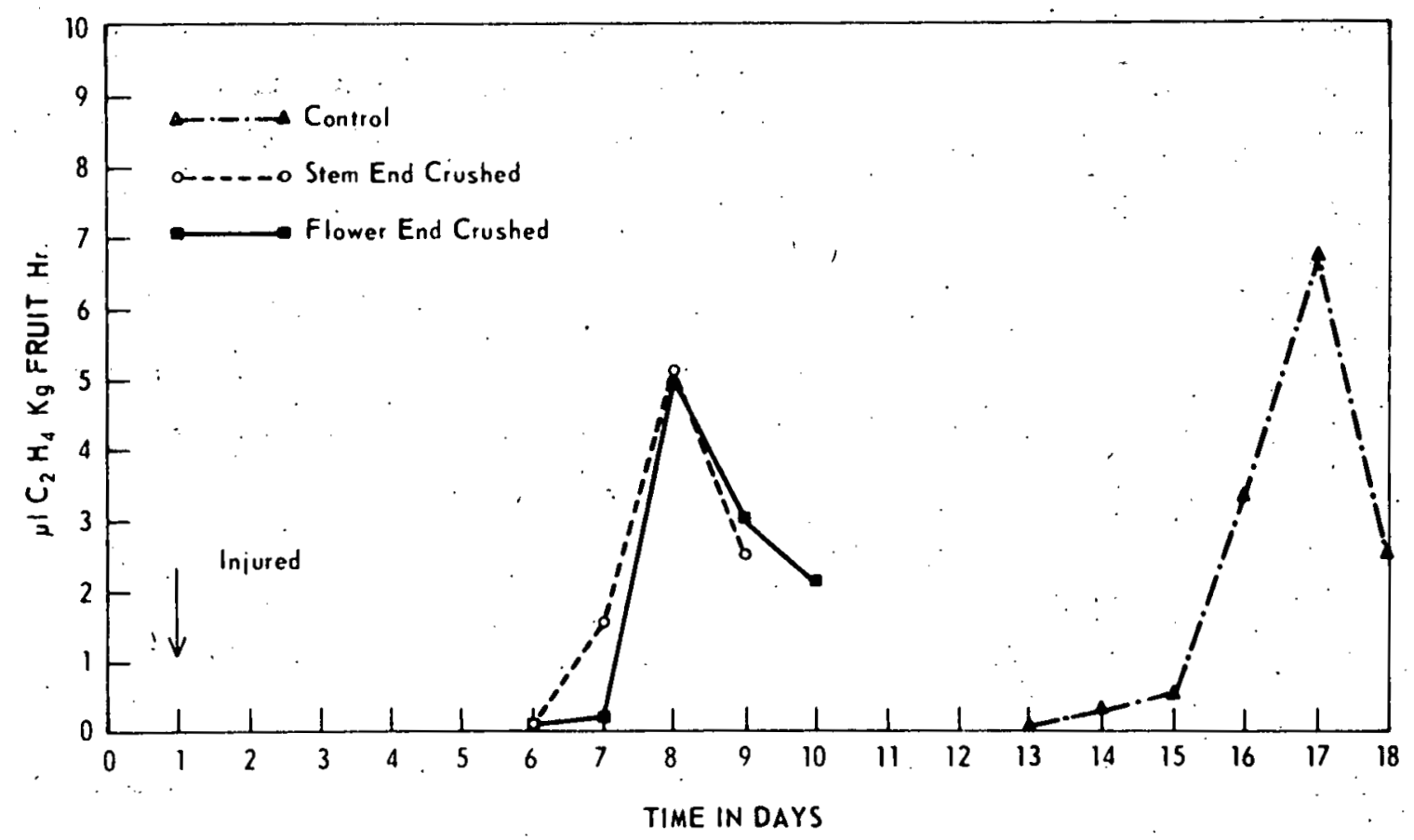

Fig. 2. Effect of crushing injury on evolution of ethylene by individual linirradiated preclimacteric 'Valery' bananas. 
With 'Gros Michel' variety, each experiment was repeated 4-6 times. The results of one typical experiment of each type are presented graphically in Figs. 3-8. The results of all experiments are summarized in Tables $1-3$.

Figure 3 shows the effect of scraping either the stem end or the flower end on the respiratory rate of 'Gros Michel' banana fruits. The stimulus was about the same as noted above for fruits with the ends crushed. The onset of climacteric was as much as 9 days earlier in injured than in control fruits. The magnitude of the effect was greatest in the fruits subjected to injury of the flower end. As shown in Fig. 4, ethylene production followed the same pattern as the respiratory rise.

The results of carbon dioxide and ethylene production for all replicates are presented in Table 1 . In no case was the onset of the climacteric by injured fruits later than that of uninjured fruits, and most injured fruits started their climacteric 4 or more days earlier. The evolution of ethylene always began at the same time, or one day earlier than the respiratory rise. The time required for the fruits to reach the respiratory peak after the onset of the climacteric was about the same for all fruits, ranging between 3 and 4 days. As noted above, ethylene evolution reached the peak rate within 24-48 hours after the first measurable amount was detected. There was no significant difference in peak values between fruits subjected to different types of injury. In some samples, injury to the flower end caused the earliest onset of the climacteric, while in others injury to the sten end was more effective.

Figure 5 shows the effect of mechanical injury and gamma irradiation alone and in combination on the respiratory rate of 'Gros Michel.' bananas. Doses of 50 Krad markedly delayed the onset of resptratory rise in both injured and uninjured fruits.

Figure 6 shows that the retarding effect of irradiation on ethylene evolution was equally as great as the effect on the respiratory rate. 


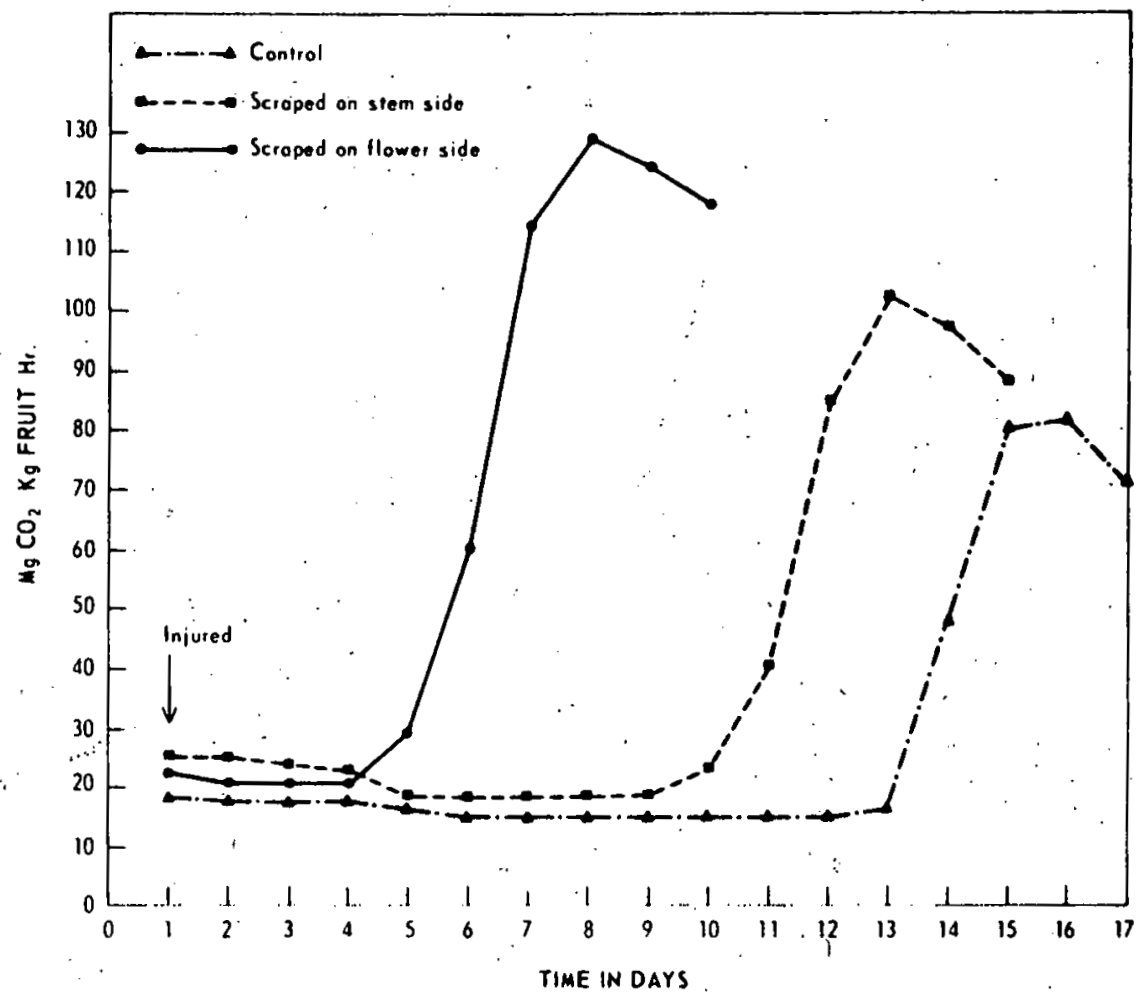

Fig. 3. Fffect of scraping injury on the respiratory rates of individual unirradiated preclimacteric 'Gros Michel' bananas. 


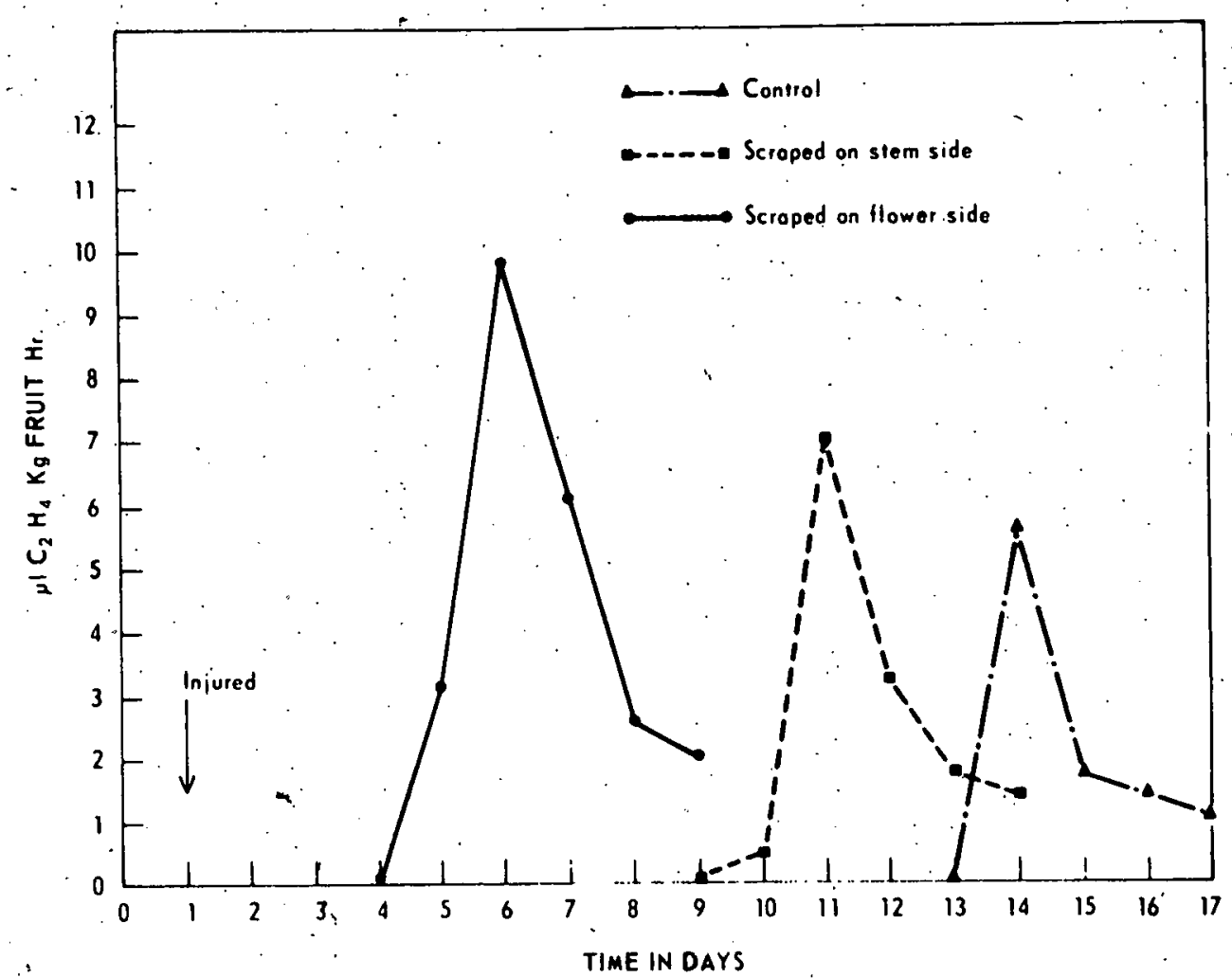

Fig. 4. Effect of: scraping injury on evolution of ethylene by individual unirradiated preclimacteric 'Gros Michel' bananas.

$-10-$ 
Table 1. Summary of 6 replicates showing the effect of mechanical injury on the ripening of unirradiated 'Gros Michel' bananas.

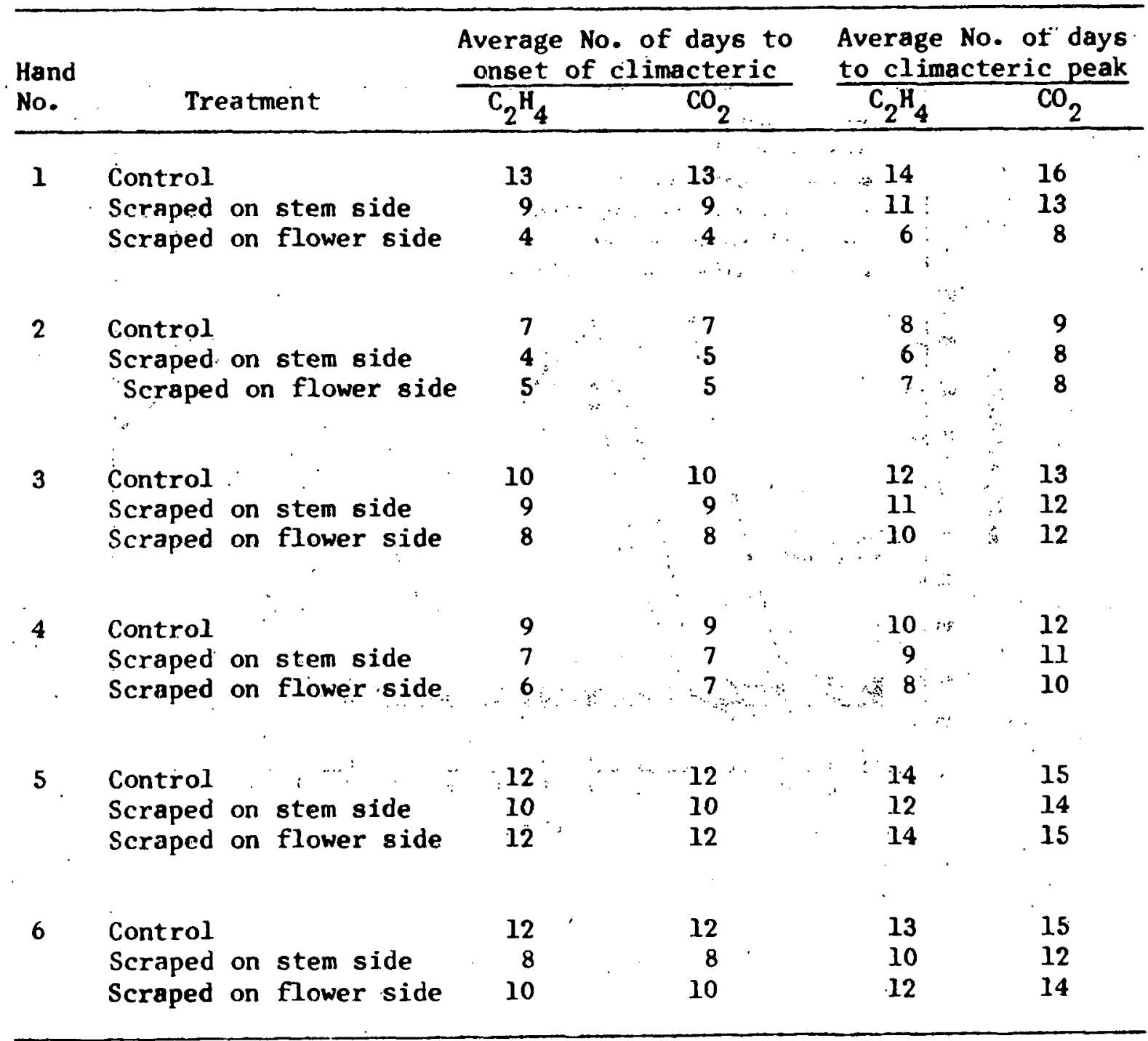




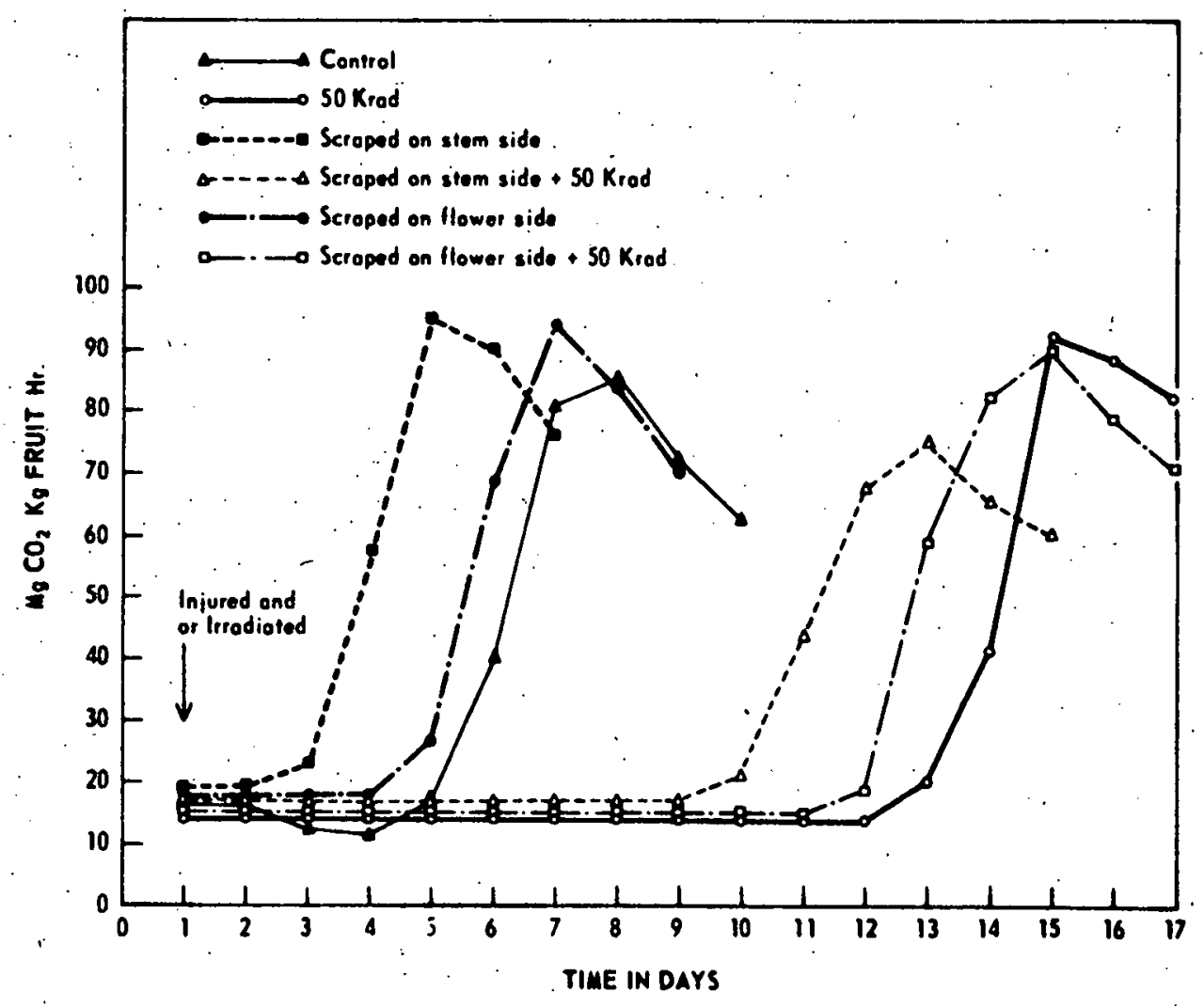

Fig. 5. Effect of mechanical injury and gamma irradiation on the respiratory rates of individual preclimacteric 'Gros Michel' bananas. 


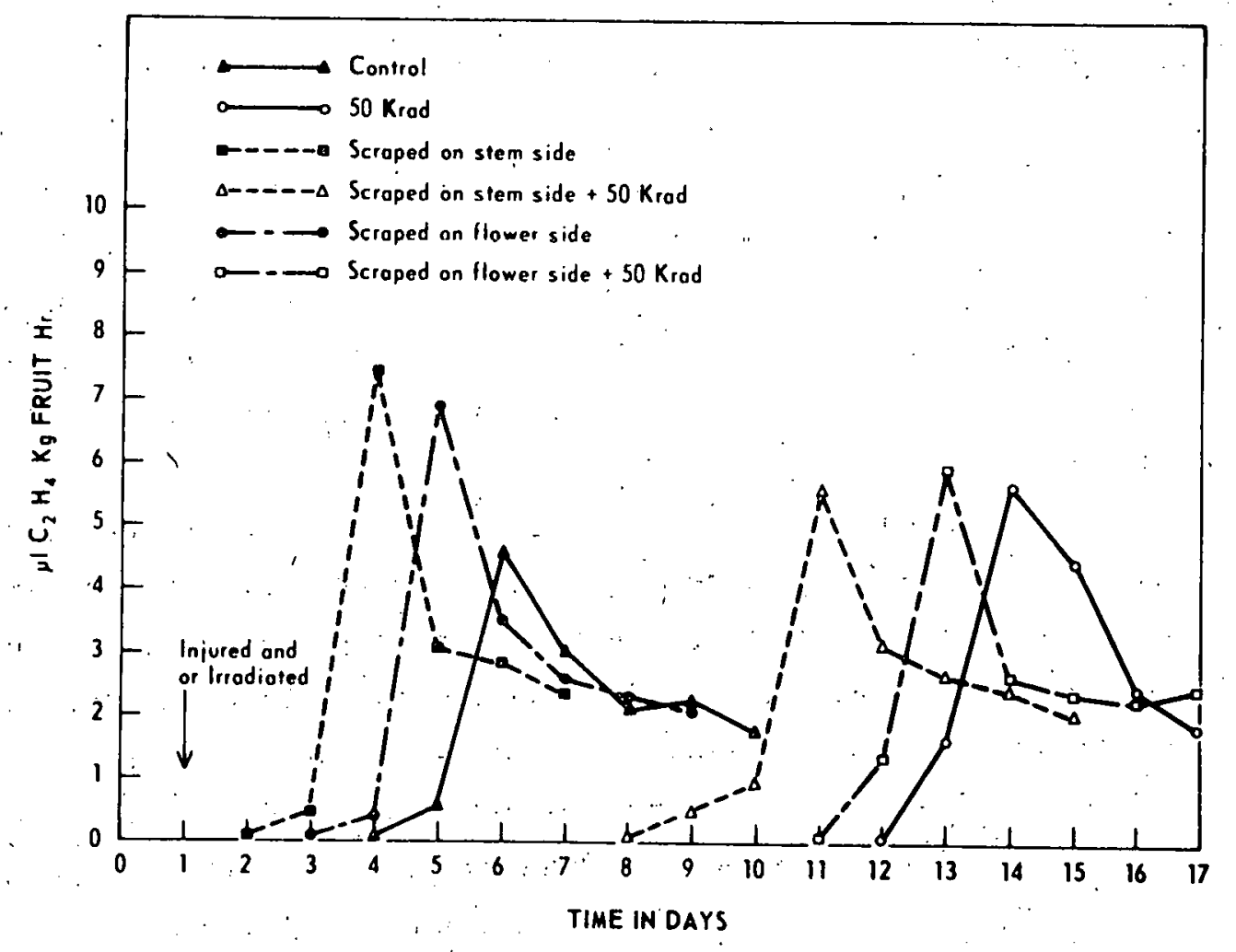

Fig. 6. Effect of mechanical injury and gamma irradiation on evolution of ethylene by individual preclimacteric 'Gros Michel' bananas. 
Table 2 summarizes the results for all the replicates involving gamma irradiation. In every case, gamma irradiation delayed both the onset of the respiratory climacteric and ethylene production. The effect of irradiation seemed to be more pronounced on fruits injured on the flower end but the differences were not great enough to allow a generalized conclusion. In fruits where the climacteric had begun before the irradiation treatment, no retarding effect was found on either the respiratory rate or rate of ethylene production.

Figure 7 shows the effect of post-irradiation mechanical injury on the respiratory rate of 'Gros Michel' banana fruits. The respiratory climacteric was delayed 5-7 days in both injured and uninjured fruits.

As shown in Fig. 8, the effect of post-irradiation mechanical injury on the stimulation of ethylene production was less in gamma irradiated fruit, to about the same degree as was the onset of the respiratory climacteric.

Table 3, summarizes the results of all replicates subjected to post-irradiation mechanjcal injury. In every case except for hand no. 2, there was a delay in the onset of the respiratory rise and ot ethylenc production. The fruits in hand no. 2 have already entered the climacteric rise and irradiation exerted no delaying effect on either the respiratory rate or rate of ethylene production.

Figure 9 shows the immediate effect of mechanical injury on ethylene production by small pieces cut from the flower end of unirradiated bananas. The rate of ethylene production by crushed tips increased steadily immediately following injury, reaching a peak rate after 4-6 hours then decreased. The curve resembles the climacteric in ethylene production associated with ripening which precedes the onset of the respiratory climacteric in bananas. The rate of ethylene production by uninjured tips remained high for a short time but soon declined. By the third day after crushing, the crushed tips were clearly ripening as indicated by loss of green, and appearance of yellow color. 
Table 2. Summary of 4 replicates showing the effects of mechanical injury and gamma frradiation alone and in combination with 'the ripening of 'Gros Michel' bananas.

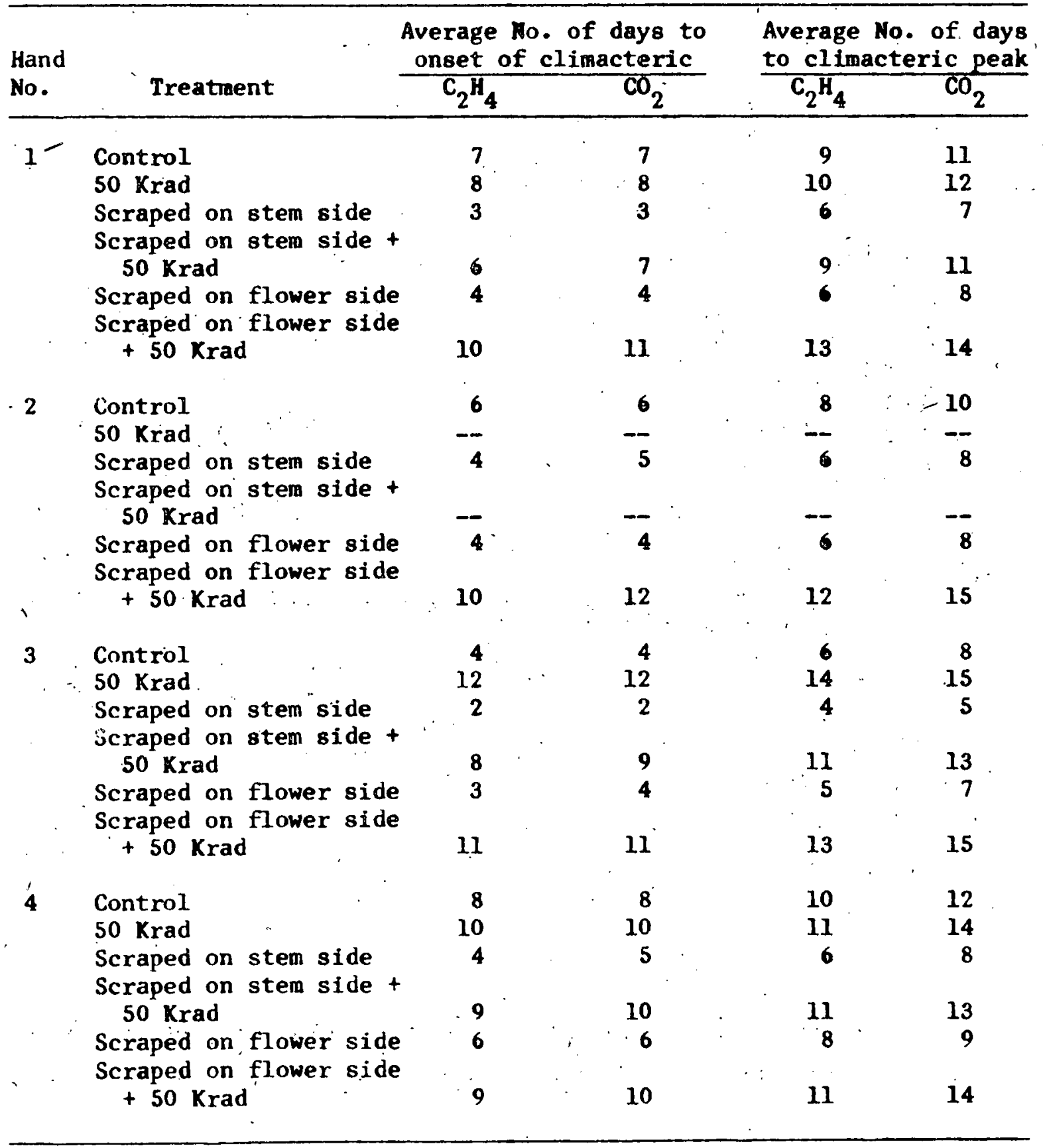




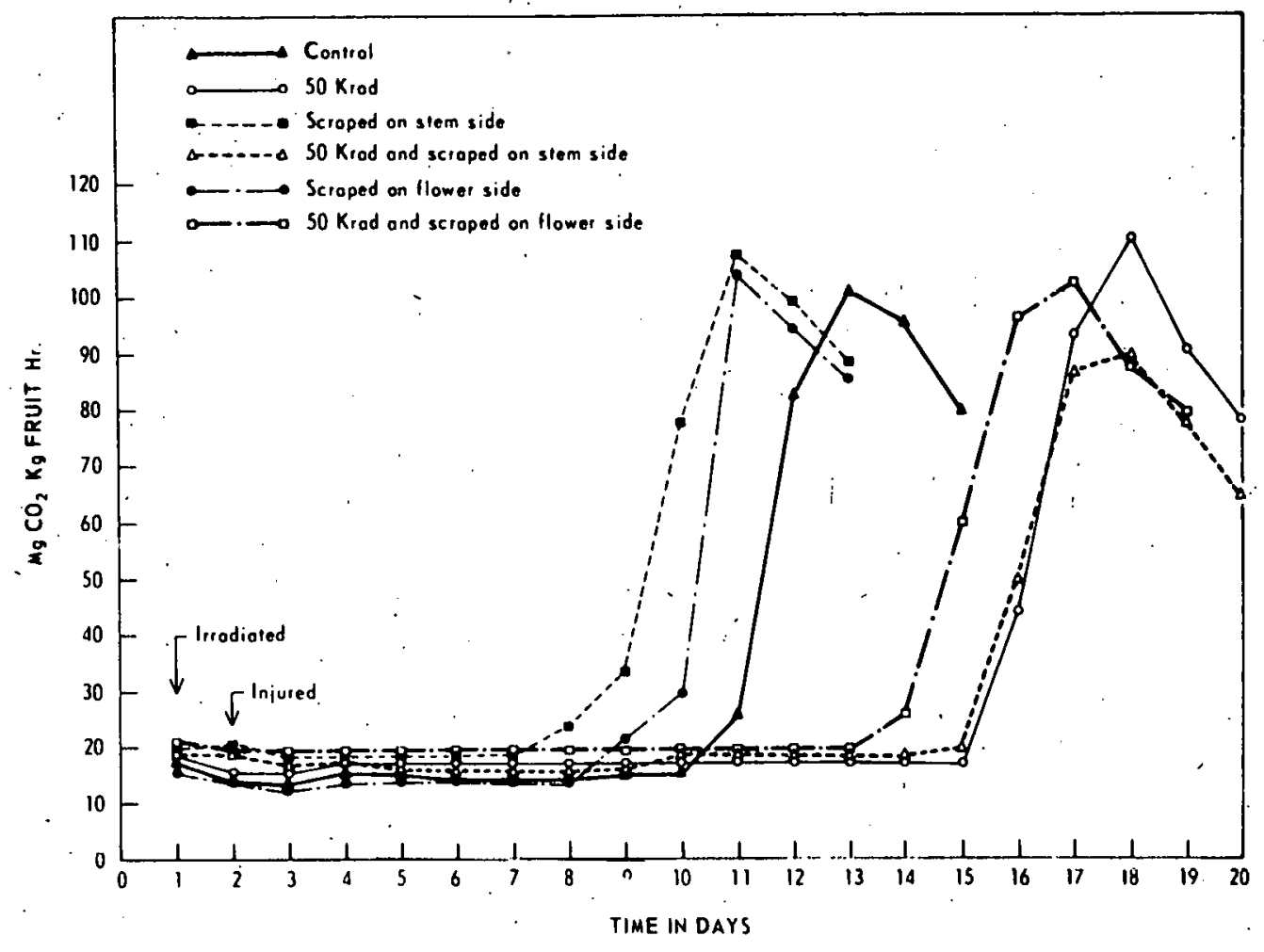

Fig. 7. Effect of post-irradiation mechanical injury on the respiratory rates of individual preclimacteric 'Gros Michel' bananas. 


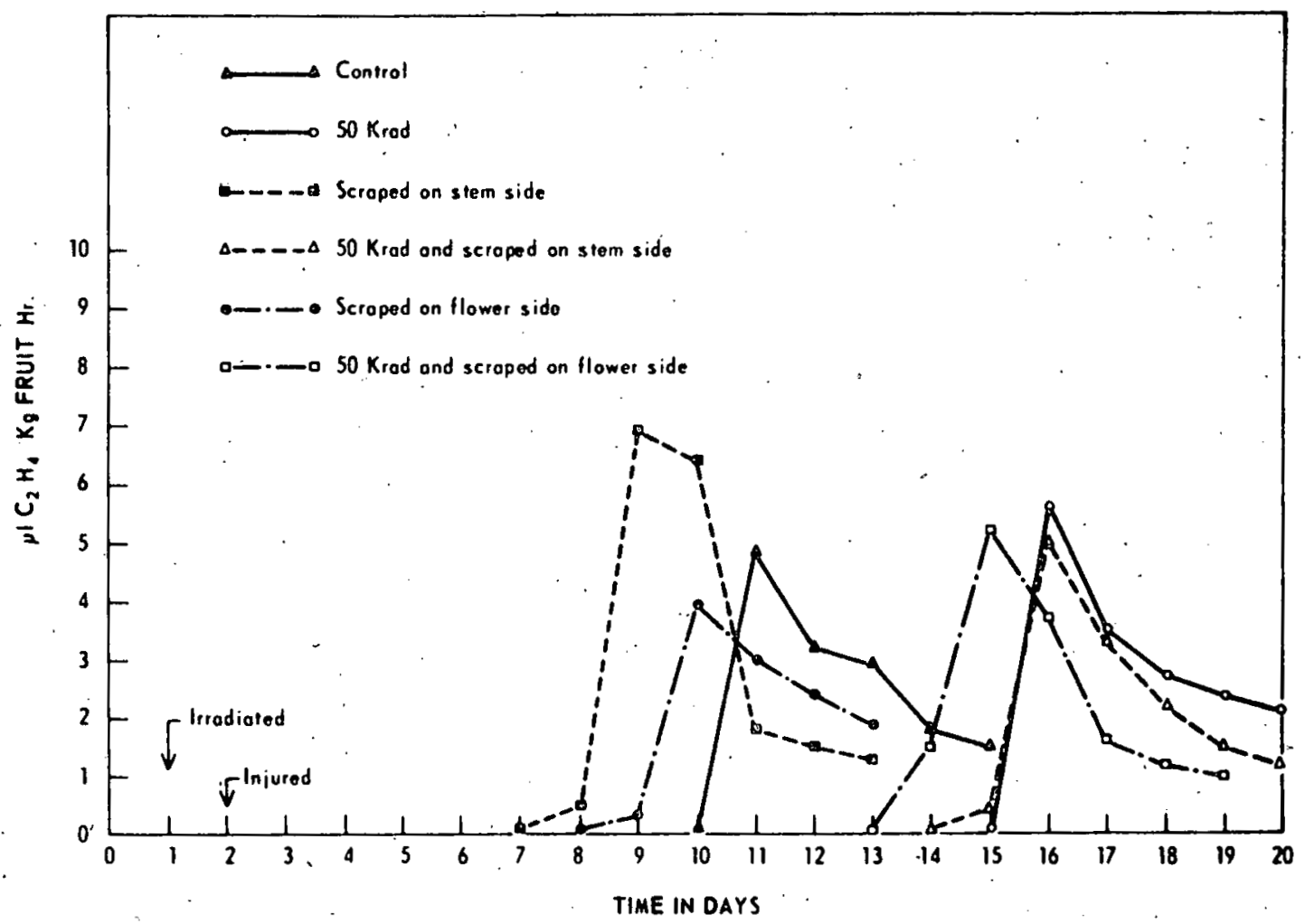

Fig. 8. Effect of post-irradiation mechanical injury on evolution of ethylene by. individual preclimacteric 'Gros Michel' bananas. 
Table 3. Summary of 4 replicates showing the effects of post-irradiation mechanical injury on the ripening of 'Gros Michel' bananas.

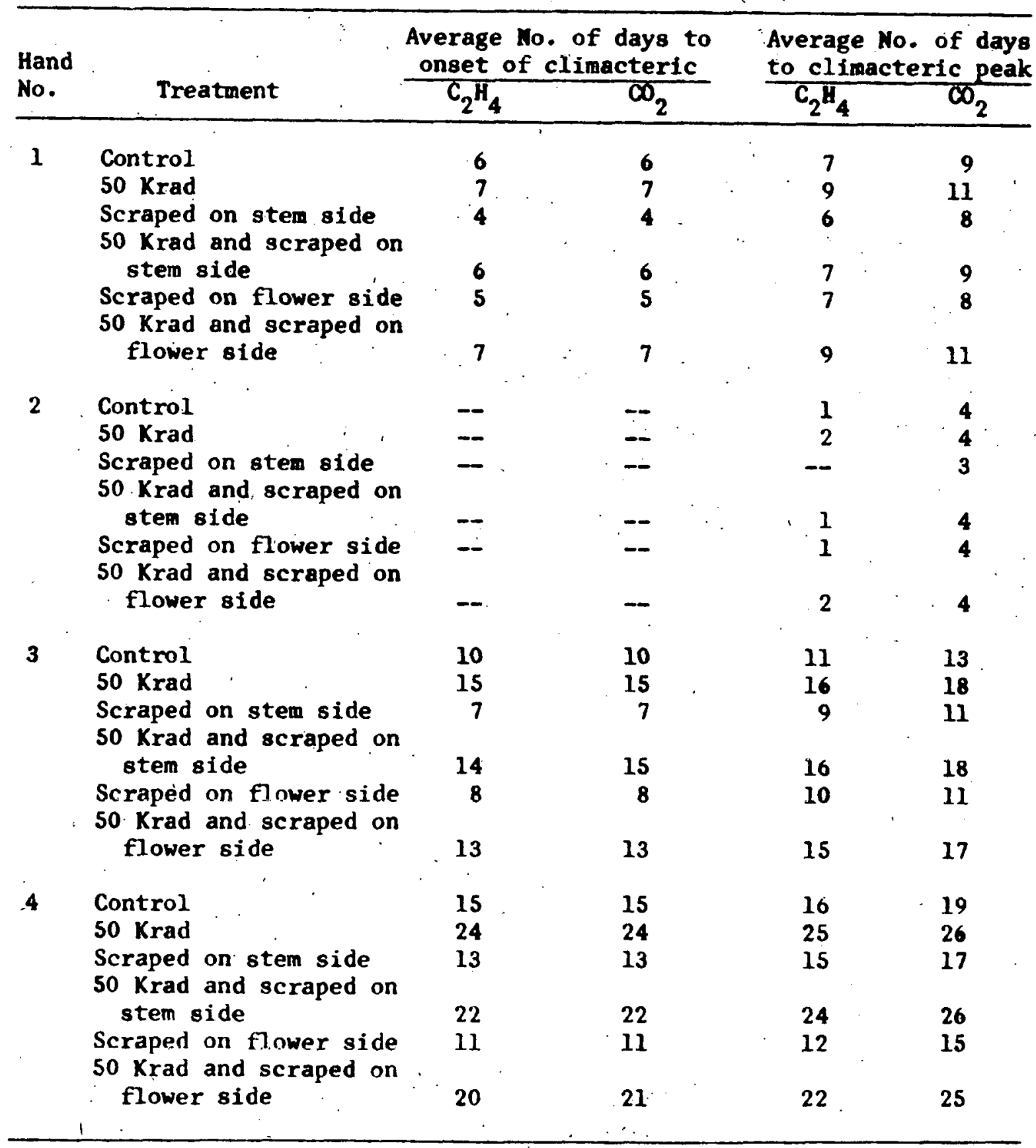




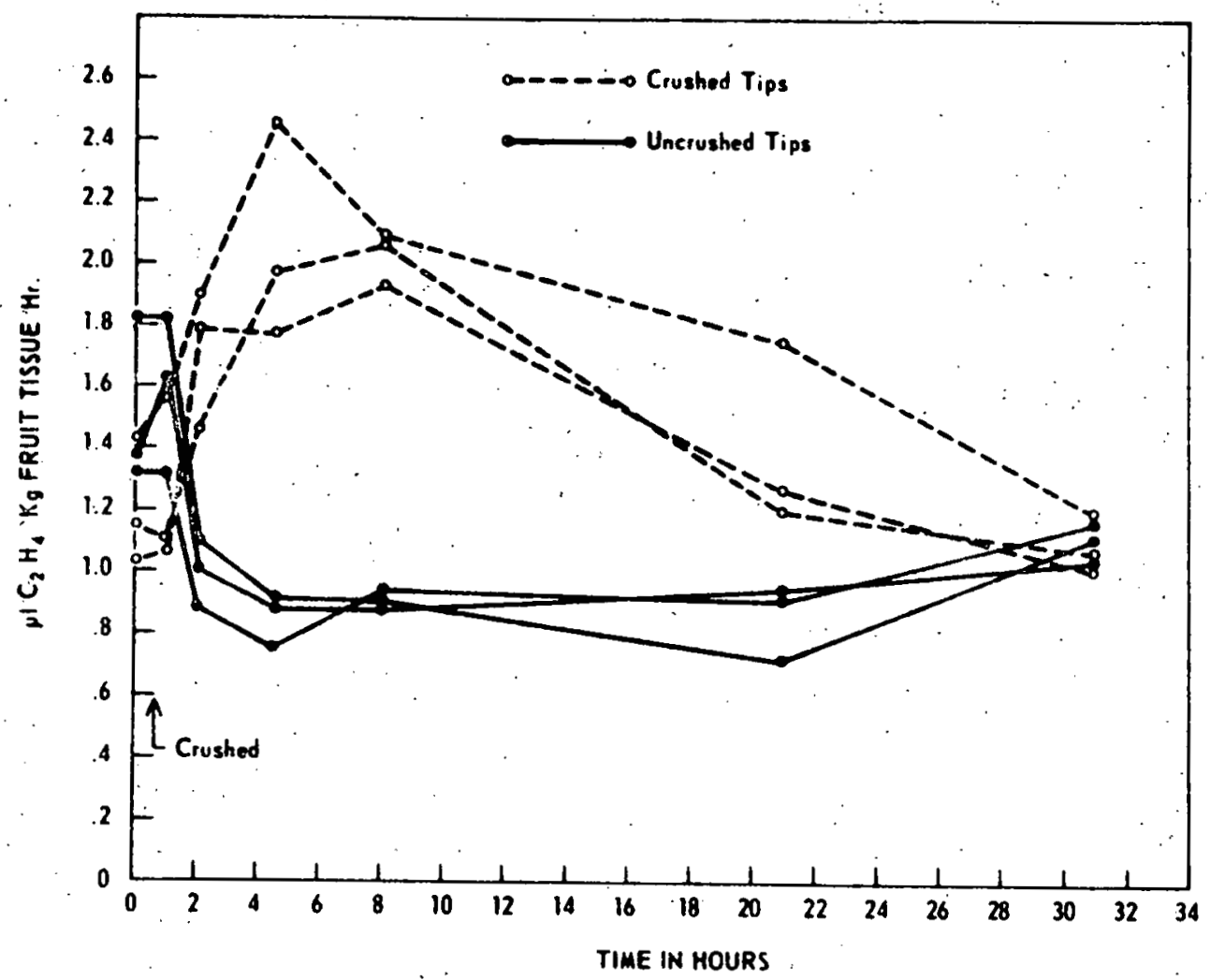

Pig. 9. Immediate effect ot mechanical injury on evolution of ethylene by unirradiated banana tissues. 
DISCUSSION .

Individual bananas were used as replicates within samples in these studies because of the variability in ripening even among fingers from the same hand (3). Any stimulatory or inhibitory effect on ripening of bananas can be measured more precisely with individual fruits than with mass samples.

Ethylene production by bananas used in these studies always increased 1-2 days before there was a measurable increase in respiratory rate. This agrees with the work of Burg and Burg (13) and Amesquita (3). The delay, between the increased ethylene production and the onset of the respiratory climacteric could be interpreted to mean. that banana tissues are less sensitive to the ripening action of the gas than are tissues of some other fruits. The often observed failure of a ripening banana to influence adjacent fruits in the same hand can be interpreted in the same way. If ethylerie is a ripening homone as proposed by Burg and Burg (13); and if the banana is less sensitive to it than other fruits, one would expect gama irradiation to more easily interfere with the onset of ripening in the banana than in fruits more responsive to the "hormone."

Mechanical injury to preclimacteric banana fruits hastens the onset of their respiratory climacteric and ripening as shown in Figs. 1 and 3 . Injury is known to stimulate ethylene production in some plant tissues (12). However, studies with intact frults have not shown an inmediate, measurable production of ethylene by injured bananas (Figs. 2 and 4 ). However, failure to detect an increase in ethylene production probably reflects an inadequate sensitivity of the instrument and method employed to detect the minute amounts involved. Onder optimum conditions, the method can accurately detect minimum ethylene concentration in air of 5 parts per billion ( $\mathrm{ppb}$ ). With bananas, the minimum measurable rate is about 0.05 microliters/Kg fruit/hour. If we apply Burg and Burg's (13) equation for calculating the internal ethylene concentration in a fruit from the production rate $(\mathrm{ppm}=2 \times$ microliters ethylene/ $\mathrm{Kg}$ fruit/hour), 
the minimum change in internal ethylene concentration we could approximate would be $0.1 \mathrm{ppm}$. This would be a physiologically active concentration. However, the amount of injured tissues was estimated to be less than $2 \%$ of the total on a fresh weight basis. This means that an immediate increase in internal ethylene concentration of several ppm in injured tissues would not be detectable 'in rate measurements taken on the whole fruit.

The above reasoning is confirmed by the data of Fig. 9 showing results where only the fruit tips were used. Mechanical injury caused an immediate and marked increase in ethylene production by crushed tips with the rate reaching a peak in about 4-6 hours.' Signs of ripening were noticed on the following day. Production of ethylene by the uncrushed tips reflected the cutting injury.

If Increased ethylene production by injured tissues of the banana stimulates ripening, it must áct by progressively stimulating first ethylene production, then ripening and respiratory rate in tissues leading away from the injured areas. Once enough tissue is involved to produce sufficient éthylene to stimulate ripening in a major part of the fruit, the climacteric is observed. The rapidity of the climacteric sequence indicates that the bulk of the tissues are involved by the time a measurable increase in carbon dioxide production can be measured.

It could be argued that increased gas exchange resulting from injury to bananas might be a factor in stimulating ethylene and carbon dioxide evolution as was shown in avocado by Ben-Yehoshua (8), in sweet potatoes by Johnstone ( 30 ), and in papaya by Wardlaw et al. (55). High concentration of carbon dioxide and low concentrations of oxygen counteract the ripening influence of ethylene (26). Thus, if the internal carbon dioxide concentration in the banana was high and oxygen concentration low, injury might give a greater gas exchange which would permit endogenous ethylene to stimulate ripening. However, the internal atmosphere of most preclimacteric fruits is not greatly 
different from the ambient atmosphere (19-20\% oxygen and $0.5-1 \%$ carbon dioxide vs. $21 \%$ oxygen and $0.03 \%$ carbon dioxide) (14). Further, the latex exuded from injured banana tissues soon seals the wounded area and it is doubtful that gas exchange in these areas is any greater if as great - as in comparable uninjured tissues.

Gama irradiation inhibits ripening in banana fruits as reported by Amezquita (3) and Teas (51). The mechanism involved is not known, but it seems clear that a decreased sensitivity to the ripening action of ethylene is involved $(3,4)$. It is clear that whatever the action of irradiation may ie, it partially counteracts the effect of injury on ripening whether the injury occurs before or after irradiation 、 (Figs. 5 and 7 ). The fact that irradiation has a residual inhibitory effect on ripening which counteracts the stimulatory influence of injury after irradiation is important from a practical standpoint. If post-irradiation injuries readily overcame the inhibitory effects of irradiation on ripening, the use of radiation would be much less attractive as a commercial process. 
1. The effects of mechanical injury and gamma irradiation on ripening of banana fruits were studied.

2. Mechanical injury caused an immediate production of ethylene by banana fruit tissues.

3. Mechantcal injury caused early ripening of banana fruits averaging from 4-7 days, as manifested by an earlier ethylene production and the onset of the respiratory climacteric.

4. Ripening is believed to reflect the progressive action of ethylene starting first at the injured areas and spreading to uninjured tissues.

5. Doses of 35-50 Krad of garma rays partially counteract the injury effect on ripening whether the injury occurs before or after irradiation.

6. The inhibitory effect of the low doses of gamna irradiation on ripening most likely reflects a reduced sensitivity of the banana to the ripening action of ethylene.

7. Irradiation, to be effective as an inhibitor of ripening, must be applied to preclimacteric bananas. 


\section{LITERATURE CITED}

1. Abdel-Kader, A. 1966. Physiological studies of gamma irradiated tomato fruits. Ph.D. Thesis. UCD.

2. Abdel-Kader, A., L. L. Morris, and E. C. Maxie. 1963. The effect of gama irradiation on the postharvest behavior of tomato fruits. In: "Radiation Technology in Conjunction with Postharvest Procedures as a Means of Extending the Shelf Life of Fruits and Vegetables," pp. 7-47. U.S. Atomic Energy Conmission Research and Development Rept. No. UCD-34P80-2.

3. Anezquita, R. 1965. Effect of gamma irradiation on the postharvest behavior of 'Gros Michel' bananas. M.S. Thesis. UCD.

4. Amezquita, R., E. C. Maxie, and C. F. Johnson. 1965. Effect of gamma irradiation on the postharvest behavior of 'Gros Michel' bananas. In: "Radiation Technology' in Conjunction with Postharvest Procedures as a Means of Extending the Shelf Life of Fruits and Vegetables," pp. 1-36. U.S. Atomic Energy Commission Research and Development Rept. No. UCD-34P80-4.

5. ASHRAE, Guide and Data Book. 1964. Bananas: Effect of exposure to excessively high or low temperatures: p. 631 .

6. Audus, L. J. 1935. Mechanical stimulation and respiration rate in the cherry laurel. New Phytologist 34:386-402.

7. Banana Ripening Manual. 1961. Published by United Fruit Sales Corporation, 30 'st. James Ave., Boston.

8. Ben-Yehoshua, S., R. N. Robertson, and J. B. Biale. 1963. Respiration and internal atmosphere of avocado fruit. Plant Physiol. 38:194-201.

9. Biale, J. B. 1960. Respiration of fruit. Encyclopedia of Plant Physiol. 12(2):536-592. 
10. Biale, J. B., R. E. Young, and A. J. Olmstead. 1954. Fruit respiration and ethylene production. Plant Physiol. 29:168174.

11. Buhler, D. R., E. Hansen, and C. H. Wang. 1957. Incorporation of ethylene into fruits. Nature 179:48-49.

12. Burg, S. P. 1962. The physiology of ethylene formation. Ann. Rev. Plant Physiol: 13:265-302.

13. Burg, S. P., and E. A. Burg. 1962. Role of ethylene in fruit ripening. Plant Physiol. 37:179-189.

14. Burg, S. P., and E. A. Burg. 1965. Gas exchange in fruits. Physiologia Plantarum 18:870-884.

15. Burg, S. P., and E. A. Burg. 1965. Relationship between ethylene production and ripening in bananas. Bot. Gaz. 126:200-204.

16. Bussel, J. 1965. Gas exchange in 'Bartlett' pears in relation to gama irradiation. M.S. Thesis. UCD.

17. Claypool, L. L., and R. M. Keefer. 1942. A colorimetric method for carbon dioxide detemination in respiration studies. Proc. Amer. Soc. Hort. Sci. 40:177-186.

18. Eaks, I. L. 1956. Physiology of bruising citrus fruits.'Proc. Tenth National Conference on Mandling Perishable Agricultural Commodities: $81-98$.

19. Fidler, J. C. 1960. Naturally occurring volatile organic compounds. Encyclopedta of Plant Physiol. 12(2):347-359.

20. Hackett, D. P. 1956. Studies on' the "wound respiration" of potato tuber tissue. Plant Physiol. 31:XL (abstract).

21. Hall, W. C. 1951. Studies on the origin of ethylene from plant tissues. Bot. Gaz. 113:55-65. 
22. Hannan, R. S. 1955. Scientific and technological problems involved in using lonizing radiation for the preservation of food. Grt. Brit. Dept. Sci. Ind. Res., Food Invest. Special Report No. 61 .

23. Hansen, E. 1937. Chemical changes of fruit ripened in the presence of ethylene. Science 86:272 p.

24. Hansen, E. 1939. Effect of ethylene on certain chemical changes assoclated with the ripening of pears. Plant Physiol. 14: 1.45-161.

25. Hansen, E. 1943. Relation of ethylene production to respiration and ripening of premature pearś. Proc. Amer. Soc. Hort. Sci. $43: 69-72$.

26. Hansen, E. 1942. Quantitative study of ethylene production in relation to respiration of pears. Bot. Gas. 103:543-558.

- 27. Hansen, E. 1966. Postharvest physiology of fruits. Ann. Rev. Plant Physiol. 17:459-480.

28. Hansen, E. and H. Hartman. 1935. The occurrence in pears of metabolic gases other than carbon dioxide. Oregon State Agr. College, Agr. Expt. Sta. Bul. 342 .

29. Hopkins, E. F. 1927. Variation in sugar content in potato tubers caused by wounding and 1 ts possible relation to respiration. Bot. Gaz. 84: 75-88.

30. Johnstone, G. R. 1925. Effect of wounding on respiration and the exchange of gases. Bot. Gaz. 79:339-340.

31. Kidd, F. and C. West. 1938/39. The rate of respiration and production of volatiles of 'Conference' pears: Effect of treatments with ethylene, temperature, and wounding. Report Fd. Inivest. Brd. Lnnd. 139-142. 
32. Lyons, J. M., W. B. McGla'sson, and H. K. Pratt. 1962. Ethylene production, ripening, and internal gas concentration in. cantaloupe fruits at various stages of maturity. Plant Physiol. $37: 31-36$.

33. Marks, J. D. and J. E. Varner. 1957. Effects of bruising on the metabolism' of fruits. Plant Physiol. 32:XIV (suppl.).

34. Marks, J. D. and J. E. Varner. 1957. The effect of bruising, injury on the metabolism of fruit. Plant Physiol. $32:$ XLV . (suppl.).

35. Maxie, E. C., H. L: Rae, I. L. Eaks and N. F. Sommer. 1966: Studies on radiation-induced ethylene production by lemon fruits. Rad. Bot. 6:445-455.

36. Maxie, E. C., I. L. Eaks, N. F. Somer, H. L. Rae, and S. E. Batal. 1965. Effect of gamma radiation on rate of ethylene and carbon dioxide evolution by lemon fruit. Plant Physiol. 40:407-409.

37. Maxie, E. C., N. F. Sommer, C. F. Johnson, and R. Stallman. 1963. Nectarines and peaches. In: "Radiation Technology in Conjunction with Postharvest Procedures as a Means of Extending the Shelf Life of Fruits and Vegetables," pp. 89-101. U.S. Atomic Energy Commission Research and Development Rept. No. UCD-34P80-2.

38. Maxie, E. C., N. F. Sommer, C. F. Johnson, and H. L. Rae. 1966. Effect of gama radiation on the ripening of 'Bartlett' pears. Plant Physiol. 41:437-442.

39. Maxie, E. C., R. Amezquita,. C. F. Johnson, C. Boyd, and H. L. Rae. 1965. Effect of gamma irradiation on ripening of 'Valery' bananas. In: "Radiation Technology in Conjunction with Postharvest Procedures as a Means of Extending the Shelf Life of Fruits and Vegetables," pp. 49-61. U.S. Atomic Energy Commission Research and Development Rept. No. UCD-34P80-4. 
40. Maxie, E. C. and R. Stallman. 1962. Papayas and pineapples. In: "Radiation Technology in Conjunction with Postharvest Procedures as a Means of Extending the Shelf Life of Fruits and Vegetables," pp. 89-91. Tech. Rept. SAN 2001, TID 4500; Division of Isotopes Development, U.S.-A.E.C.

41. Meigh, D. F., K. H. Norris, C. C. Craft, and M. Lieberman. 1960. Ethylene production by tomato and apple fruits. Nature $186: 902-903$.

42. Morris, L. L. and N. F. Sommer. 1961. Packing, cooling, and loading: Blological factors in product handling. Transportation of Perishables. Fifth Conference Proceedings: 30-40.

43. Niederl, J. B., M. W. Brenner, and J. N. Kelley. 1938. The identification of ethylene in the volatile products of ripening banana. Amer. J. Bot. 25:357-361.

44. Pratt, K. K. and M. Workman. 1962. Studies on the physiology of tomato fruits:. III. The effect of ethylnee on respiration and ripening behavior of fruits stored at $20^{\circ} \mathrm{C}$ after harvest. Proc. Amer. Soc. Hort. Sci. 81:467-478.

45. Ram Chandra, G. and M. Spencer. 1962. Ethylene production by subcellular particles from tomatoes. Nature 194:361-364.

46. Ram Chandra, G., M. Spencer, and M. Meheriuk. 1963. Evolution of ethylene by subcellular particles from tomatoes as influenced by components of the system. Nature 199:767-769.

47. Salunkhe, D. K! 1961. Gamma radiation effects on fruits and vegetables. Econ. Bot. 15:28-56.

48. Smock, K. H. and A. H. Sparrow. 1957. A study of the effect of ganma radiation on apples. Proc. Amer. Soc. Hort: Sci. $70: 67-69.1$ 
49. Smock, R. M: and C. R. Gross: 1950." Studies on réspiration of apples. Cornell Univ. Agr. Expt. Sta. Mem. No. 297.

50. Spencer, M. and M. Meheriuk. 1963. Influence of temperature and aging on ethylene production by a subcellular fraction from tomatoes. Nature 199:1077-1078.

51. Teas, H. J., D. C. Quintana, and 0. J. Campos. 1962. Inhibition of banana fruit ripening by garma radiation. 2nd International Congress. Radiation Research. Harrogate, England (Abst. 179).

52. Trade Year Book. 1964. F.A.0. - United Nations vol. 18:179-182.

53. Von Loesecke, H. W. 1950. Banana. Interscience Publishers, N.Y.

54. Wardlaw, C. W. and C. P. McGuire. 1933. Banàna storage. Enpire Marketing Board Publ. 72:35 p.

55. Wardlaw, C. W. and E. R. Leonard. 1935. The storage and physiology of tropical fruits. Trop. Agr. 12:313-319.

56. Williamson, C. E. 1950. Ethylene, a metabolic product of diseased or injured plants. Phytopath. 40:205-208.

57. Wolfe, H.S. 1931. Effect of ethylene on the ripening of banana. Bot. Gaz. $92: 337$ p. 


\title{
EFFECT OF GAMMA IRRADIATION ON ASCORBIC-ACID, CONTENT, OF STRAWBERRY FRUITS
}

\author{
Heñry L. Rae, Camilla Bnyd, and E. C: Maxie
}

\section{EXPERIMENT NO. I}

In view of the anticipated use of $300 \mathrm{Krad}$ as the upper limit in feeding studies to test the wholesomeness of irradiated strawberries, an experiment was conducted during 1966 to test the effect of 0,100 , $150,200,250$, and $300 \mathrm{Krad}$ on the ascorbic-acid content of 'Lassen'. strawberries.

Berries air freighted from Los Angeles County were sorted into carefully matched samples of 25 fruits each. Quadruplicate samples. were used at each level of irradiation. The fruits were irradiated at a temperature of $43^{\circ} \mathrm{F}$, placed immediately at $43^{\circ} \mathrm{F}$ and a relative humidity of $93 \%$, and held for 9 days. One set of unirradiated samples were analyzed on the day that the others were irradiated to give the ascorbic-acid level in the fruits at the time of treatment.

For analyses, one quarter of each fruit in a sample was used to make a composite sample weighing 50-60 $\mathrm{gm}$. The method of Loeffler and Ponting (Ind. Eng. Chem. Anal. Ed. 14:846-849. 1942) was used to determine the ascorbic-acid content.

Table 1 shows, the results of this study. At 150 and $200 \mathrm{Krad}, \mathrm{a}$ measurable though nonsignificant reduction in total ascorbic acid occurred. Even at 250 and $300 \mathrm{Krad}$, where the loss in total ascorbic acid was $12-14.6 \%$, the losses would not be nutritionally significant because $51.60 \mathrm{mg} / \mathrm{L00}$ gm fresh weight would still be considered an excellent source of the vitamin.

It should be emphasized that $200 \mathrm{Krad}$ is the maximum tolerable dose for 'lassen' strawberries because ot textural changes and the associated increased susceptibility to mechanical injury at higher doses. 
Table i. Effect of gamma irradiation on ascorbic-acid content of 'Lassen' strawberries after a simulated.marketing period (9 days at $43^{\circ} \mathrm{F}$ ). Results expressed as $\mathrm{mg} / 100 \mathrm{gm}$. fresh weight.*

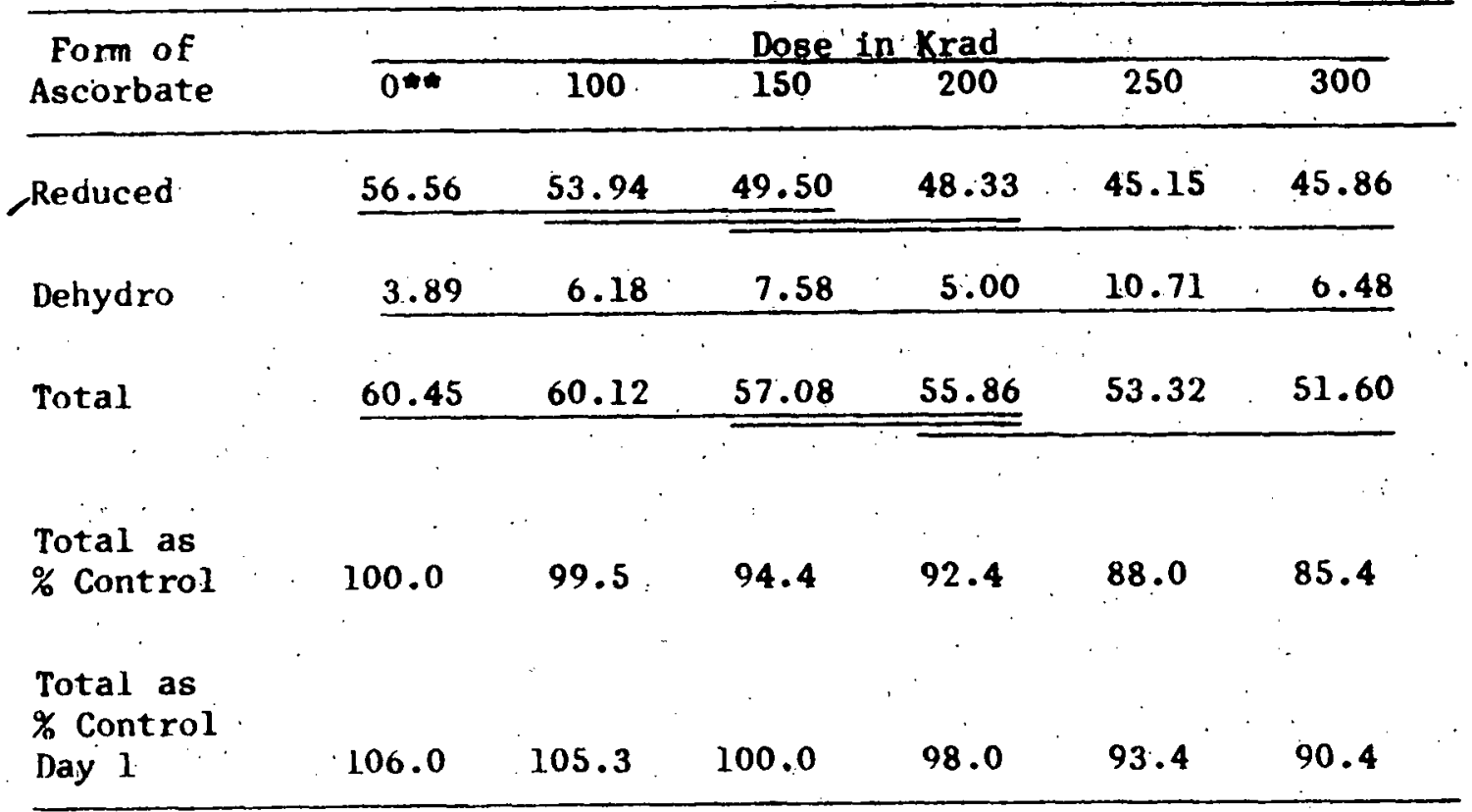

* Any scores connected by the same line are not statistically signj ficant at 0.05 level of probability.

* Unirradiated fruits on Day 1 , contained $51.24 \mathrm{mg}$ reduced, $3.89 \mathrm{mg}$ dehydro, and $57.07 \mathrm{mg}$ total ascorbic acid/100 gm fresh weight. 
We consider, as purely academic, the work of Clarke (Intern. J. Appl. Radiation and Isotopes 6:175-181. 1959) in which very high losses of vitamin $C$ were found at doses of 0.3-0.5 megarad. Since strawberry fruits subjected to these high doses would be unmarketable, it does not matter that ascorbic acid is destroyed.' Even so, we extended our studies to the 300-500 Krad dose range. Unforțunately, we were unable to get 'Lassen' berries and used 'Fresno' berries instead.

Berries were obtained from the cooler immediately after harvest, separated into samples of uniform ripeness, and 4 samples irradiated at each of the following doses: $0,300,350,400,450$, and $550 \mathrm{Krad}$. The fruit temperature, the air temperature in the irradiator, and the post-irradiation storage temperature was $43^{\circ} \mathrm{F}$. One set of unirradiated samples were analyzed on the irradiation date to determine the ascorbicacid content at the start of the experiment. Following irradiation the fruit was held for 8 days at $43^{\circ} \mathrm{F}$ to simulate a transcontinental shipment, then analyzed as described above.

The results of this experiment are shown in Table 2. While $550 \mathrm{Krad}$ gave $18-25 \%$ reduction in total ascorbic acid depending on which control lot was used as the reference sample, it is questionable that the loss is nutritionally significant considering the high remaining ascorbic-acid content of the berries. Certainly, these data are at great variance with those of clarke, in which very high losses of ascorbic acid were reported for strawberries in the dose range used here. 
Table 2. Effect of gama radiation at doses of 300-550 Krad on the ascorbic-acid content of 'Fresno' strawberry fruits after 8 days at $43^{\circ} \mathrm{F}$.: Results are expressed as mg ascorbic acid/100 gn fresh weight.

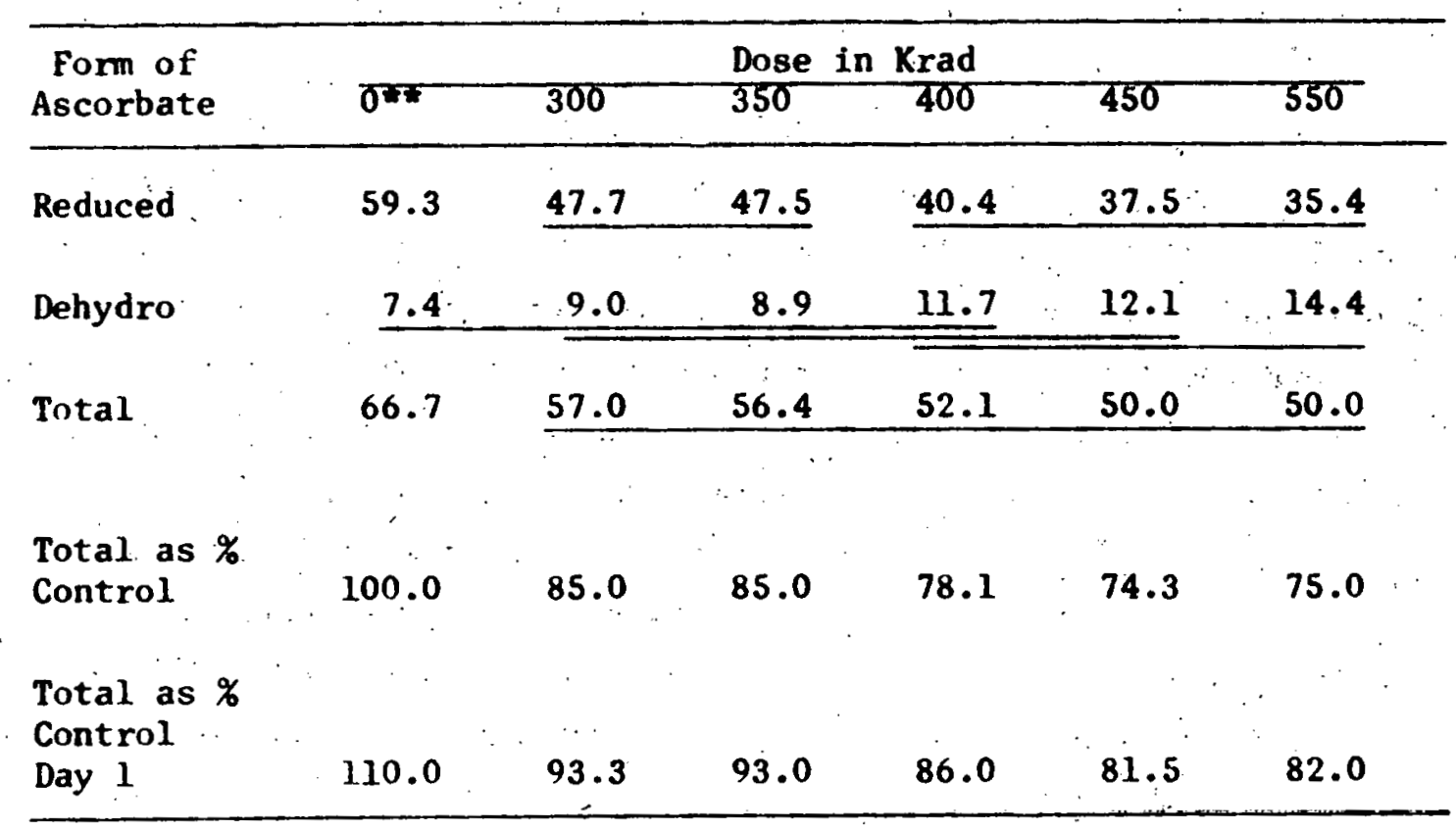

- Any scores connected by the same line are not statistically significant at 0.05 level of probability.

* Unirradiated fruits on Day 1, contained $57.2 \mathrm{mg}$ reduced, $3.6 \mathrm{mg}$ dehydro, and $60.8 \mathrm{mg}$ total ascorbic acid/100 gm fresh weight. 


\section{AIR TEST SHIPMENT OF IRRADIATED STRAWBERRIES}

F. P. Guerrero, Dale Ravetto, and E. C. Maxie

Delays in getting the Mobile Gamma Irradiator operational prevented any rail test shipment of irradiated strawberries during 1966. However, in view of the fact that Harvey e.t al. reported that in the air-transport of strawberries losses to decay may be as high as $40 \%$, an air test shipment was made to evaluate the effects of radiation on control of rot and on susceptibility of the fruits to transit injury.

Forty-eight trays of strawberries (Goldsmith var.), trade name Z5A, were purchased on the day of harvest from Driscoll Associates; Watsonville, California. They were hauled in a refrigerated box and cooled to $43^{\circ}$ while en route to Davis. Four replicates were used at 0 , 100, and $200 \mathrm{Krad}$. Irradiation was done in the Mobile Gamma Irradiator (MGI) with the temperature of the irradiator chamber about $40^{\circ} \mathrm{F}$. Air was passed through the chamber at a rate of $125 \mathrm{cfm}$. The controls were run through the irradiator with the plaque in the cask to subject the fruits to the same mechanical forces imposed upon the irradiated lots. The trays were labeled with "Caution Food Additives" stickers. Twenty-four trays were left at Davis and 24 trays were hauled back to watsonville, placed on a pallet with 36 other trays, covered with a fiberboard sleeve, then hauled to the San Francisco airport and loaded on an "igloo" master pallet holding 6 smaller pallets. The master pallets were covered with a fiberglass canopy, and loaded aboard a non-stop jet for delivery to New York.

1 Harvey, J. M., Couey, H. M., Harris, C. M. and F. M. Porter. July 1966. Air Transport of California Strawberries. Marketing Research Report No. 751 ARS United States Department of Agriculture. 
A time schedule was set up 80 as to try and coordinate lengths of time at a given temperature between. the fruit held at Davis and that shipped to New York. In general, the fruit was cooled in the refrigerated truck en route to Davis to about $43^{\circ} \mathrm{F}$. After irradiation

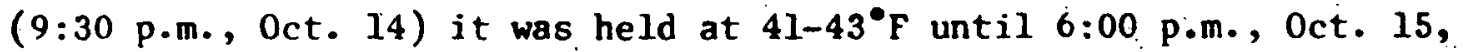
when the Davis lot was moved to the $59^{\circ} \mathrm{F}$ room and the lot to be shipped to New York, which had been hauled to Watsonville, was placed in a refrigerated truck and hauled to the San Francisco airport.' In the airplane the temperatures were assumed to be $55-70^{\circ} \mathrm{F}$. On 0ct. 16 at. 6:00 p.m. the Davis lot was moved to $68^{\circ} \mathrm{F}$ and kept at that temperature until evaluated. The fruit in New York was kept in a room with the temperature range about $60-70^{\circ} \mathrm{F}$.

The transport distance by truck of the Davis lot was about 150 miles and that shipped to New York approximately 430 miles.

At Davis the evaluations (Ravetto) were made 14 and 54 hours after the arrival time of the lot shipped to New York. At New. York the evaluations (Guerrero) were made at 14, 36, and 54 hours after arrival.

The condition categories used for evaluation were sound, soft and decayed. The fruit in the soft category were still considered marketable. The number of nests and fruits per nests were recorded and the decay organisms were identified as Botrytis, Rhizopus, and other.

The Davis lot was subjected to texture analysis using the AlloKramer shear press. Four, 100 gram samples from,each tray or 16 samples per treatment were used. The shear-press data were analyzed using the analysis of variance techniques.

All of the fruit in New York was disposed by mixing with soil and other refuse at a dump. 
RESULTS.

Davis Lot (Table 1). The first evaluation showed that the control fruit had developed $2.0 \%$ decay versus less than $1 \%$ decay in each of the irradiated lots. No nests were found in the irradiated fruit. 'In the controls only 3 nests were found in all. 4 trays. Only about $5 \%$ of the fruit was categorized as soft. There was no difference in the amount of soft fruit between the control and irradiated lots. The second evaluation, taken 40 hours after the first, showed a significant increase in the amount of decay. Control fruit showed $37 \%$ decay; $100 \mathrm{Krad}, 23 \%$; and $200 \mathrm{Krad}, 8.9 \%$. The average number of nests were 12,4 , and less than 1 in the control, $100 \mathrm{Krad}$, and $200 \mathrm{Krad}$ lots respectively. The. number of fruit per nest varied from 2-7. There was an increase in the per cent of fruit in the soft class in all lots, but no difference between control and irradiated fruit. The fruit receiving $200 \mathrm{Krad}$ had a higher per cent of sound fruit than did the control and the fruit receiving $100 \mathrm{Krad}$.

New York Lot (Table 2). The average of 2 trays per treatment in the 14 and 36-hour evaluations show that there was very little decay. The average of 4 replicates for the 54-hour evaluation'show that $19.5 \%$ of the control fruit were decayed; $100 \mathrm{Krad}, 17.5 \%$; and $200 \mathrm{Krad}, 2.1 \%$. The number of fruits per nest in the control varied from 2-7; $100 \mathrm{Krad}$, $2-3$; and at $200 \mathrm{Krad}$, only 2 .

When the data in Table 1 is compared to the data in Table 2 it is very evident that the lot shipped to New York had a higher amount of fruit in the soft category and consequently a much lower amount of fruit in the sound category. In the New York lot there was considerable difference between the three treatments; in general, the fruit subjected to irradiation had a higher amount of fruit in the soft category.

Botrytis was the major pathogen found in the decayed fruit evaluated at 14 hours; however, in the fruit evaluated at 54 hours about $20 \%$ of the fungus was found to be Rhizopus and other decay organisms. 
Table 1. Decay in strawberries as related to 3 levels of gamma irradiation. Results of 2 evaluations taken on fruit held at Davis. Average of 4 replications.

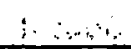

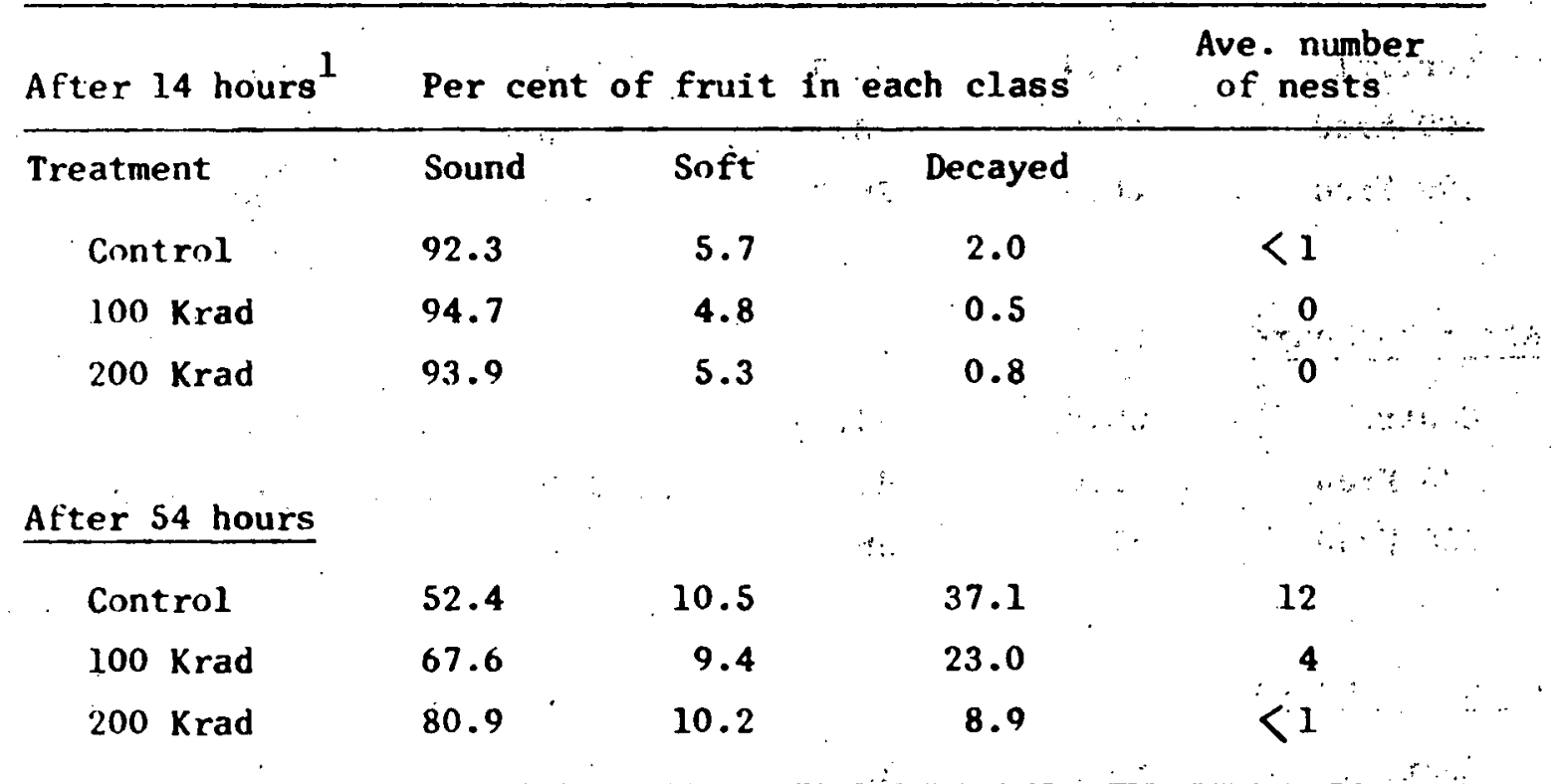

1 Hours after time of arrival of fruit shipped to New York: 
Table 2. Decay in strawberries as related to 3 levels of gamma irradiation. Results of 3 evaluations made on fruit shipped to New York.

After 14 hours $^{1} \quad$ Per cent ${ }^{2}$ of fruit in each class Ave. number

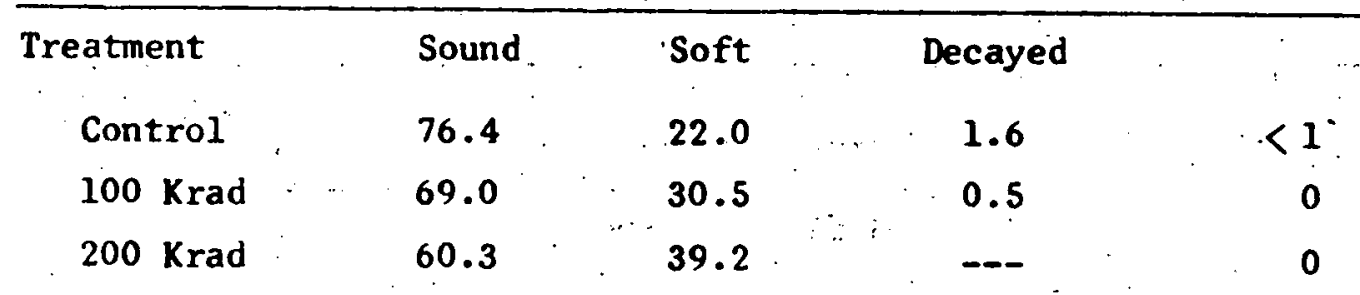

After 36 hours

$\begin{array}{lllll}\text { Control } & 59.8 & 35.4 & 4.8 & \text { 1 } \\ 100 \mathrm{Krad} & 55.6 & 42.9 & 1.5 & 0 \\ 200 \mathrm{Krad} & 61.2 & 38.4 & 0.4 & 0\end{array}$

After 54 hours

$\begin{array}{lrrrr}\text { Control } & 50.2 & 30.3 & 19.5 & 7 \\ 100 \mathrm{Krad} & 48.6 & 33.9 & 17.5 & 6.5 \\ 200 \mathrm{Krad} \cdot & 52.7 & 45.2 & 2.1 & <1 .\end{array}$

1 Hours after time of arrival.

2

Average of 2 replications in the 14 and 36 hour evaluations and 4 replications in the 54 hour evaluation. 
The results of the shear-press readings are given in Table 3 . There was a significant decrease in the crushing resistance of fruit receiving 200 , but no real difference between fruit receiving 0 and $100 \mathrm{Krad}$.

\section{DISCUSSION AND CONCLUSIONS}

The first evaluation made about 32 hours after harvest showed that very little decay had developed. The limiting factor was time. This is evident in that by the end of 4 days after harvest the control fruit had developed as much as $37 \%$ decay. An irradiation dose of $200 \mathrm{Krad}$ was very beneficial in reducing the incidence of decay. Dose levels of $100 \mathrm{Krad}$ had very little effect on controlling decay and the predetermined range of $175-225 \mathrm{Krad}$ is the best.

The reason that the lot shipped to New York had a higher amount of soft fruit is due partly to the fact that it underwent more transit injury. Another factor responsible for this difference was the presence of picker damage on the fruit. This damage was more severe after the fruit had been irradiated and shipped. The evaluator at Davis considered these fruit as sound and placed them in that category; whereas, the New York evaluator considered them soft and placed them in the soft category. The reason that the Davis lot showed more decay than the New York lot was because it was held at higher temperatures throughout the experiment. It was difficult to coordinate the times and temperatures of the two lots.

The results of the shear-press readings merely confirmed that irradiation levels of $200 \mathrm{Krad}$ have a softening effect on strawberries.

Irradiation as a means of controlling losses due to decay in air-transported strawberries may be practical only if the fruit is subjected to warm temperatures for excessive periods. If the retailers keep the fruit at low temperatures and can sell the fruit within two days after receiving it frum the wholesaler the probability of decay is. substantially reduced. 
Table 3. Allo-Kramer shear-press readings of control and irradiated strawberries.

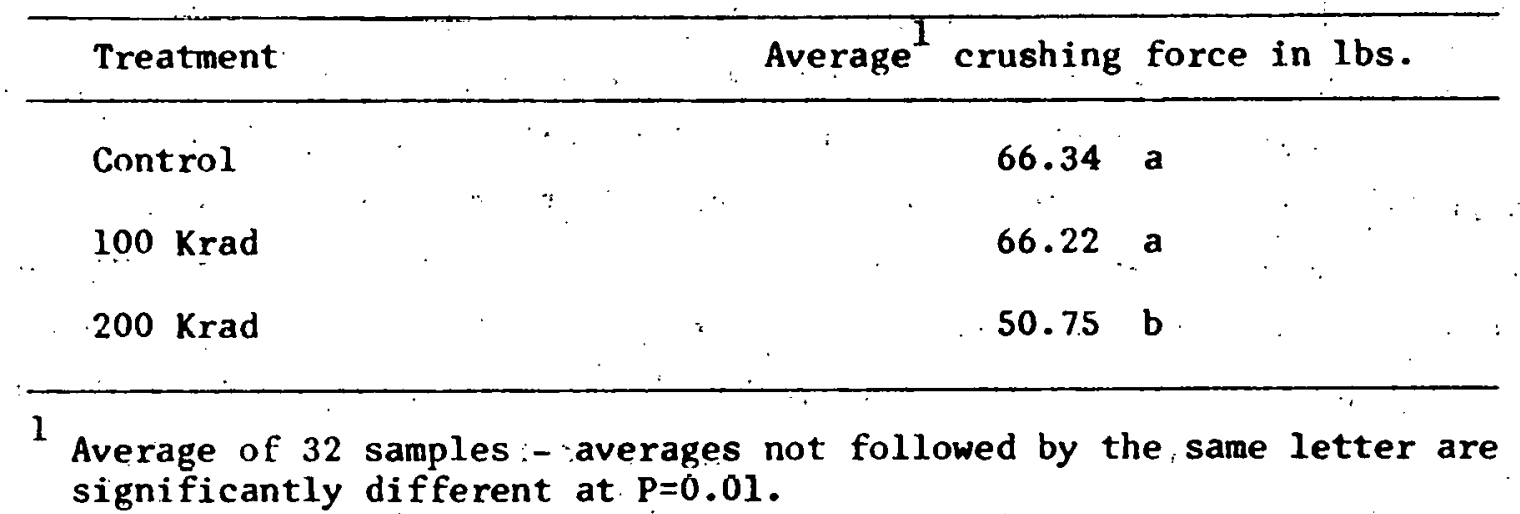
significantly different at $P=0.01$.

$-40-$ 
The greater amount of soft fruit found in New York is in part a reflection of transit injury. However, there was also a difference in the way the fruit was graded with the evaluator at Davis including picker damage in the sound category.

At the moment, irradiation to $200 \mathrm{Krad}$ is beneficial in the air transport of strawberries. If the airlines improved their service to keep the fruit continuously cold, this benefit might not be found. 
EFFECT OF HEAT AND IRRADIATION ALONE AND IN COMBINATION ON COLOR CHANGES IN PEACHES AND NECTARINES

Carol F. Johnson, Camilia Boyd, and E. C." Maxie

I. GARDNER COLORIMETER READINGS ON THE FLESH OF PEACHES AND NECTARINES TREATED TO 0 and $100 \mathrm{KRAD}$.

$\begin{array}{cc}\text { Samples: Peaches - Elberta } & \text { Nectarines - Gold King } \\ \text { Fay Elberta } & \text { Le Grand } \\ \text { Rio Oso Gem } & \text { Red Grand } \\ \text { Suncrest } & \end{array}$

\section{GENERAL PROCEDURE}

The fruit was sorted into groups of 10 representative of the harvest maturity. Half of the fruit (70) was irradiated to $100 \mathrm{Krad}$ and both control and irradiated fruit were placed at $68^{\circ} \mathrm{F}$ to ripen. Ten fruit from each treatment were sampled each day for 6 consecutive days. A slice was removed from one side and the color reflectance of the flat surface of the flesh of each fruit was measured using a Gardner Color Difference Meter fitted with a 1-1/2 inch diameter exposure area. A yellow standard was used having the following readings; $\mathrm{Rd}=56.6$, $a=+8.2, b=+49.6$. Prior to the color readings, pressure readings were taken on each fruit with a Magness Taylor pressure tester with a $5 / 16$ inch tip.

\section{RESULTS}

The data are presented in Figs. 1 through 6. With peaches, the "Rd" values (lightness) in irradiated fruit read lower by a statistically significant amount in three varieties ('Fay Elberta,' 'Rio Oso Gem,' and 'Suncrest'). There was an overall decrease in the "Rd" value over the 6 days in all varieties. The "+a" values (redness) increased 


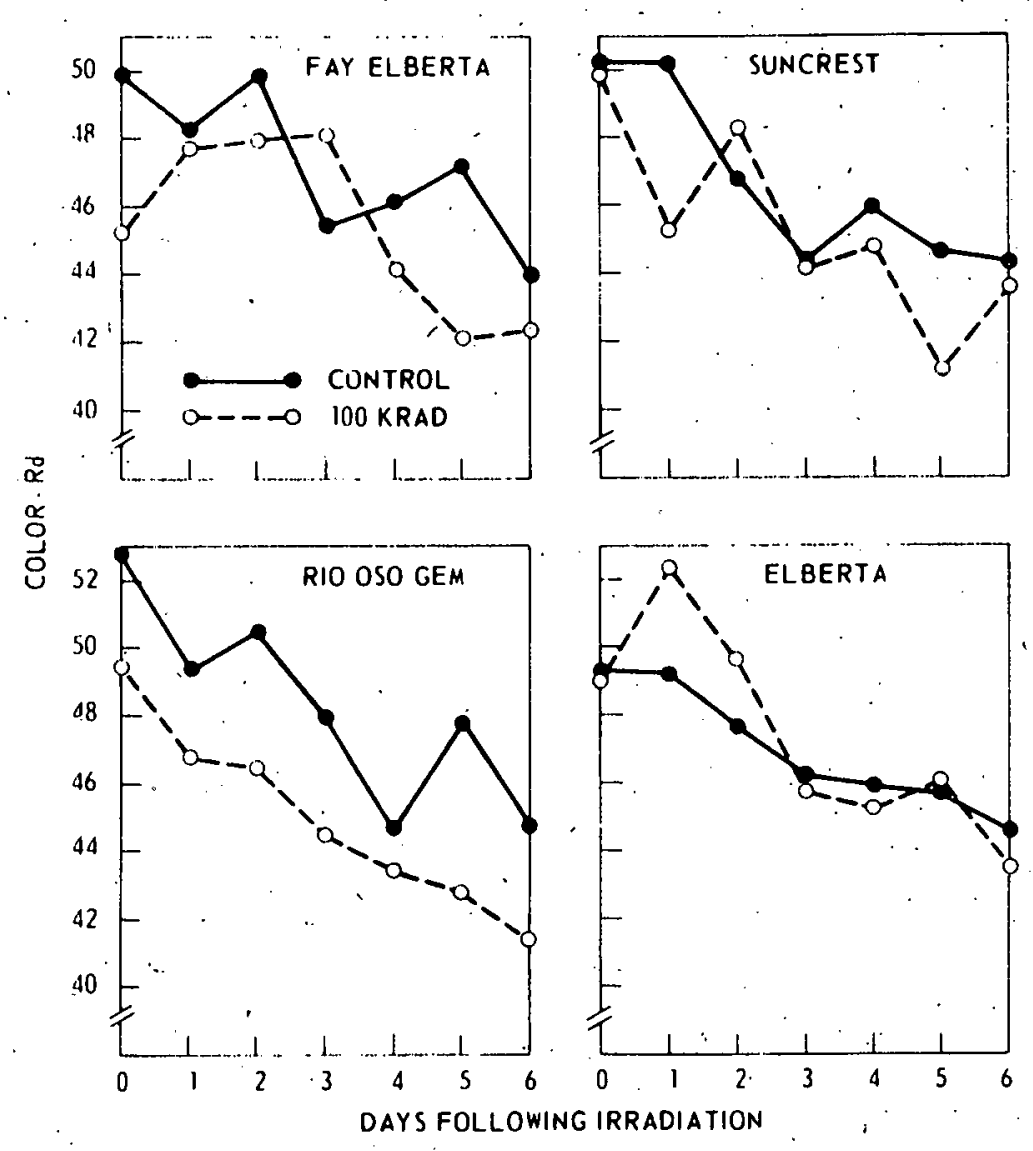

Fig. 1. "Rd" values (lightness) from Gardner Color Difference Meter used for flesh color of 4 varieties of peaches treated to 0 and 100 Krad. 


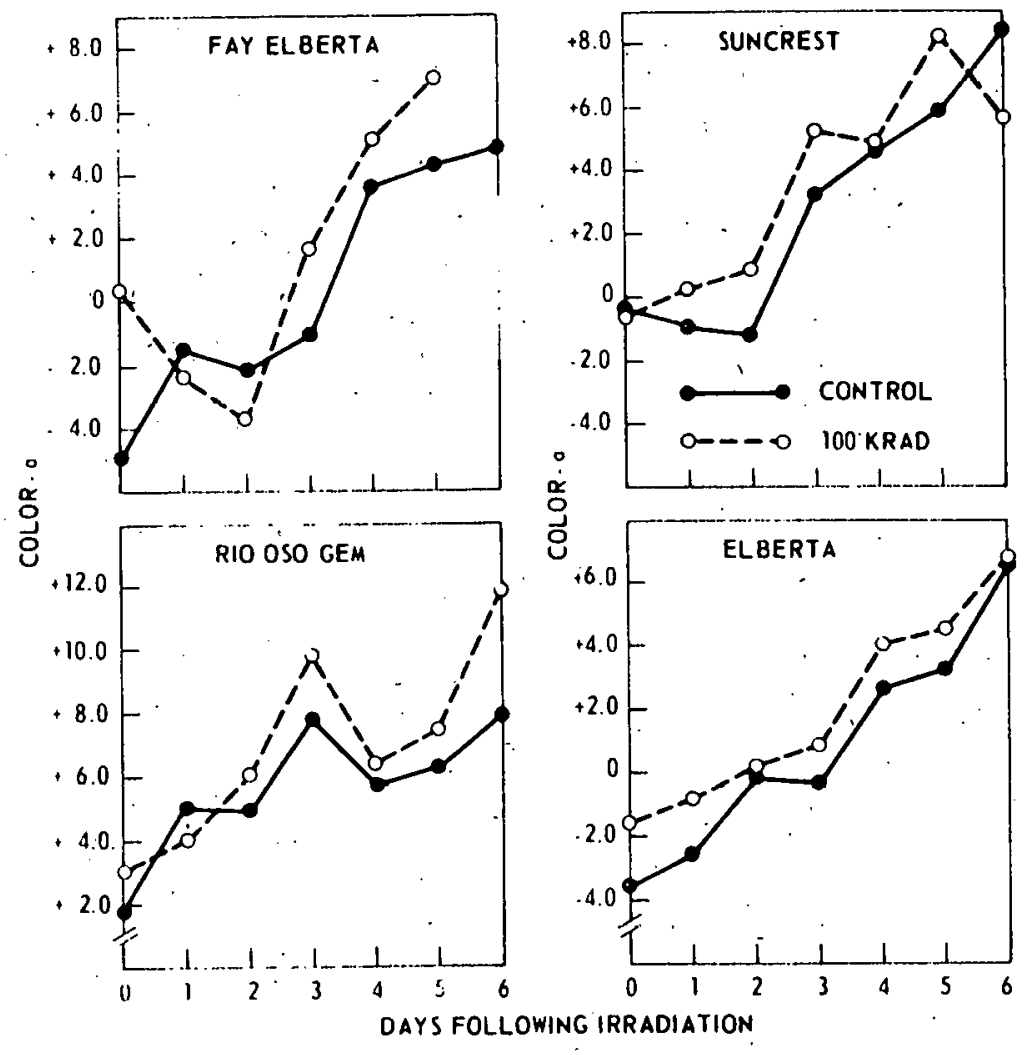

Fig. 2. "a" values (redness) from Gardner Color Difference Meter used for flesh color of 4 varieties of peaches treated to 0 and 100 Krad. 


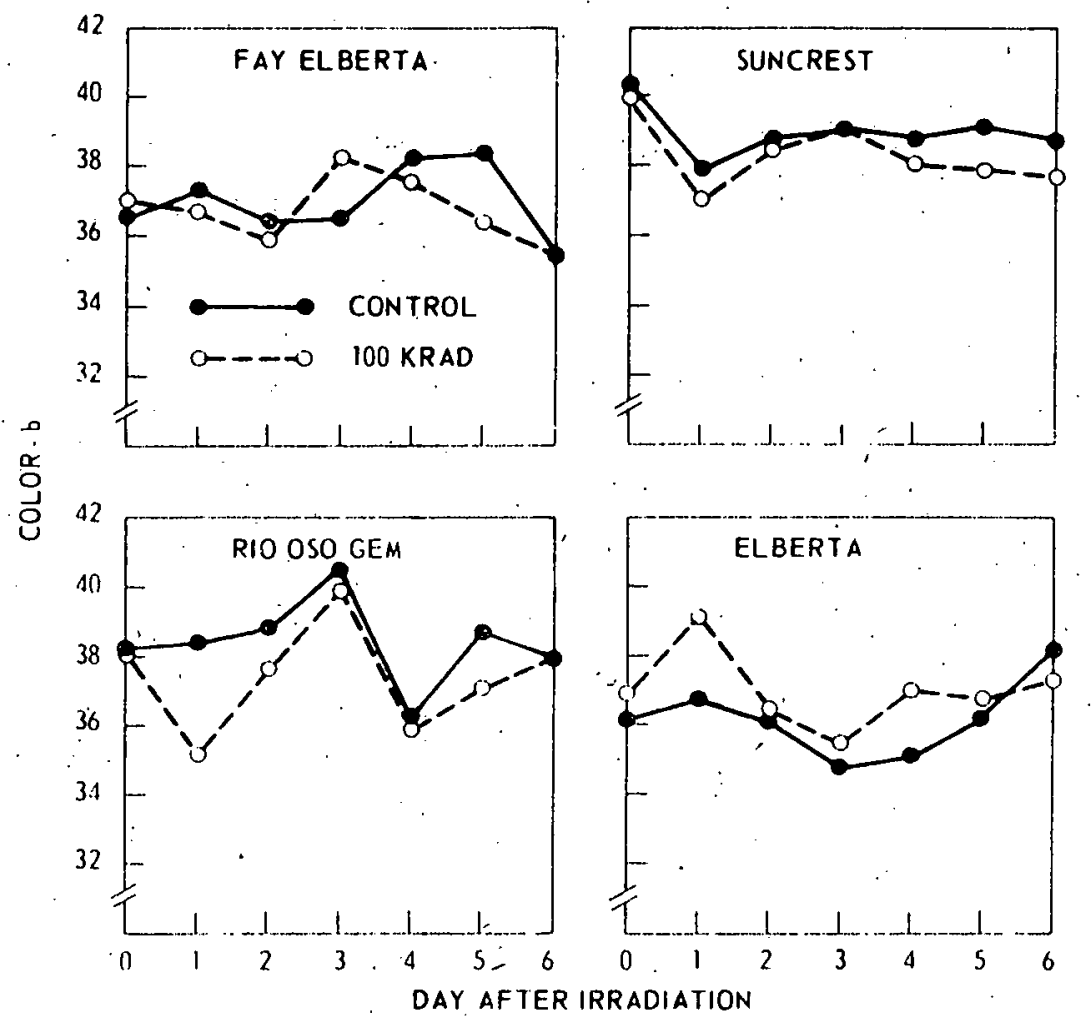

Fig. 3. "b" values (yellowness) from Gardner Color Difference Meter used for flesh color of 4 varieties of peaches treated to 0 and 100 Krad. 

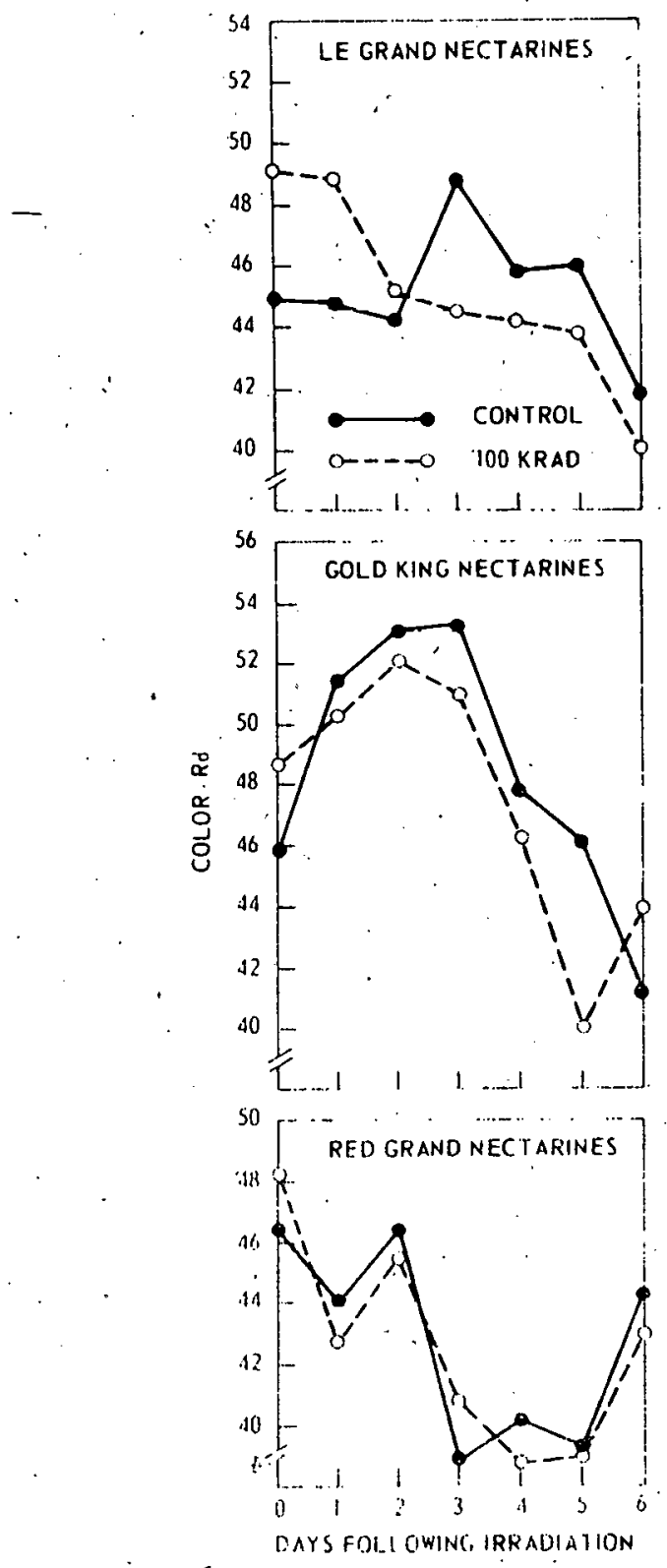

Fig. 4. "Rd" values (lightness) from Gardner Color Difference Meter. used for tlesh color of 3 varieties of nectarines treated to 0 and $100 \mathrm{Krad}$. 

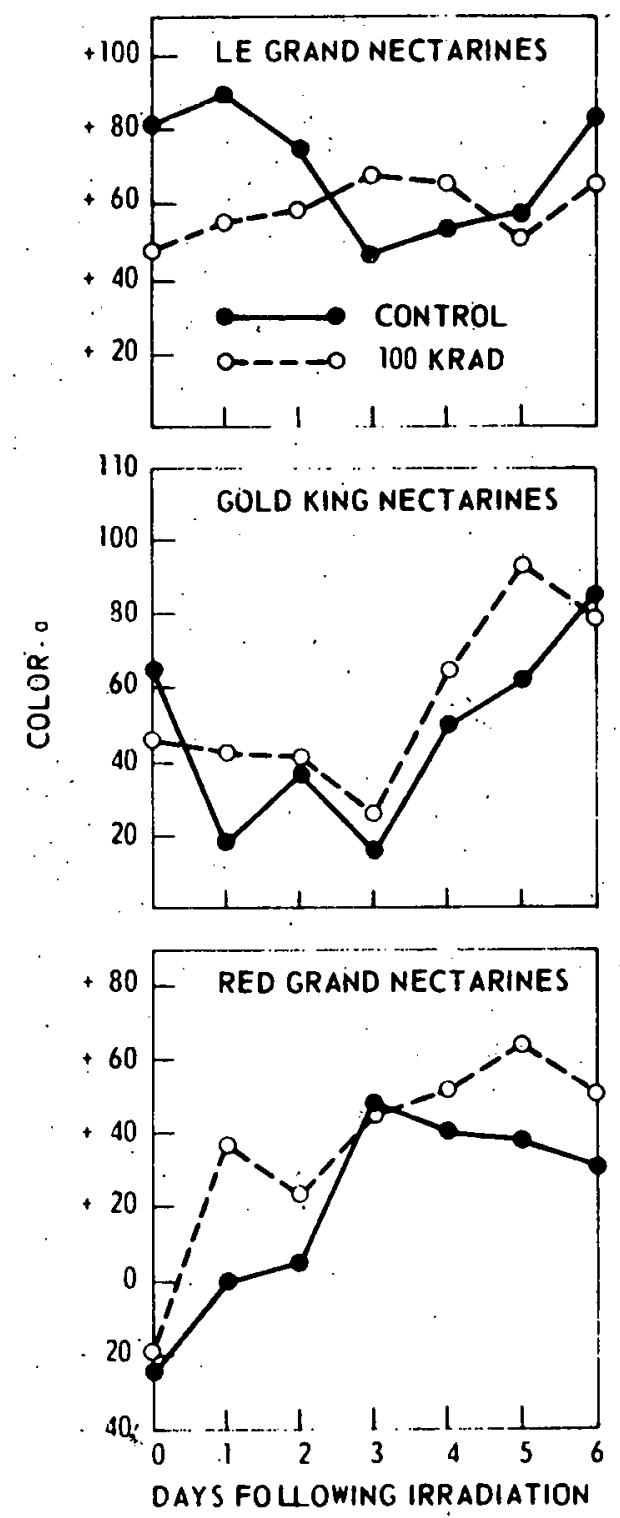

Fig. 5. "a" values (redness) from Gardner Color Difference Meter used for flesh color of 3 varieties of nectarines treated to 0 and 100 Krad. 

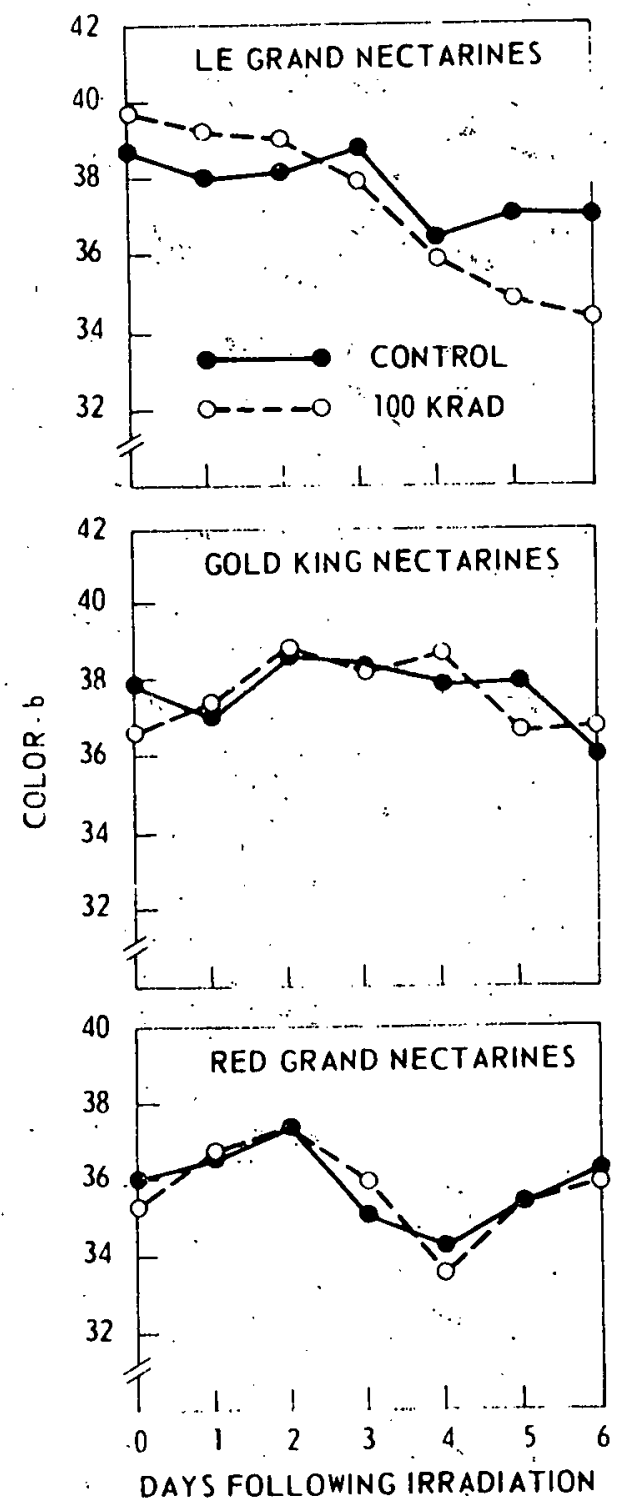

Fig." "6. "b" values" (yellowness) from Gardner Color Difference Meter uséd for flesh color of 3 varieties of nectarines treated to 0 and $100 \mathrm{Krad}$. 
significantly in only 2 of the peach varieties with irradiation ('Elberta' and 'Fay Elberta'). The "a" values increased in each variety over the 6 days. The " $b$ " values (yellowness) were not as consistent. They were higher after irradiation in the 'Elberta' variety, but slightly lower overall in the 'Rio 0so Gem' and 'Suncrest' varieties. Although there were significant differences between days for the " $b$ " values there were no consistent trends.

The nectarines were red fleshed near the pit which resulted in considerable variation depending on the depth of the slice removed before readings were taken. Treatment to $100 \mathrm{Krad}$ appeared to have little measurable effect on color of the nectarines. Only the "a" values of the 'Red Grand' nectarines were significantly different, with an increase in the irradiated samples. The "a" values increased over the 6 days ('Gold King' and 'Red Grand' varieties), while the "Rd" values decreased (all 3 varieties).

Since pressure test readings for flesh firmness are a good indication of ripeness, they were correlated with color values to determine if this objective method of color evaluation could also be used to indicate ripeness (Table 1 ). Only the control fruit was analyzed $(n=70)$. Peaches showed a better correlation, with all of the "Rd" and "a" values giving a significant correlation. For the nectarines, only the 'Red Grand' variety had correlation coefficients high enough to be of value.

II. SKIN COLOR READINGS ON ONE VARIETY OF PEACHES HEAT AND IRRADIATION TREATE.D.

Samples: Merrill Fiesta peaches

The fruit was sorted into groups of 5 having a slightly red skin undercolor. Treatments consisted of $0 \mathrm{Krad}$ (control); $52^{\circ} \mathrm{C}$ for $3-1 / 4 \mathrm{~min}$ and cooled for $3-1 / 2 \mathrm{~min}$ in ice water; $100 \mathrm{Krad}$; and $52^{\circ} \mathrm{C}+$ $100 \mathrm{Krad}$. The fruit was stored at $68^{\circ} \mathrm{F}$ and readings were taken on 
Table 1. Correlation coefficients between texture (Magness Taylor - pressure gun) and color readings (Gardner Color Difference Meter) for nectarines and peaches. The readings follow ripening over 6 6-day period.

\begin{tabular}{c} 
Pressure v8: \\
\cline { 2 - 2 } Rd
\end{tabular}

\section{PEACHES:}

Elberta

Fay Elberta

Rio Oso Gem

Suncrest
$0.47 * *$

$0.49 * *$

$0.64 *$

$0.49 * \star$
$-0.60 *$

$-0.69 * *$

$-0.51 *$ *

$-0.72 \star \star$
$-0.06$

$-0.34 * *$

0.16

0.03

NECTARINES:

Gold King

0.20

$-0.32 * *$

0.08

Le Grand

0.10

0.03

0.28 *

Red Grand

$0.43^{\star \star}$

$-0.60 *$

0.23

* Significant at $P=0.05$.

** Significant at $\mathrm{P}=0.01$. 
$0,3,5$, and 7 days following treatment. Skin color of both sides of: the fruit was determined on the intact, curved surface of the fruit and on the skin of the same spot excised and flattened. The light yellow standard ( $\mathrm{Rd}=61.3, a=-2.3, b=+22.1$ ) was used for all readings.

The above experiment was repeated, with fruits from the same group using $200 \mathrm{Krad}$ instead of $100 \mathrm{Krad}$. For this experiment the fruit had been left in cold storage 1 week prior to ripening.

\section{RESULTS}

The results were very similar whether the readings were taken on the curved (Fig. 7) or tlat surface (Fig. 8). High correlation coefficients (Table 2) also indicate this.

Irradiation to $100 \mathrm{Krad}$ resulted in a measurable skin color difference for the "a" value only (increased redness). Although significant, the differences are slight. The heat treatment resulted in a significant difference for the "Rd" and "b" values. The readings were both higher - that is lighter and more yellow in color. The heat treated fruit had less peach hairs (tuzz), which possibly could have affected the values.

In the second part of the experiment, irradiation to $200 \mathrm{Krad}$ did not measurably affect the "a" values, but resulted in lower " $b$ " values. This tendency was evident at $100 \mathrm{Krad}$ but not significant. The heat treatment did not significantly affect the readings. 

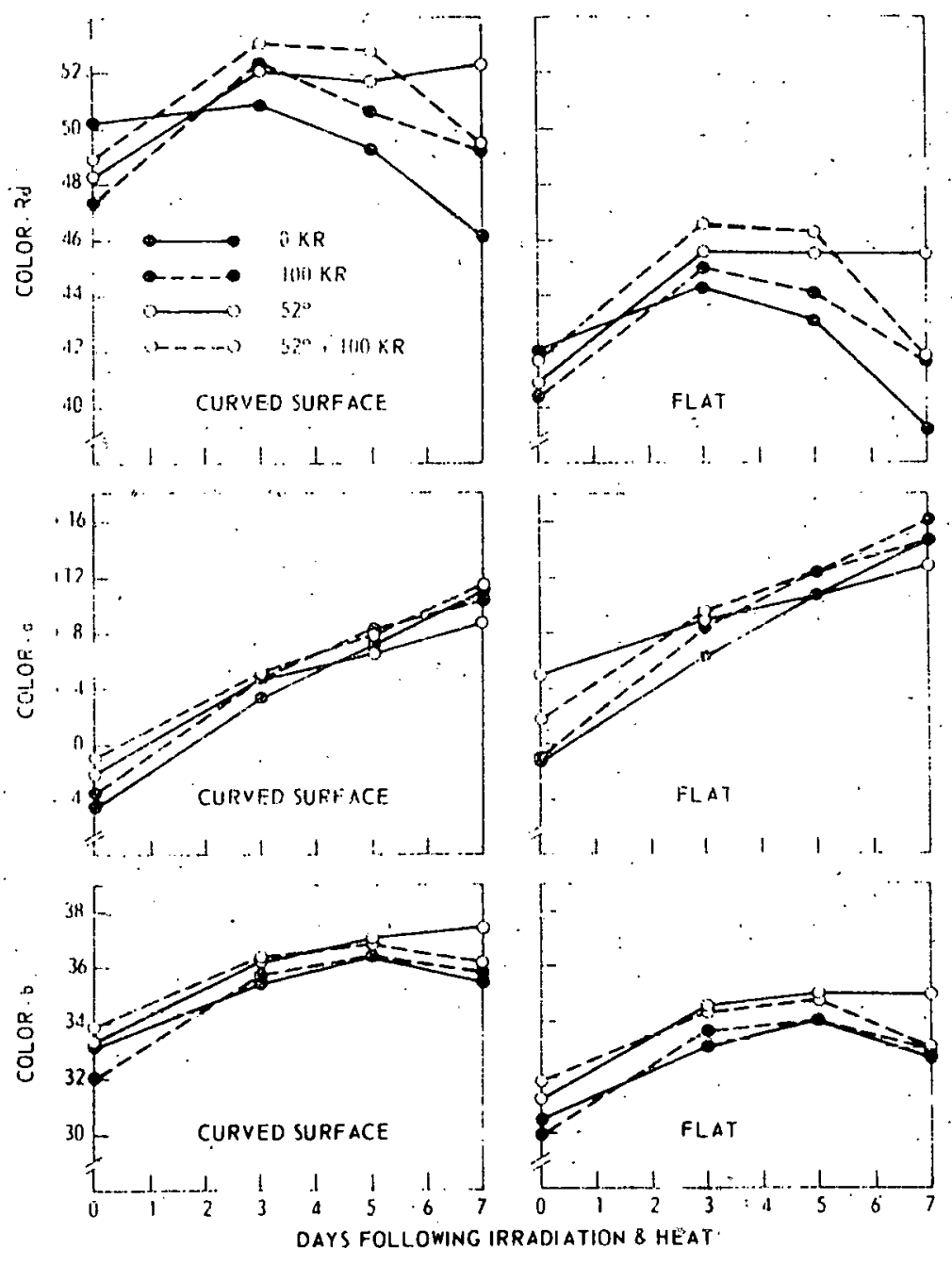

Fig. 7. Skin color readings using the Gardner Color Difference Meter on 'Merrill Fiesta' peaches treated with heat and irradiation (100 Grad). Readings were taken on curved intact fruit and on the same area after flattening.

$-52-$ 


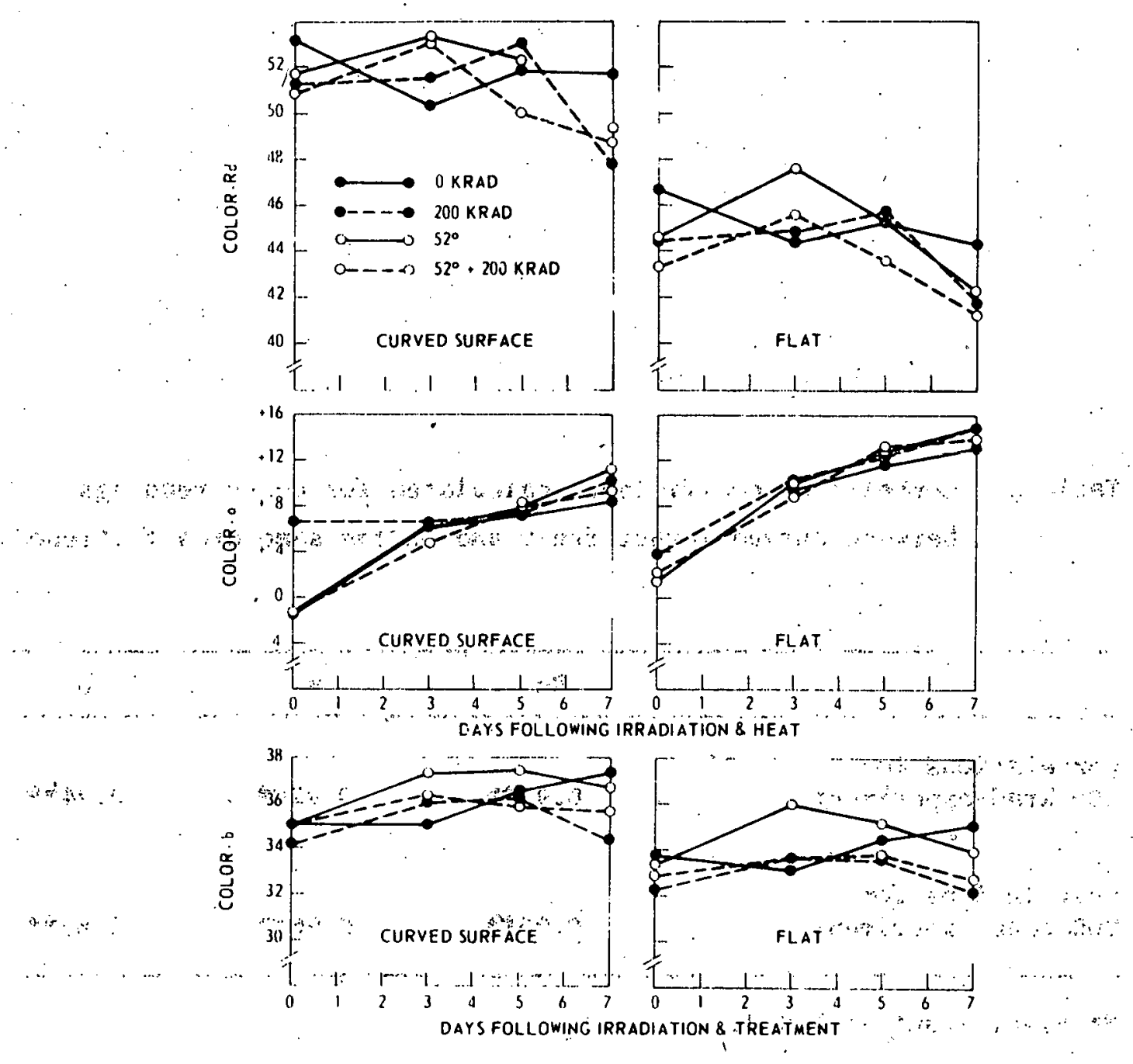

Fig. 8. Skin color differences using the Gardner Color Difference Meter on 'Merrill Fiesta' peaches treated with heat and irradiation $(200 \mathrm{Krad})$. Readings were taken on curved . intact fruit: and on the same area after flattening. 
Table 2. Correlation coefficients calculated for color readings between curved intact fruit and on the same area flattened.

\begin{tabular}{|c|c|c|c|}
\hline & Rd. & a & b \\
\hline $\begin{array}{l}\text { Correlations for } \\
100 \text { Krad experiment }\end{array}$ & 0.95 & $0.97^{* 4}$ & $0.94=$ \\
\hline $\begin{array}{l}\text { Correlations for } \\
200 \text { Krad experiment }\end{array}$ & $0.95^{* *}$ & $0.96 * *$ & $0.88^{* *}$ \\
\hline
\end{tabular}

** Significant at $\mathrm{P}=0.01$. 


\section{SUMMARY}

In one study, peaches and nectarines were irradiated to 0 and $100 \mathrm{Krad}$ and flesh color was measured over a 6-day period with a Gardner Color Difference Meter. Significant differences between control and irradiation were found in 2 out of the 3 color readings for each peach variety. There was generally no measurable difference at this level of irradiation in the nectarines. Significant day-to-: day differences were evident in almost all readings, but particularly: for the "Rd" and "a" values.

Skin color was measured on one peach variety treated with both heat and irradiation $\left(100 \mathrm{Krad}, 200 \mathrm{Krad}\right.$, and $\left.52^{\circ} \mathrm{C}\right)$. There was a : tendency for higher "a" values for the irradiated fruit, but there were significant differences only for the $100 \mathrm{Krad}$ and not $200 \mathrm{Krad}$ treated fruit. Irradiation to $200 \mathrm{Krad}$ resulted in lower "b" values. In the experiment using $100 \mathrm{Krad}$ plus heat, the heat resulted in higher "Rd" and "b" values. 


\section{EFFECT OF GAMMA RADIATION ON MUSHROOMS}

-E. C. Maxie, Carol F. Johnson, Henry L. Rae, and Camilla Boyd :.

Recent work at Michigan State University has indicated that gamma irradiation may be beneficial in retarding cap opening and stem growth in mushrooms. This report covers preliminary investigations in our laboratory on these phenomena.

\section{GROWTH MEASUREMENTS.}

\section{PROCEDURES}

Mediúm sized, brown mushrooms were obtained from Morgan Hill, California, tránsported to Davis, stored overnight at $41^{\bullet} \mathrm{F}$ and irradiated the following day.

For growth measurements, mushrooms were selected for uniformity of color and size, and divided into 8 lots of 20 mushrooms each. Cap diameter and mushroom height were measured using vernier calipers. India-ink marks were drawn across the caps so that measurements were made at precisely the same point each time. For storage, the mushrooms were placed in brown paper bags, containing a moist paper towel, then placed at 32,41 and $68^{\circ} \mathrm{F}$. Samples held at $68^{\circ} \mathrm{F}$ were measured daily, and those at 32 and $41^{\circ} \mathrm{F}$ every $2-4$ days.

\section{RESULTS}

As shown in Fig. 1, there was little or no advantage of irradiation on the rate of cap opening of mushrooms stored at $32^{\circ} \mathrm{F}$. At 41 and $68^{\circ} \mathrm{F}$, the rate was reduced by the treatment. The differences, relative to dose, were not great at either temperature, and all irradiated samples were considerably better than were unirradiated samples.

As shown in Fig. 2, there was no real advantage in the use of irradiation at any dose and temperature on the rate of stem growth. 


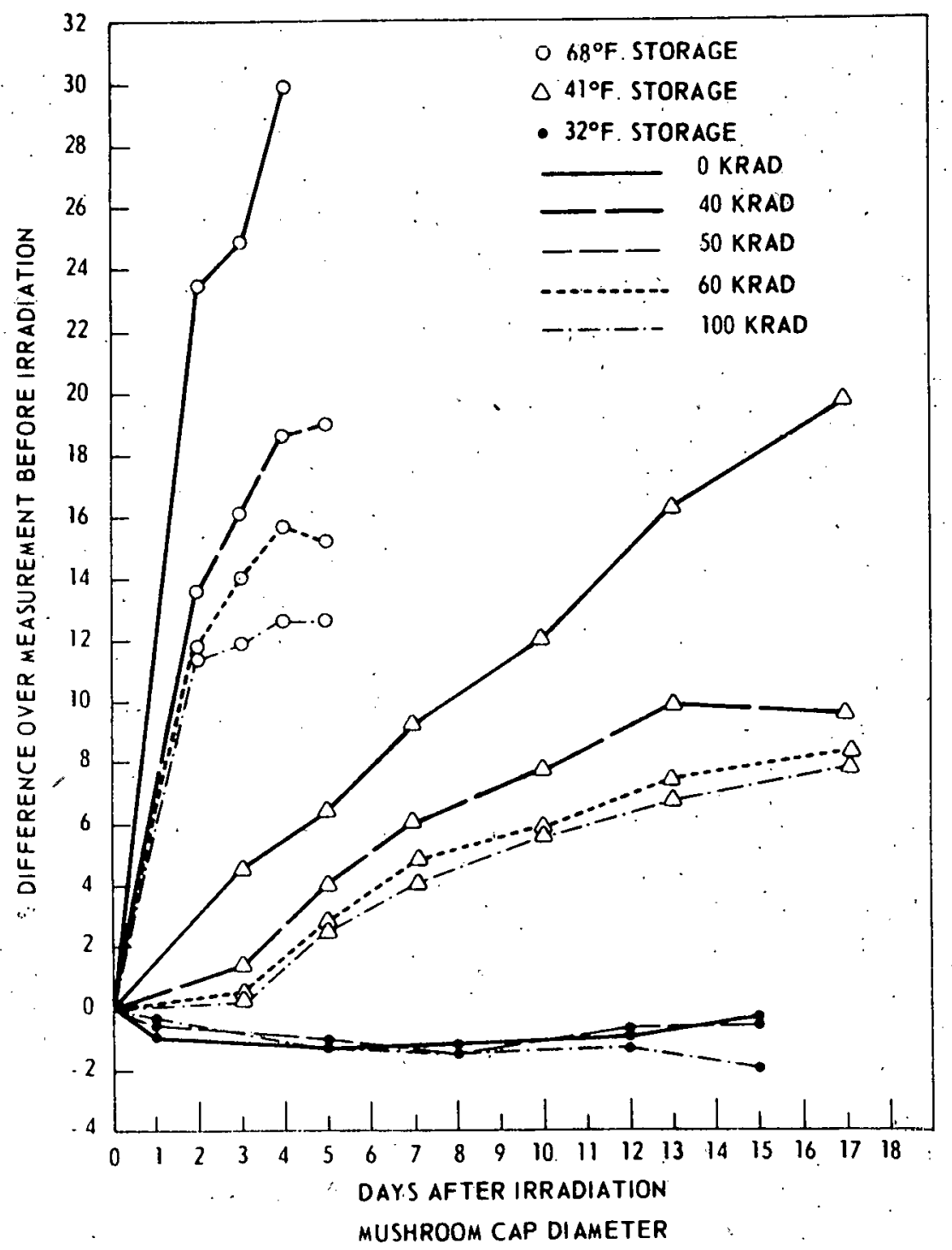

Fig. 1. Effect of gamma irradiation on rate of cap opening of mush rooms. 


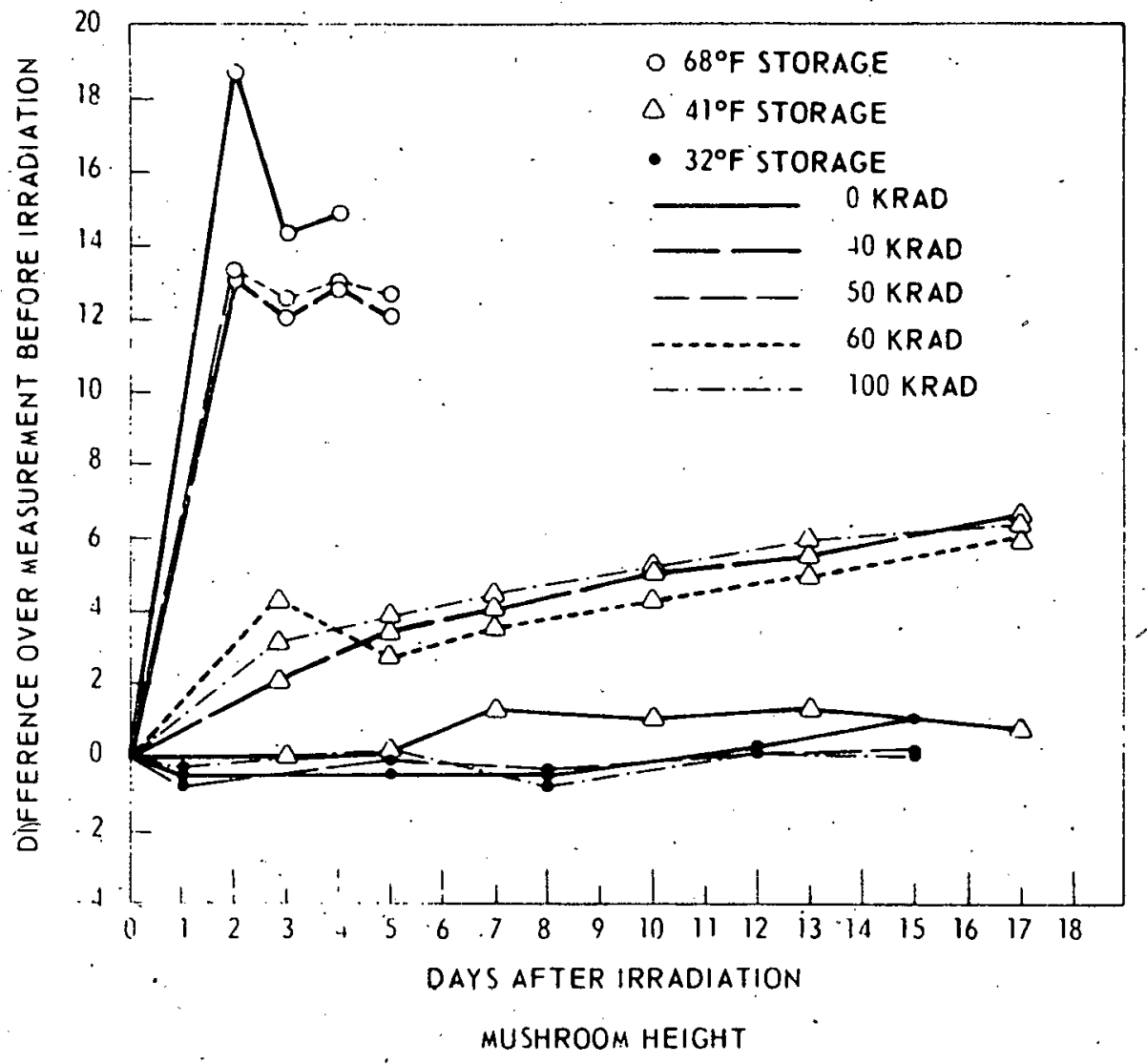

Fig. 2. Effect of gamma irradiation on rate of stem growth of mushrooms. 
II. SENSORY EVALUATTON.

\section{TEST I}

Medium sized, brown mushrooms were obtained from Morgan Hill, California, transported to Davis, stored overnight at $41^{\circ} \mathrm{F}$, and irradiated to 0 and $100 \mathrm{Krad}$ the next morning. They were stored at $41^{\circ} \mathrm{F}$ in open commercial containers 4-8 days until sampled for sensory evaluation.

\section{SENSORY EVALUATION}

Ten judges evaluated the mushrooms after 3 days preliminary testing. Over the 4-day testing period the mushroom caps remained closed in both the control and 100-Krad group. No open caps were tested. Prior to evaluation, all mushrooms were washed and those to be served cooked were steamed over boiling water for 10-15 min. depending on the size. They were then cooled and both cooked and raw mushrooms were sectioned into pie-shaped pieces after removing part of the stem. Ten gm samples were used for aroma evaluation in capped glasses. A triangle difference test was used for all evaluations.

\section{RESULTS}

The results are sumnarized in Table 1 . There were no significant differenres between $0 \mathrm{Krad}$ and 100-Krad treated mushrooms.

\section{TEST II}

This test was a repeat of the one described above: The mushrooms were chosen with slightly opened caps. The source of the mushrooms and the general procedures were as described above.

The mushrooms were irradiated in the closed button stage one day following harvest. The irradiated samples were placed at $59^{\circ} \mathrm{F}$ (with humidifier) for about 5-6 days and controls, 1-2 days, prior 
Table 1. Summary of sensory evaluation of mushrooms treated with. irradiation to 0 and $100 \mathrm{Krad}$.

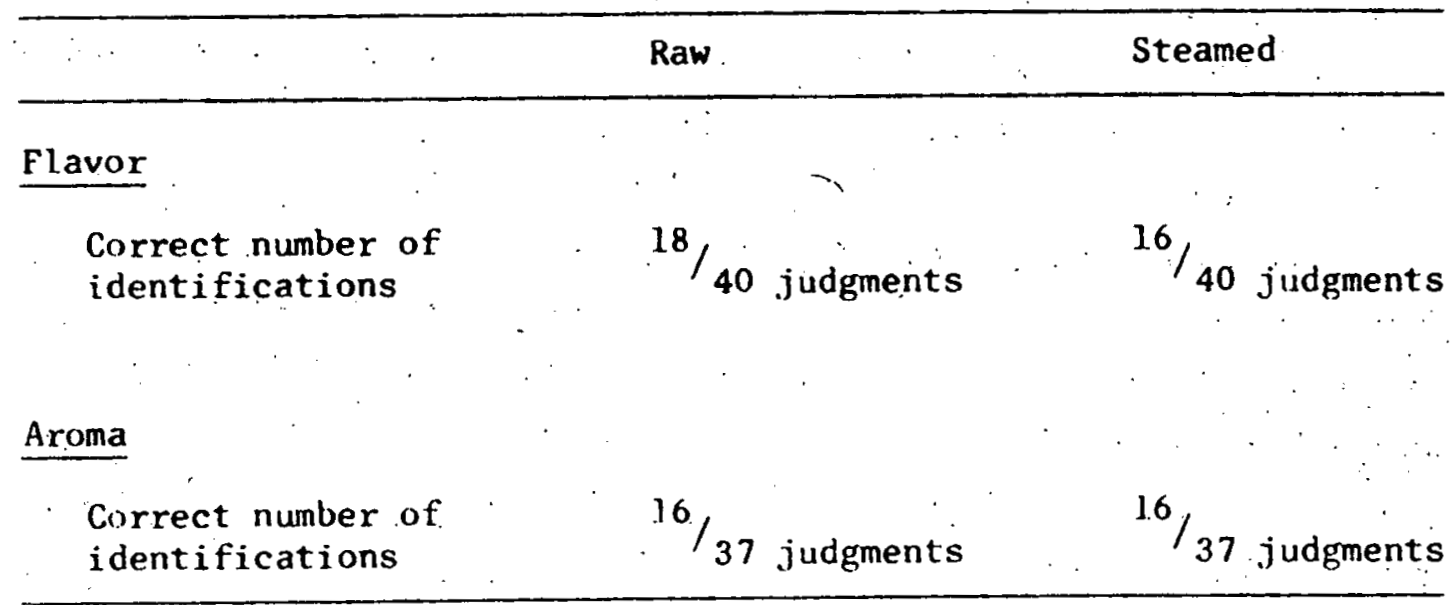


to evaluating. In neither case were very many of the veils completely broken.

The comparisons were again made on both raw and steamed mushrooms. Nine to ten judges evaluated flavor and aroma using a triangle difference test.

\section{RESULTS}

The mushrooms were stronger in flavor for this test as compared to the study on tightly closed caps. Even though the irradiated mushroom veils remained unbroken at $59^{\circ} \mathrm{F}$ for 5-6 days, the gills had opened and darkened. The mushrooms which were irradiated tended to dry out and become porous at the end of this storage period. These texture differences undoubtedly influenced the judges ability to differentiate between the control and irradiated samples.

The results of the sensory evaluation are given in Table 2. A significant difference was found in the flavor (and/or texture) of the raw samples only. The judges indicated texture differences. The flavor comparisons on the cooked mushrooms were just short of being significantly different. Comments by the judges indicated a slightly stronger flavor in the irradiated mushrooms. This may possibly be accounted for by differences in the stage of button opening. According to N. Tape (Mushroom News $9(12): 4-5$ ), mushrooms with open caps have more intense flavor than the closed button stage. There were no significant differences in the aroma samples.

III. EFFECT OF IRRADIATION ÓN THE ASCORBIC-ACID CONTENT OF MUSHROOMS. Mushrooms were purchased at Morgan Hill, California, on January 18,1967 . After overnight storage at $32^{\circ} \mathrm{F}$ the mushrooms were randomly divided into 24 lots of approximately $200 \mathrm{gms}$ each. After a second overnight storage at $32^{\circ} \mathrm{F}$ the mushrooms were irradiated, 8 lots each to 0,50 and $100 \mathrm{Krad}$. Immediately following irradiation, half 
Table 2. Second sensory evaluation on mushrooms treated to 0 and $100 \mathrm{Krad}$. Triangle test was made on slightly opened caps.

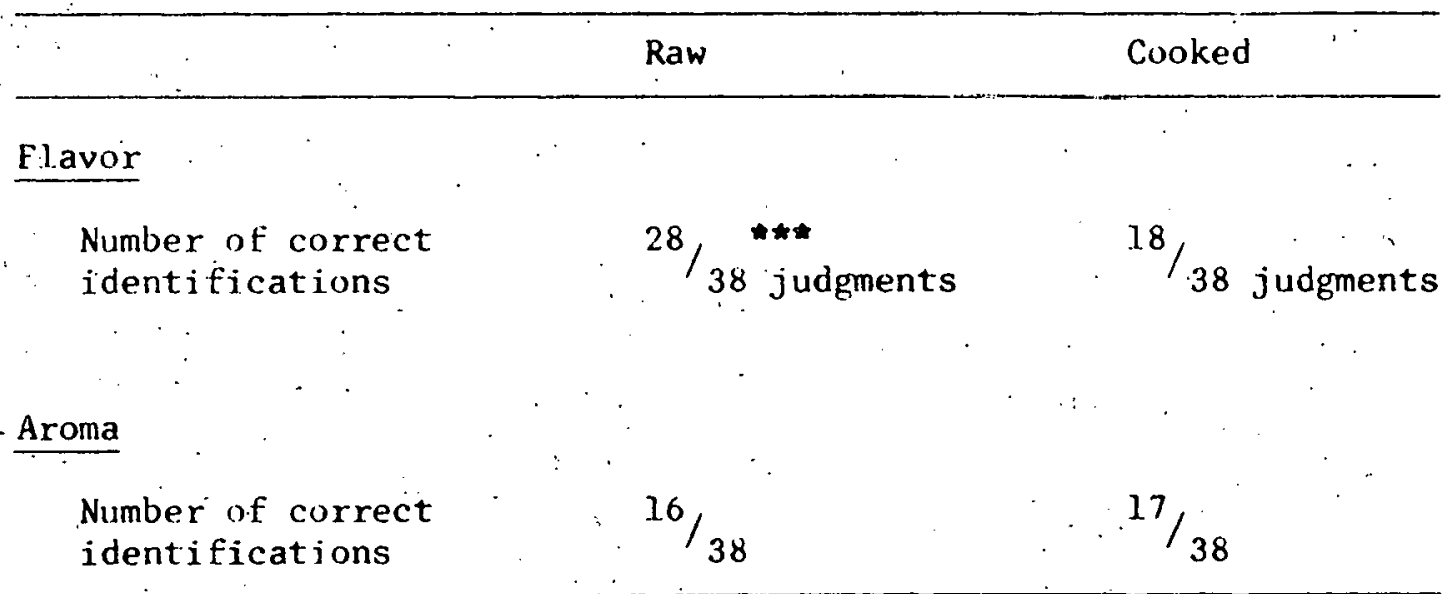

*** Significant at $\mathrm{P}=0.001$. 
of the mushrooms were analyzed for ascorbic acid and the remainder returned to $32^{\circ} \mathrm{F}$ until analyzed 2 weeks later.

Whole mushrooms were washed, then 100 gms promptly. blended for $3 \mathrm{~min}$. at full speed in a Waring Blendor with $250 \mathrm{ml}$ of $1 \% \mathrm{HPO}_{3}$. The slurry was filtered through 4 layers of cheesecloth and then a portion of this filtrate cleared by centrifugation at $10,000 \mathrm{rpm}$ for $15 \mathrm{~min}$.

Since previous trials had yielded only trace amounts of reduced. ascorbic acid, this form of ascorbate was determined by making one composite sample per treatment. The method of Loeffler and Ponting (1942, Ind. Eng. Chem. Anal. Ed. 14:846-849) was used to assay reduced ascorbic acid. For total ascorbic acid a $5 \mathrm{ml}$ aliquot per replicate for a given treatment was composited for titration with $45 \% \mathrm{~K}_{2} \mathrm{HPO}_{4}$ to pH 6.8 using a Beckman pH Meter. Using the method of Hughes (1956, Biochem. J.:64:203-208), the same size aliquot was pipetted into a $10 \mathrm{ml}$ volumetric flask and the procedure carried out making $\mathrm{pH}$ adjustments using the predetermined volume of $45 \% \mathrm{~K}_{2} \mathrm{HPO}_{4}$. Òne milliliter of the solution was taken for the color reading the same as for reduced ascorbic acid. Values for dehydroascorbic acid were obtained by subtracting the average value for reduced from the average total ascorbic acid present. All data are reported as $\mathrm{mg}$ ascorbic acid per $100 \mathrm{gms}$ mushrooms fresh weight.

Table 3 gives a summary of the results. There was no significant effect of gamma irradiation on the ascorbic-acid content of the mustirooms. 
Table 3. Effect of gamma irradiation on the ascorbic-acid content of mushrooms. stored at $32^{\circ} \mathrm{F}$. Results are expressed as $\mathrm{mg} / 100 \mathrm{gm}$ fresh weight.

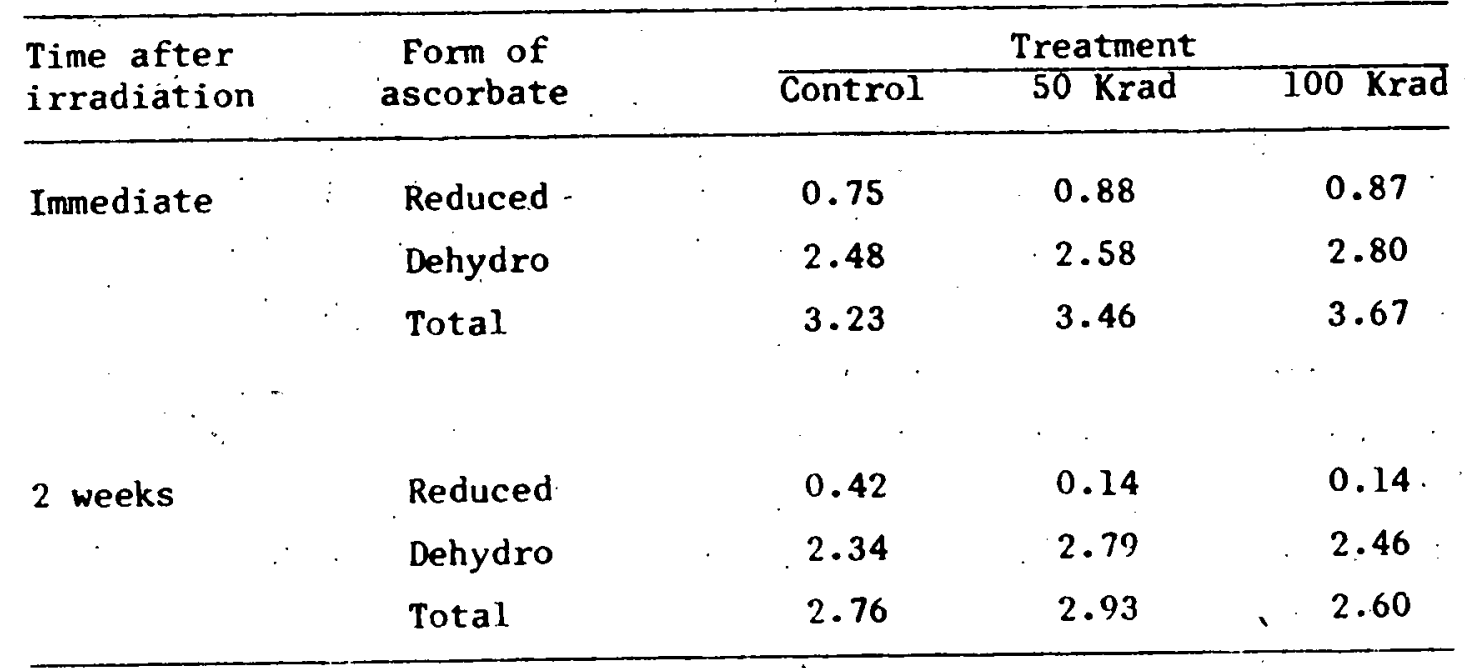




\title{
EFFECT OF GAMMA IRRADIATION ON \\ POSTHARVEST BEHAVIOR OF THE CANTALOUPE
}

Dale Ravetto, L. L. Morris, Carol F. Johnson, and E. C. Maxie

\begin{abstract}
Gamma irradiation to $400 \mathrm{Krad}$ has minimal effects on quality, ripeness, per cent soluble solids, flesh color, and flavor of cantaloupes. The flesh of irradiated melons is softened at all doses. Respiration, rate is increased but ethylene production is suppressed at 100-300 Krad. Ascorbic-acid content of melons is decreased by. irradiation. Sensory evaluation of different maturities of irradiated melons indicated an effect on texture but not on flavor. Storage temperature, length of storage, and maturity at the time of irradiation only slightly influenced the responses.
\end{abstract}

\section{INTRODUCTION}

The term "cantaloupe" is used to designate the small, netted, salmon-fleshed muskmelon classified as Cucumis melo var. reticulatus Nauden. Cantaloupes are the fourth most important of Californi.a's major vegetable crops, with over 43,000 acres, having a crop value of 40.5 million dollars, in 1966. Each year $3-5 \%$ of the total crop is lost to postharvest decay. With such an economically important crop, any means of reducing decay and extending shelf life would be beneficial.

Recently gamma irradiation has proven. effective in reducing decay and extending shelf life for certain fruits and vegetables. Little attention has been given to the effects of irradiation on cantaloupes. The U. S. Army Quartermaster Corps (6) reported that irradiated cantaloupes were softened and lost flavor. Bramlage et al. (1) stated that stem scar mold is reduced at low doses but higher doses (above 
$250 \mathrm{Krad}$ ) predisposed the melons to decay. They indicated only a slight softening of the flesh. Details were vague as to any extension of shelf life and other effects. Therefore, during the summer of 1966 studies were initiated with the objectives of determining the effects of irradiation on: 1) the physiology, 2) flavor, and 3) decay and shelf-iife extension of cantaloupes.

- The data reported here are concerned with the first two of the objectives. Large-scale and long-term storage studies were precluded by the lack of adequate amounts of fruit.

\section{MATERIALS AND METHODS}

During the summer of 1966 five experiments were conducted, as outlined below, using the Powdery Mildew Resistant \#45 (PMR-45) variety or the "Jacumba" variety. The melons were obtained from either the Firebaugh-Mendota area of California or from Experiment Station plantings at Davis. They were either sorted and treated on the day of harvest or held overnight at $59^{\circ} \mathrm{F}$, and then irradiated in the Mark II Co ${ }^{60}$ Experimental Food Irradiator. 'Storage temperatures were $68^{\circ} \mathrm{F}$ continuously and $41^{\circ} \mathrm{F}$ for 6 or 7 days followed by $68^{\circ} \mathrm{F}$. The . melons obtained from commercial packing sheds were treated with Brogdex, a chemical fungicide. Those harvested from Experiment Station plantings did not receive this treatment. Each melon was evaluated for quality, ripcness, flesh firmness, and soluble solids. The quality and ripeness classes, and numerical scores assigned to each class, are given in Tables $\mathrm{l}$ and 2 .

Quality attributes-included size, net height and fullness, ground spot, growth cracks, aroma, and decay.

Flesh firmnes's was measured with the Allo-Kramer shear press, Model. SP-12, with the standard shear compression cell with a 30-second down stroke. A $40 \mathrm{gm}$ sample of flesh for shearing was prepared as follows: An equatorial slice, averaging $7 \mathrm{~cm}$. thickness, was cut from each melon. The rind, innermost portion of the flesh near the seed 
Table 1. Quality parameters and numerical scores used to evaluate cantaloupes subjected to gamma irradiation.

\begin{tabular}{cl}
$\begin{array}{c}\text { Quality } \\
\text { score }\end{array}$ & \multicolumn{1}{c}{ Description } \\
\hline 9 & Excellent, no defects \\
7 & Good, minor defects \\
5 & Fair, defects present, but not serious \\
3 & Poor, major defects, unsalable but usable \\
1 & Unusable
\end{tabular}


Table 2. Ripeness classes and numerical scores used to evaluate cantaloupes subjected to gamma irradiation.

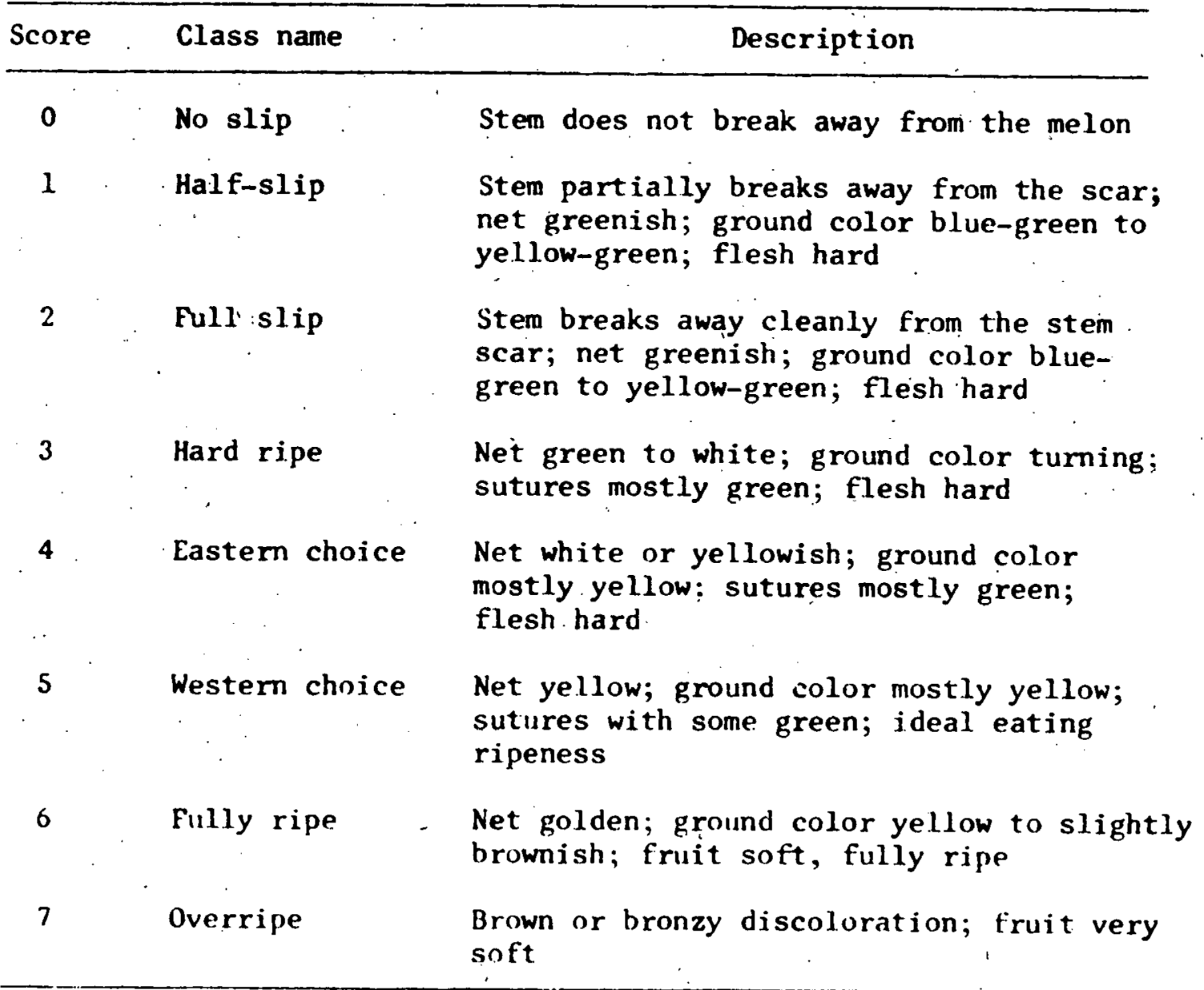


cavity, and the area of flesh containing vascular bundles and placentae attachment were removed and discarded, leaving 3 retangular pieces of flesh for shearing. The firmness was measured in pounds force required to pass through the sample.

Soluble solids were taken for each melon by collecting the juice expressed from the shear sample and placing a small amount on a Bausch and Lomb hand refractometer. Measurement of the rate of carbon dioxide evolved was done by the Claypool-Keefer. (2) method. Ethylene determinations were made by the method of Maxie et al. (5):

EXPERIMEN'I \#1. Effects of High Doses of Gamma Irradiation on Quality, Ripeness, Flesh Finniess, and Soluble Solids of Cantaloupes.

Two groups of 7 lots each ( 18 melons per lot) were prepared on August 9 as follows:

Group A: Held continuously at $68^{\circ} \mathrm{F}$.

\begin{tabular}{ccc} 
Lot \# & & Dose in kilorad \\
\cline { 2 - 2 } 1 & $\ddots$ & 0 \\
2 & $\cdots$ & 100 \\
3 & & 200 \\
4 & & 300 \\
5 & & 400 \\
6 & & 700 \\
7 & & 900
\end{tabular}

Group B: Identical to A, except the storage temperature was $41^{\circ} \mathrm{F}$. Six melons were evaluated at each of the following times: Group A: immediately after irradiation, after 2 and 4 days at $68^{\circ} \mathrm{F}$, Group B: after 6 days at $41^{\circ} \mathrm{F}$ and after 2 and 4 days at $68^{\circ} \mathrm{F}$.

EXPERIMENT \#2. Effect of Gamma Irradiation on Various Maturity C.lasses of Cantaloupes.

Cantalnupes of the following maturity classes were harvested on 
August 5: $1 / 2$ to $3 / 4 \mathrm{slip}$, hard ripe, eastern, and western choice. Twelve melons of each maturity were divided into 2 lots of 6 fruits each and treated to 0 and $300 \mathrm{krad}$. The fruit was then placed at $68^{\circ} \mathrm{F}$ and evaluated every 2 days until termination of the test.

EXPERIMENT \#3. Effect of Gamma Irradiation on Respiratory Behavior of "Jacumba" Cantaloupes.

Melons of uniform maturity, size, and quality were harvested, sorted, and irradiated to 0, 100, 200, and $300 \mathrm{Krad}$ on August 18. Three replicates of each dose level ( 6 melons per replicate) were sealed in ammunition cans and connected to flowneter boards. Carbon dioxide and ethylene measurements were made before, and 4, 8, 12, 16, 20 and 24 hours after treatment, and then daily until $50 \%$ of each replicate was discarded.

EXPERIMENT \#4. Effect of Low Doses of Gamma Irradiation on the Quality, Ripeness, Flesh Firmness, and Soluble Solids of Cantaloupes.

Fruit was harvested, sorted, and treated on August 24. Doses were $0,25,50$, and $75 \mathrm{Krad}$. The experimental plan was identical to Experiment $\# 1$, except only 5 melons of each treatment were evaluated at any one time.

EXPERIMENT \#5. Effect of Gamma Irradiation on Flavor, Texture, Aroma, and Color of Cantaloupes.

The fruit was harvested from 3 maturity classes: hard ripe, eastern, and western choice. They were irradiated to 0 and $300 \mathrm{Krad}$, at ambient temperature, on the day of harvest, and held at either $68^{\circ} \mathrm{F}$ for evaluation or stored at $41^{\circ} \mathrm{F}$ for 6 days prior to holding at $68^{\circ} \mathrm{F}$. The melons stored at $68^{\circ} \mathrm{F}$ immediately after irradiation were sampled at 2 or more of the following times: immediately after irradiation; second day after irradiation; and on the fourth, or fifth day after 
irradiation. Thiuse held in sturage at $41^{\circ}$ F were sampled as follows: 6 days at $41^{\circ} \mathrm{F}$, with 0 days at $68^{\circ} \mathrm{F}$; and 6 days at $41^{\circ} \mathrm{E}$, with 2 days at $68^{\circ} \mathrm{F}$. Five to six melons, were sampled from each treatment on each evaluation day. Only the center 3 or 4 inches of each melon, was used for physical and organoleptic measurements. Flesh color was measured with a Gardner Automatic Color Difference Meter, Model AC-3, using the following standards: $\operatorname{Rd}=61.3, a=-2.3, b=+22.1$. A 1.5-inch diameter exposure window was used. In conjunction with sensory evaluation of irradiated cantaloupes, a study was conducted of the effects of irradiation on: ascorbic-acid content (vitamin C) of hard-ripe melons. The melons were divided into 5 lots of 4 fruits each. One set of unirradiated samples was analyzed on the date of irradiation to determine the ascorbic-acid content at the start of the experiment. Following: irradiation: at $0,100,200$, and $300 \mathrm{Krad}$, the fruit was held at $41^{\circ} \mathrm{F}$ for 7 'days to simulate a transcontinental shipment, and sampled as described above. One section of each of the 4 fruits per lot was combined to make 3 composite samples. The samples were then run through an Acme Supreme Juicerator, Model \#6001 (Acme Juicer Mfg. Co., Sierra Madre, California). All but a small amount of fiberous.. material was expressed as juice. This juice was filtered through cheesecloth as it was collected from the juicerator. An appropriate volume of the filtered juice was added to $1 \% \mathrm{HPO}_{3}$ for analys is of ascorbic acid by the methods of loeffler and Ponting (3) and Hughes. $(4)$.

Results are expressed as an average of at least 3 replicates in every case.

\section{RESULTS}

\section{EXPERIMENT \#1.}

Figure? shows the effect of gamma irradiation on the quality of melons stored continuously at $68^{\circ} \mathrm{F}$. Quality was not reduced until 
after 4 days, when some of the irradiated melons exhibited slightly sunken areas in the rind, bronzing of the sutures, off-aroma, and atypical flavors. These responses were more pronounced at dose levels above $400 \mathrm{Krad}$. Melons with off-aroma had disorganized seed cavities but the seeds were not discolored. As shown in Fig. 2, the same responses were observed for irradiated melons stored at $41^{\circ} \mathrm{F}$ for 6 days prior to cualuation. After 4. days dt $68^{\circ} \mathrm{F}$ many of the irradiated melons had stem-end rot caused by Rhizopus stolonifer (Ehrenb. ex Fr.) tsind.

Figures 3 and 4 show the effect of gamma irradiation on ripening of cantaloupes held at the two storage temperatures. There was an apparent delay in ripening in melons irradiated to $900 \mathrm{Krad}$; all others ripened normally and uniformly.

Figure 5 shows the effect of irradiation on flesh firmness of cantaloupes held continuously at $68^{\circ} \mathrm{F}$. Softening is immediate and pronounced at all doses. As the melons ripened in storage, this softening effect became less noticeable. Figure 6 shows the effect of irradiation on flesh firmness of melons stored at $41^{\circ} \mathrm{F}$ for 6 days. The softening effect was not as pronounced as in fruits stored at $68^{\circ} \mathrm{F}$.

The effect of irradiation on the per cent soluble solids of melons held at $68^{\circ} \mathrm{F}$ continunusly and at $41^{\circ} \mathrm{F}$ for 6 days is shown in Figs. 7 and 8 respectively. There does not appear to be any clearly defined influence at any dose level or at either temperature. Fruits subjected to $400 \mathrm{Krad}$ and evaluated on August 17 showed a low percentage of solids, but considering the other data this is probably an anomaly.

TXXPRIMENT \#2.

Figures ? throing 12 show the effect of gamma irradiation on quality of cantaloupes of various maturity classes. Differences between control and irradiated lots are small for each maturity class 


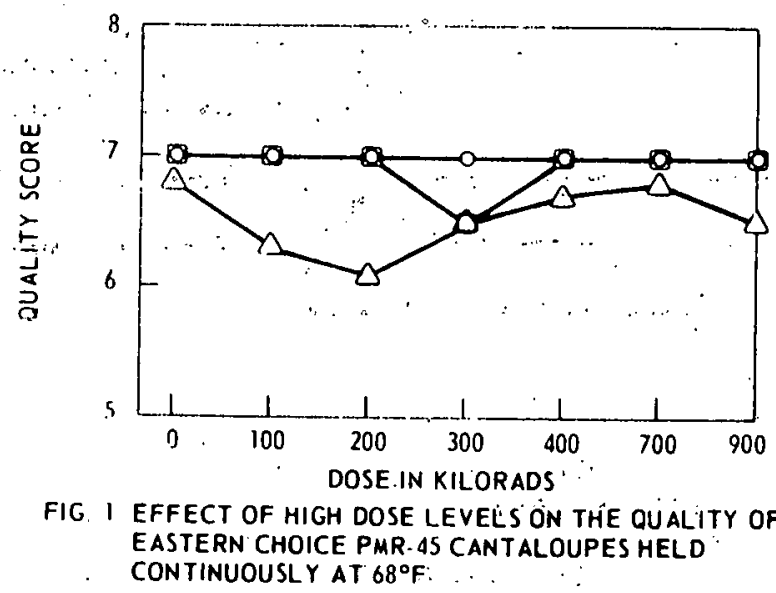

EVALUATION DATES

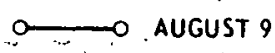

$\square$ aUgUST II

$\triangle \longrightarrow$ aUGUST 13

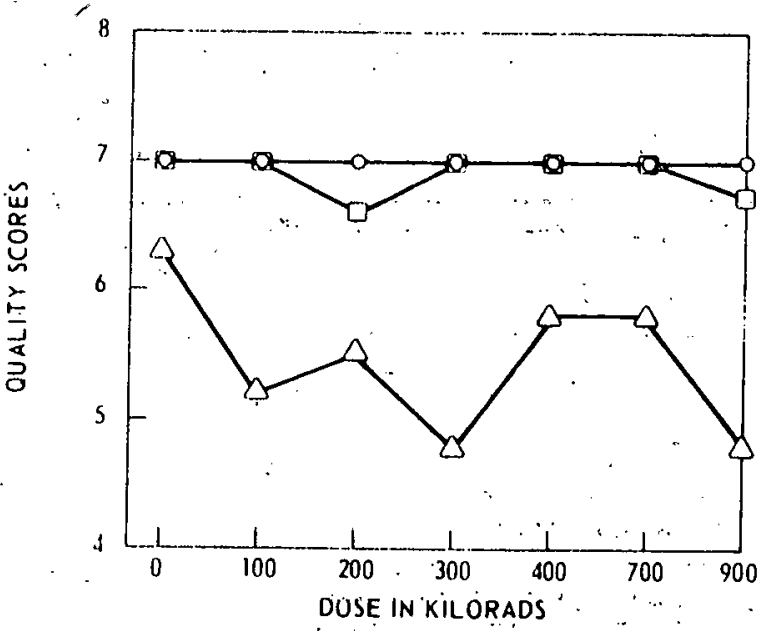

EVALUATION DATES

$\underset{0}{0}$ AUGUST 15

$\square$ AUGUST 17

$\triangle$ AUGUST 19

FIG 2 EFFECTS OF HIGH DOSE LEVELS ON THE OUALITY OF EASTERN CHOICE PMR: 45 CANTALOUPES HELD FOR 6 DAYS AT $41^{\circ} \mathrm{F}$ BEFORE STORAGE AT $68^{\circ} \mathrm{F}$ 


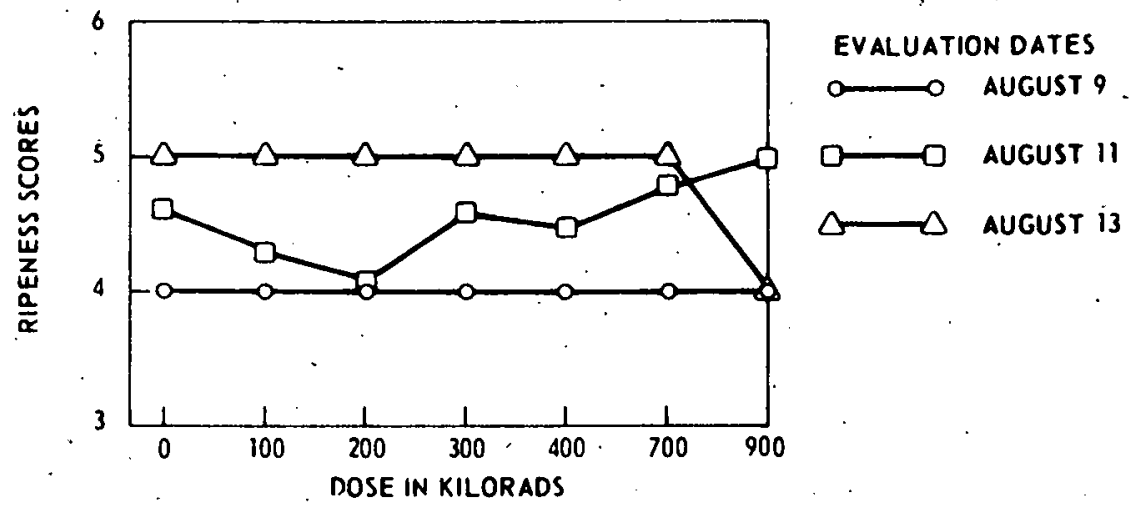

FIG 3. EFFECTS OF HIGH DOSE LEVELS ON RIPENING OF EASTERN CHOICE PMR.45 CANTALOUPES HELD CONTINUOUSLY AT $68^{\circ} \mathrm{F}$

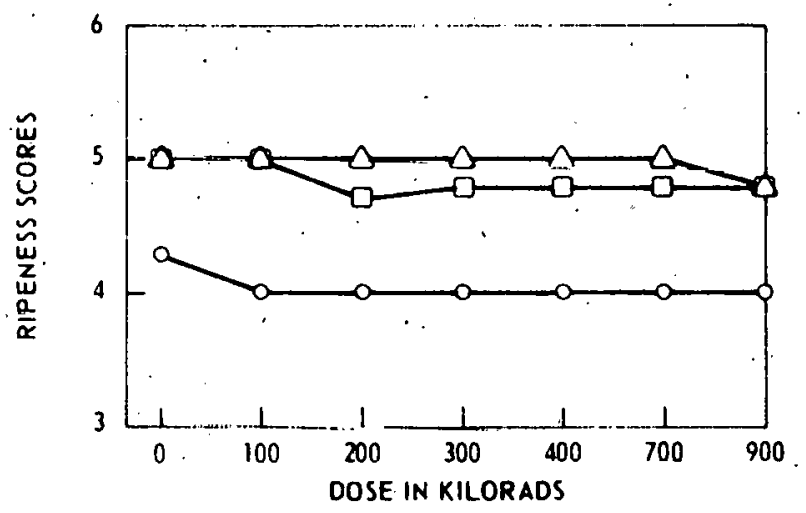

EVALUATION DATES

$\multimap$ AUGUST IS

aUGUST 17

$\triangle$ AUGUST 19

FIG. A EFFECTS OF HIGH DOSE LEVELS ON RIPENING OF EASTERN CHOICE PMR. 45 CANTALOUPES HELD FOR 6 DAYS AT $41^{\circ} \mathrm{F}$. BEFORE STORAGE AT $68^{\circ} \mathrm{F}$ 


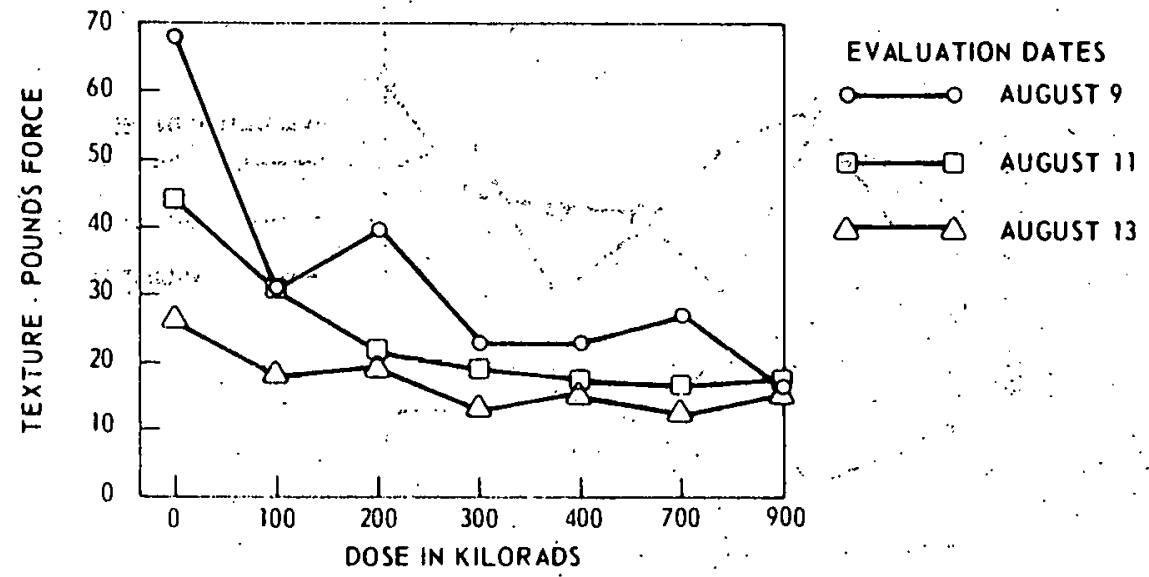

FIG. 5 EFFECTS OF HIGH DOOSE LEVELS ON THE TEXTURE OF EASTERN CHOICE PMR 45 CANTALOÚPES WHEN HELD CONTINUOUSLY YAT $68^{\circ} \mathrm{F}$,

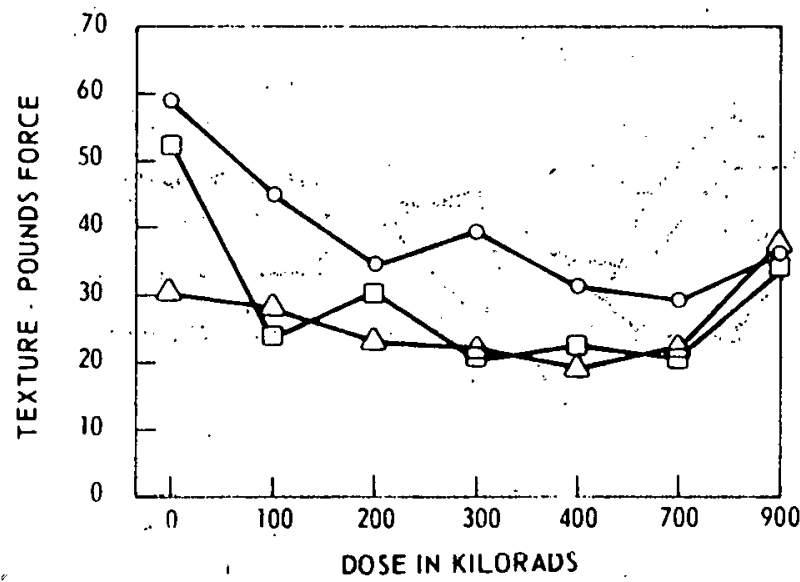

EVALUATION DATES

$\multimap$ AUGUST 15

$\square$ AUUGUST 17 $\triangle$ AUGUST 19

FIG 6 EFFECTS OF HIGH DOSE LEVELS ON THE TEXTURE OF EASTERN CHOICE PMR. 45 CANTALOUPES WHEN HELD FOR 6 DAYS AT $41^{\circ}$ F BEFORE'STORAGE AT $68^{\circ} \mathrm{F}$. 


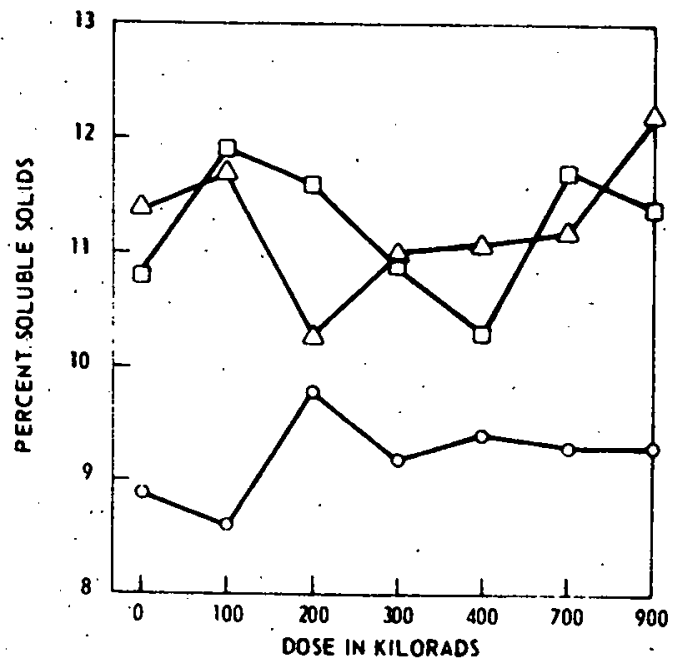

EVALUATION DATES

OLUCUST 9

$\square$ AUGUST

$\Delta \sim \Delta$ AUGUST 13

FIG 7 EFFECTS OF HIGH DOSE LEVELS ON THE SOLUBLE SOLIDS OF EASTERN CHOICE PMR. 4S CANTALOUPES WHEN HELO CONTINUOUSLY AT BB F

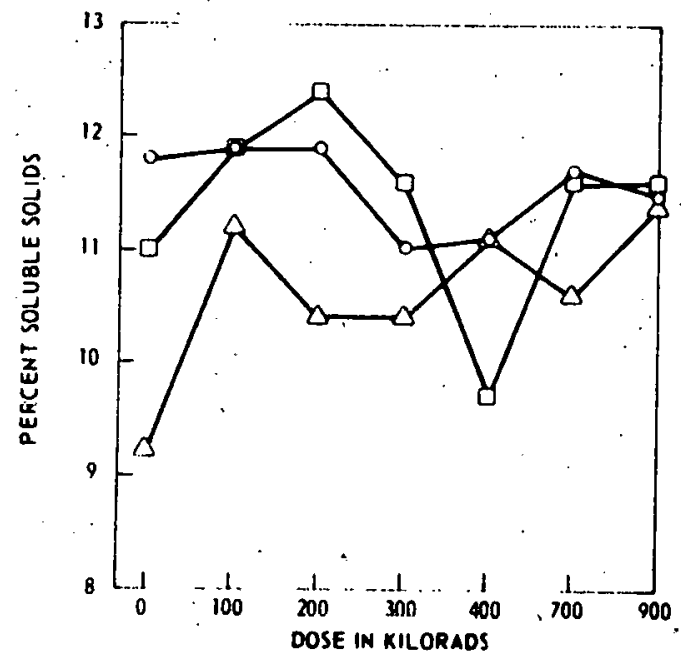

EVALUATION DATES

aUGUST is

$\square$ aUGUST 17

$\triangle$ aUcust 19

FIC 8 EFFECTS OF MIGH DOSE LEVELS ON SOL UBLE SOLIOS OF EASTERN CMOICE PMR-AS CANTALOUPES WHEN MELO FOR 6 DAYS AT AIOF BEFORE STORAGE AT $68^{\circ} \mathrm{F}$ 
$-\therefore$

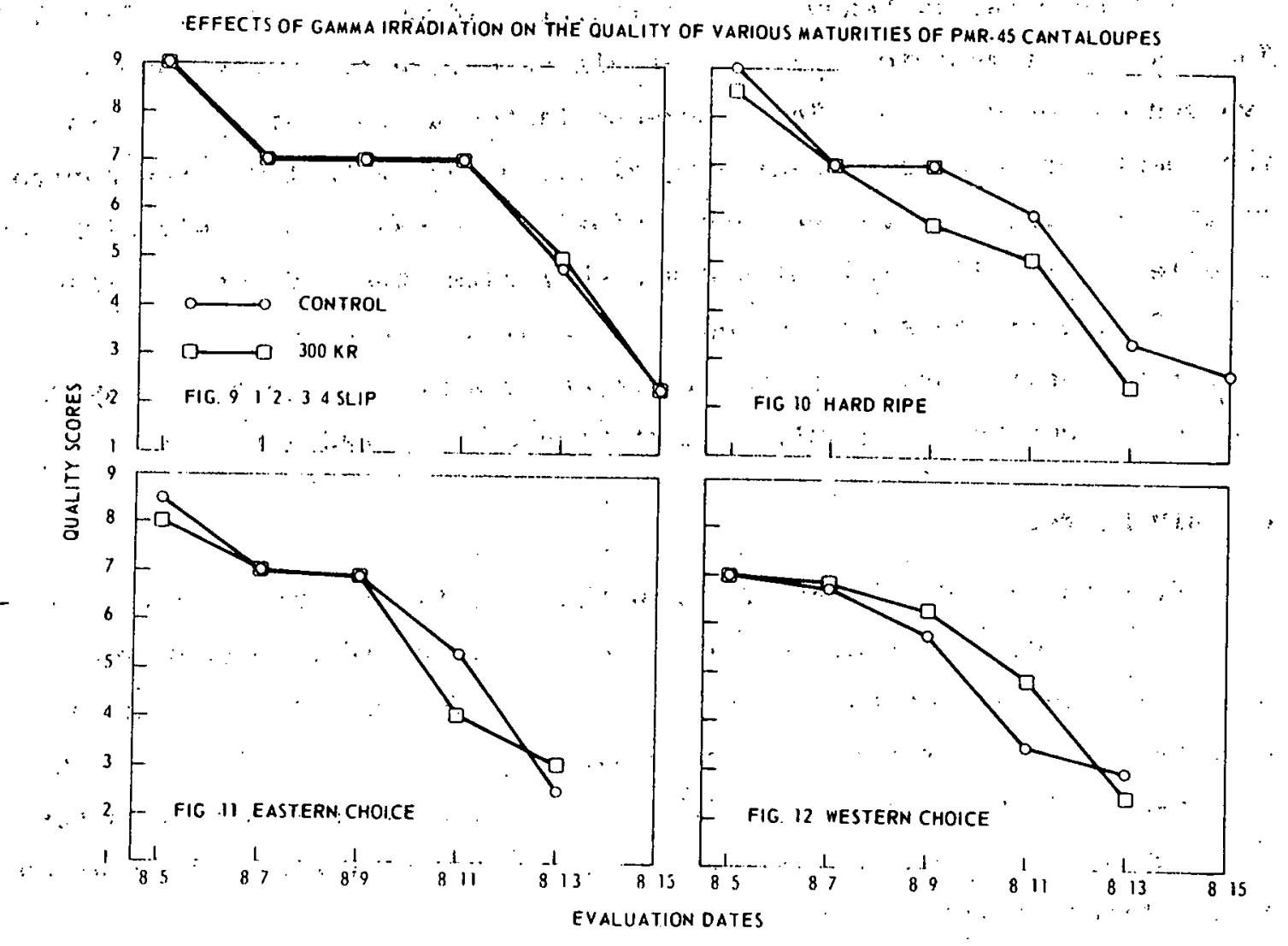


except the hard-ripe maturity where the shelf life was reduced by two days. Irradiation to $300 \mathrm{Krad}$; as shown in Figs. 13 through 16, had little effect on ripening rate of the melons. After 8 days at $68^{\circ} \mathrm{F}$ many of the melons were showing decay from Rhizopus stolonifer and Alternaria tenuis (Nees).

EXPERIMENT \#3.

The respiratory behavior of irradiated melons is shown in Fig. 17. There was an immediate increase, at all dose levels, in the rate of evolved carbon dioxide. This increase lasted approximately 8 hours then declined to a level nearly equal to, or below that, of the control fruit. The rate of evolved carbon dioxide increased inversely with the dose level; the 100-Krad lot had a higher rate than did the 300-Krad lot. Figure 18 shows an apparent suppression of ethylene production by irradiated melons. Only the 100-Krad treatment stimulated ethylene production and then for only a short time after irradiation.

\section{EXPERIMENT \#4.}

Figures 19, 20, 21, and 22 show the effects of gamma irradiation on the quality, ripeness, texture, and soluble solids, respectively, of cantaloupes stored continuously at $68^{\circ} \mathrm{F}$. The results are similar to Experiment \#l, except that there was no delay in ripening. Flesh firmness at $68^{\circ} \mathrm{F}$, as shown in Fig. 2l, is slightly increased by doses of 25 and $50 \mathrm{Krad}$ immediately after treatment, but the effect disappears by the time the melons are eating ripe.

The same general responses to irradiation occurred in melons stored at $41^{\circ} \mathrm{F}$ for 6 days prior to evaluation. As shown in Figs. 23 and 24 , there were no effects on quality or ripening. The effects on flesh firmness and per cent soluble solids were similar to those observed at $68^{\circ} \mathrm{F}$. 
EFFECTS OF GAMMA IRRATIATION ON THE RIPENING OF VARIOUS MATURITIES OF PMR-45 CANTALOUPES

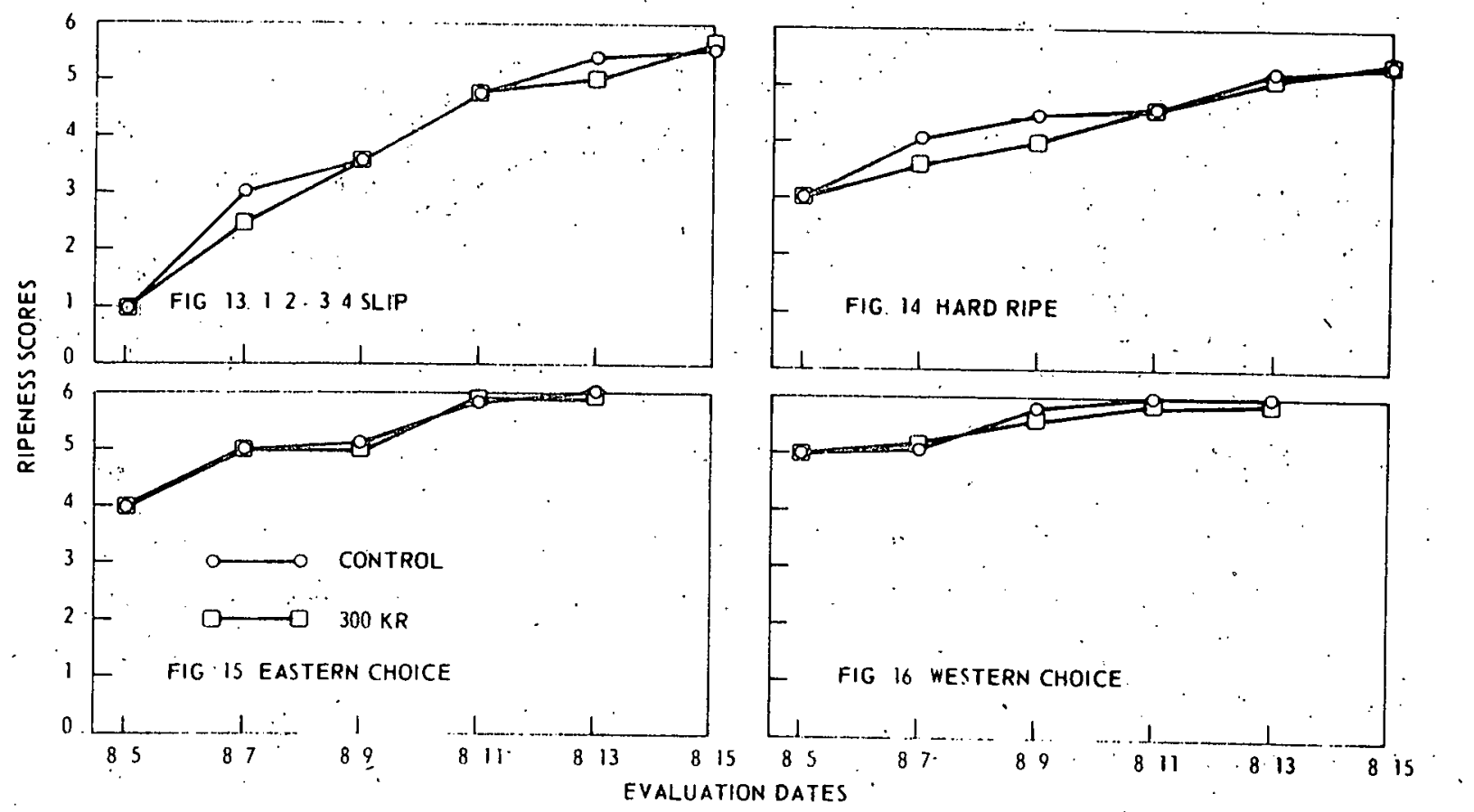

$-79-$ 


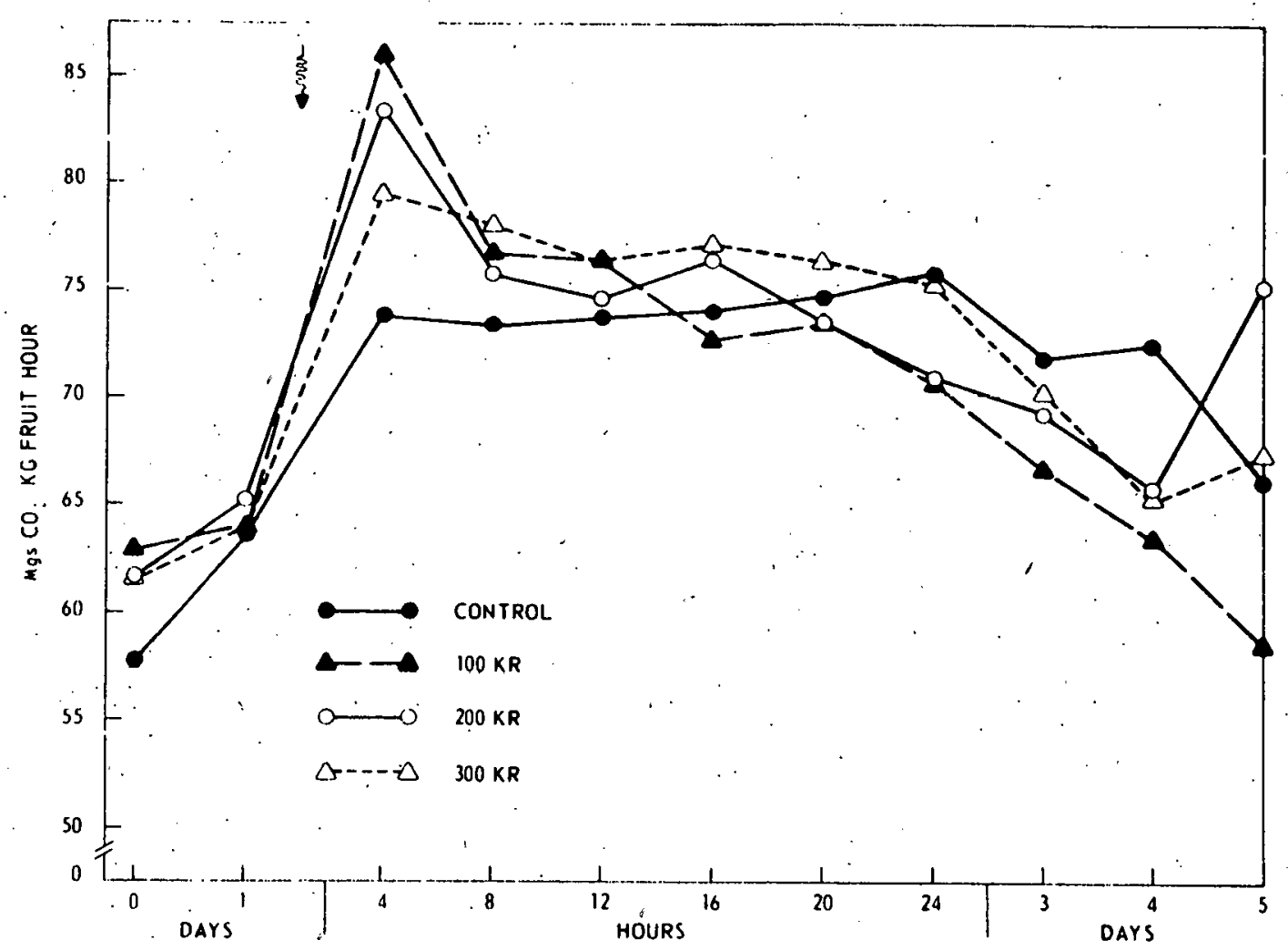

FIG 17

Fig. 17. Effects of gamma irradiation to $300 \mathrm{Krad}$ on the respiration of "Jacumba" cantaloupes he ld at $68^{\circ} \mathrm{F}$. 


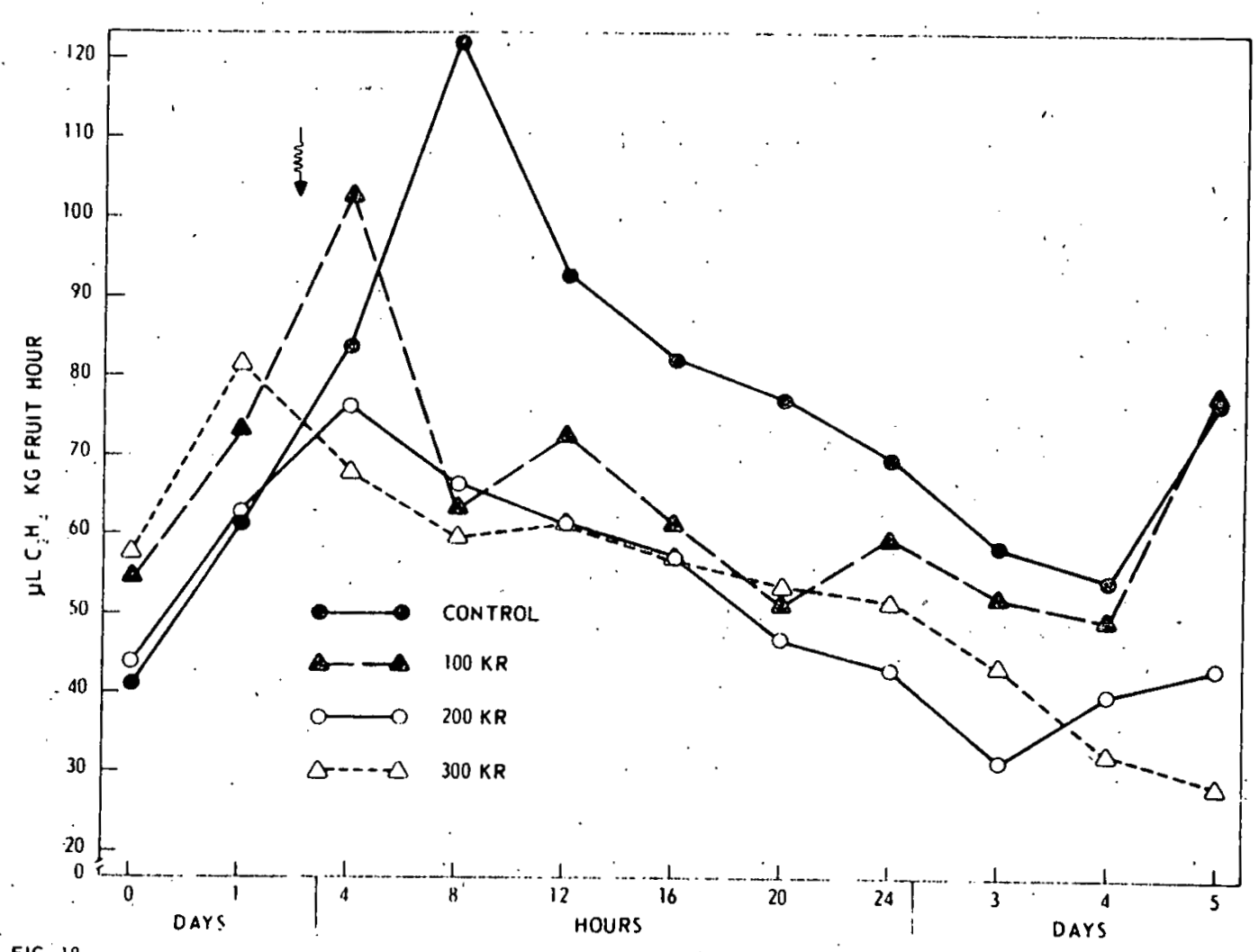

FIG 18

Fig. 18. Effect of gamma irradiation to $300 \mathrm{Krad}$ on ethylene production of "Jacumba" cantaloupes held at $68^{\circ} \mathrm{F}$. 

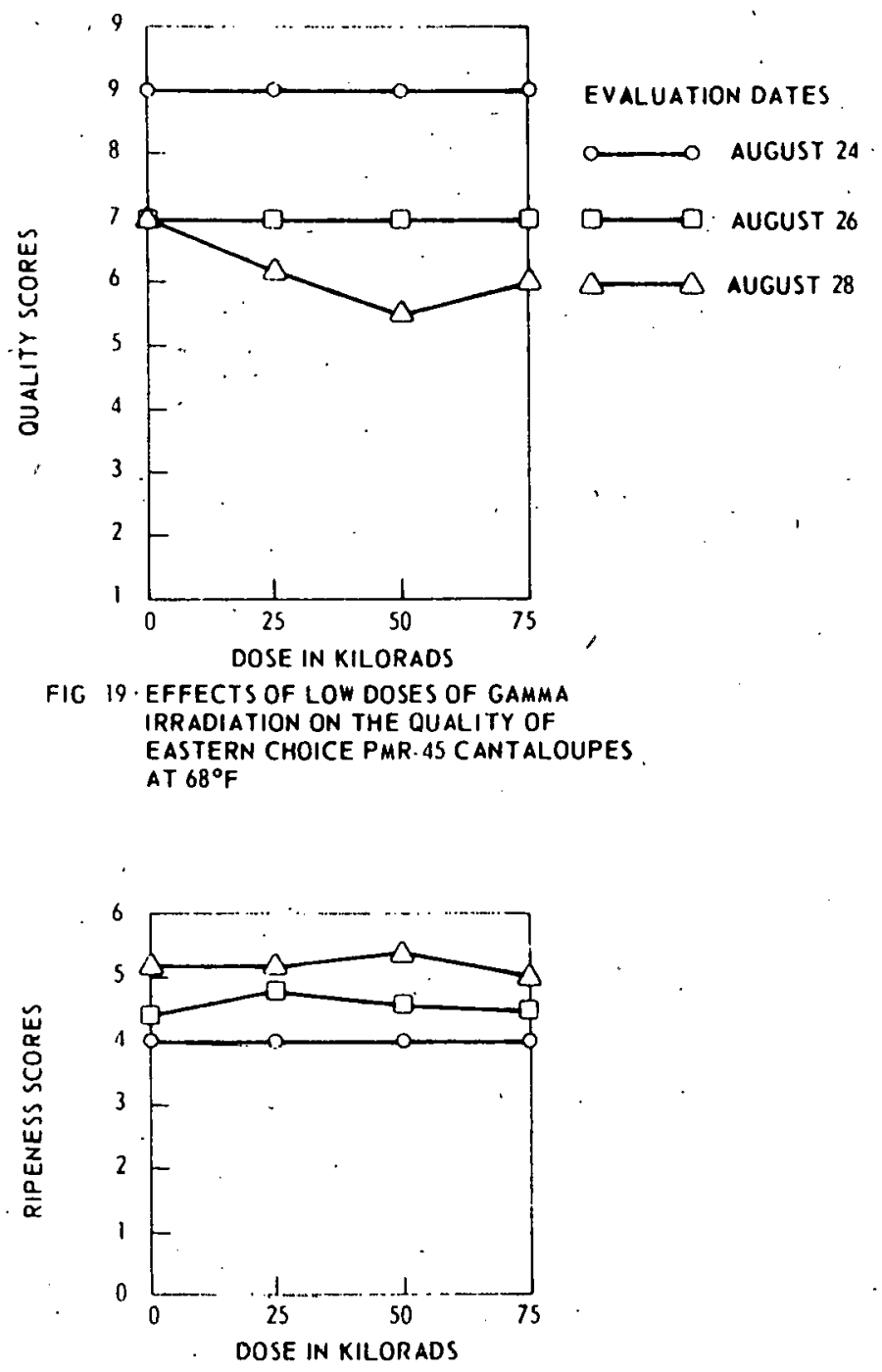

FIG 20 EFFECTS OF LOW DOSES OF GAMMA

IRRADIATION ON RIPENING OF EASTERN

CHOICE PMR. 45 CANTALOUPES AT $66^{\circ} \mathrm{F}$ 


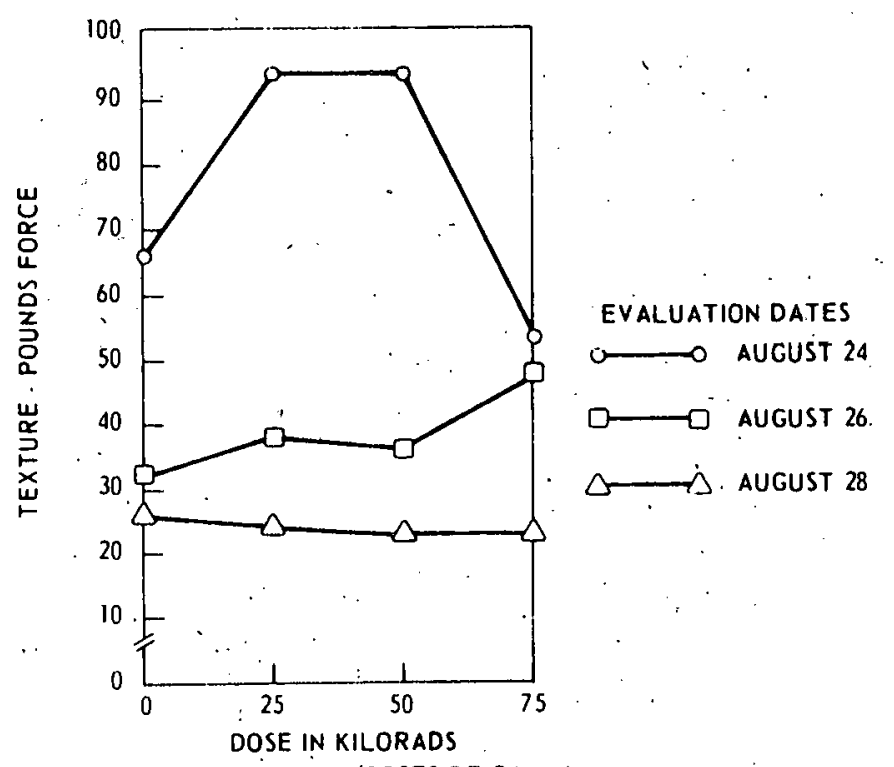

FIG 21 EFFECTS OF LOW'DOSES OF GAMMA IRRADIATION ON THE TEXTURE OF EASTERN CHOICE PMR-4S CANTALOUPES AT $68^{\circ} \mathrm{F}$

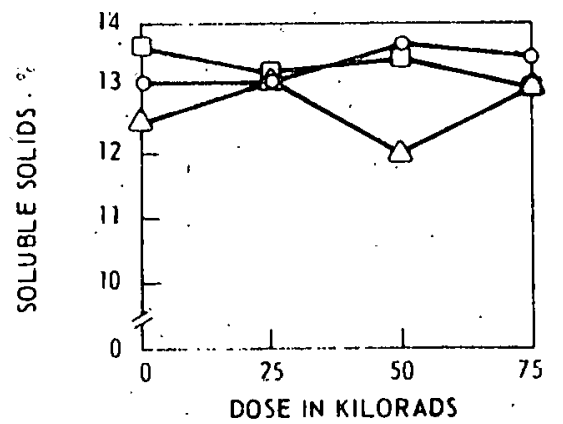

FIG 22 EFFECTS OF LOW DOSES OF GAMMA IRRADIATION ON SOLUBLE SOLIDS OF EASTERN CHOICE PER. 45 CANTALOUPES AT $68^{\circ} \mathrm{F}$

$-83-$ 


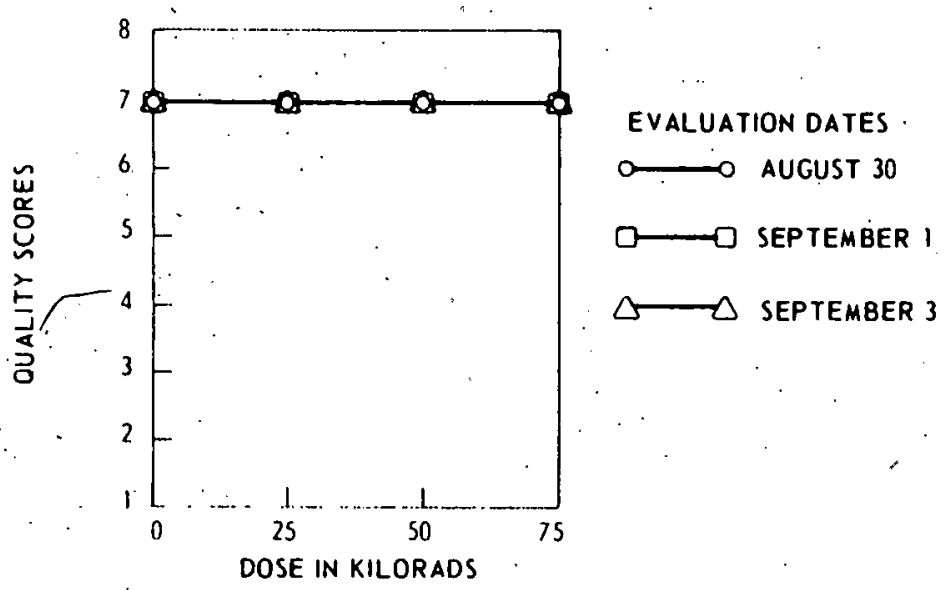

FIC 23 EFFECTS OF LOW DOSES OF GAMMA IRRADIATION ON OIIALITY OF EASTERN CHOICE PMR. 45 CANTALOUPES HELD AT $4 I^{\circ} \mathrm{F}$ FOR 6 DAYS

$\iota$

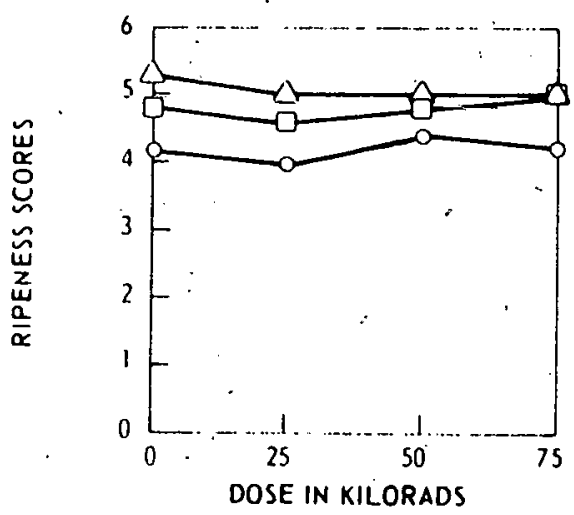

FIG 24. EFFECTS OF LOW DOSES OF GAMMA

IRRADIATION ON RIPFNING OF EASTERN CHOICE PMR. 4S CANTALOUPES HELD

AT $41^{\circ}$ F FOR 6 DAYS 
EXPERIMENT \#5.

The results of physical measurements taken on quality, ripeness, flesh firmness (texture), and soluble solids of irradiated melons used for organoleptic evaluations are in agreement with results reported for Experiment. \#l. Additional data on possible differences in color were also taken. Table 3 summarizes the analysis of variance made on the data for texture, soluble solids, and color.

There were no significant differences between control and irradiated melons in the eastern and western-choice maturities during the first week following irradiation. The comparisons for hard-ripe melons were significant immediately and 2 days following irradiation but not the fifth day. After storage at $41^{\circ} \mathrm{F}$ for 6 days, comparisons for both eastern choice and hard ripe were significant. Where significant comparisons occurred, the judges attributed the main differences to texture describing the irradiated melons as softer. There were no consistent comments on flavor. The judges could detect consistent aroma differences only in the hard-ripe maturity. A few comments indicated slightly less aroma. in the controls immediately and 2 days after irradiation.

The only consistent differences due to irradiation were found in texture. These differences paralleled those found by the panel except for the hard-ripe maturity held in storage. Because of the large variability for this maturity, no significant shear differences were found; however, the taste panel detected a difference and attributed it to texture. There were no significant shear differences (nr sensory.) in the eastern choice mejons held at $68^{\circ} \mathrm{F}$. This group also had a larger amount of variability as compared to the other groups.

The effects of gamma irradiation to the ascorbic-acid content of melons is shown in lable 5 .

There is a direct relationship between ascorbic-acid losses in cantaloupes and the dose of irradiation employed in the range of $0-300 \mathrm{Krad}$. 
Table 3. Summary of analysis of variance made on physical measurements.

\begin{tabular}{|c|c|c|c|c|c|c|}
\hline \multirow[b]{2}{*}{ Maturity } & \multirow{2}{*}{ Main } & \multirow[b]{2}{*}{ Texture } & \multicolumn{4}{|c|}{ F value and significance } \\
\hline & & & $\begin{array}{l}\text { Soluble } \\
\text { solids }\end{array}$ & Color Rd & Color a & Color b \\
\hline Hard ripe & Irradiation & $33.38^{\star \star}$ & $-N S$ & $4.39 *$ & $-N S$ & $-\mathrm{NS}$ \\
\hline No storage & Day & 146.23 t๘ & $-N S$ & $12.08 * *$ & $-N S$ & $-N S$ \\
\hline Eastern choice & Irradiation & . $\quad 1.99 \mathrm{NS}$ & $1.96 \mathrm{NS}$ & $-N S$ & $1.53 \mathrm{NS}$ & $1.39 \mathrm{NS}$ \\
\hline No storage & Day & $17.63^{\star t}$ & $6.14 \star \star$ & $-N S$ & $7.16 *$ & $5.17^{\star}$ \\
\hline Western "choice & Irradiation & $12.44^{\star \star}$ & $-N S$ & $-N S$ & $-N S$ & $-N S$ \\
\hline No storage & Day & $22.34^{\star \star}$ & $-N S$ & $-N S$ & $-N S$ & $9.98 * \star$ \\
\hline Hard ripe & Irradiation & $3.08 \mathrm{NS}$ & $-\mathrm{NS}$ & $3.85 N S$ & $10.99 * *$ & $8.85^{\star *}$ \\
\hline Storage & Day & $4.07 N S$ & $-\mathrm{NS}$ & $5.96 *$ & $4.02 N S$ & $4.29 N S$ \\
\hline Eastern choice & Irradiation & $4.73^{\star}$ & $-N S$ & $-N S$ & $-N S$ & $-N S$ \\
\hline Storage & Day & $22.42 \star \star$ & $-N S$ & $-N S$ & $-N S$ & $-N S$ \\
\hline
\end{tabular}

NS = Not significant.

* = Significant at $\mathrm{P}=0.05$.

** = Significant at $\mathrm{P}=0.01$. 
Table 4. Summary of the triangle difference test used to compare control and irradiated cantaloipes.

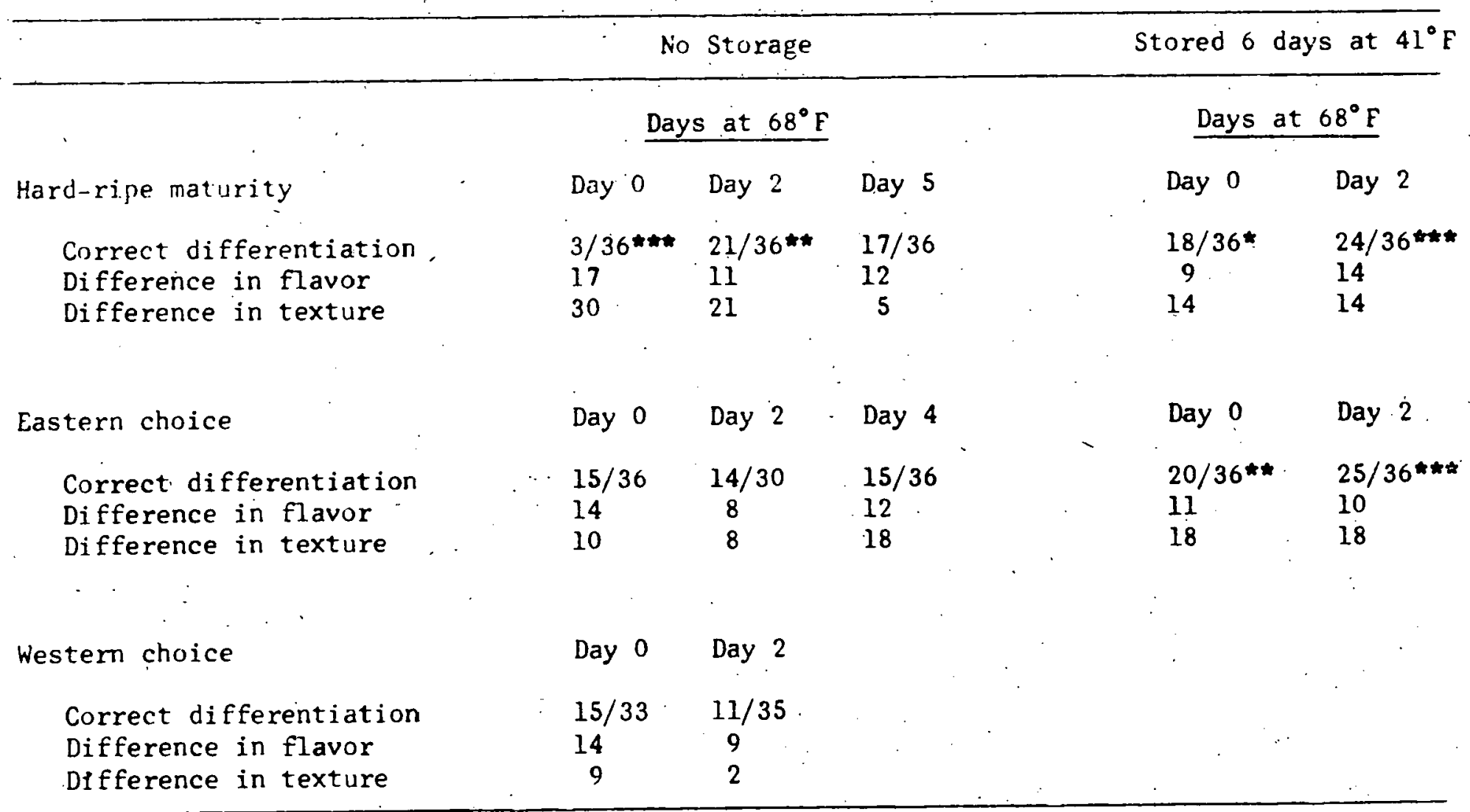

* = Significant at $\mathrm{P}=0.05$.

* Significant at $P=0.01$.

*t* = Significant at $\mathrm{P}=0.001$. 
Table 5. Elfect of gamma irradiation on the ascorbic-acid content of cantaloupes after one week at $41^{\circ} \mathrm{F}$. Results are expressed as $\mathrm{mg}$. ascorbic acid per $100 \mathrm{ml}$ juice.

\begin{tabular}{|c|c|c|c|c|}
\hline $\begin{array}{r}\text { Form of } \\
\text { ascorbate }\end{array}$ & 0 & $\frac{\text { Dose }}{100}$ & $\frac{n \text { Krad }}{200}$ & 300 \\
\hline Reduced & 43.22 & 37.25 & .25 .10 & 16.66 \\
\hline Dehydro* & 4.16 & 5.29 & 7.49 & 13.10 \\
\hline Total * & 47.38 & 42.54 & 32.59 & 29.76 \\
\hline Reduced as \% control. & 100.00 & 86.2 & 58.1 & 38.5 \\
\hline Reduced as \% control on day $1 * *$ & 113.7 & 98.0 & 66.0 & 43.8 \\
\hline Dehydro as \% control & 100.0 & 127.2 & 180.0 & 314.9 \\
\hline Dehydro as $\%$ control on day $1 * *$ & 79.8 & 101.5 & 143.8 & 251.4 \\
\hline Total as $\%$ control & 100.0 & 89.8 & 68.8 & 62.8 \\
\hline Total as $\%$ control on day $1^{* *}$ & 109.6 & 98.4 & 75.4 & 68.8 \\
\hline
\end{tabular}

- Any scores connected by the same line are not significant at 0.05 level of probability.

*: Unirradiated fruits day 1 (irradiatiun date) contained $38.02 \mathrm{mg}$ reduced, $5.21 \mathrm{mg}$ dehydro, and $4.3 .23 \mathrm{mg}$ total ascorbic acid per $100 \mathrm{ml}$.juice. 
The quality, ripeness, per cent sólubile solids, flesh color, and flavor of irradiated cantaloupes are not adversely affected by irradiation at doses up to 400 Krad. Melons subjected to doses above this level are reduced in quality whether stored at $41^{\circ} \mathrm{F}$ for 6 days prior to storage at $68^{\circ} \mathrm{F}$, or stored at $68^{\circ} \mathrm{F}$ continuously." Except for the hard-ripe maturity class; the maturity of the melon at treatment does not influence the response to irradiation. The effect of: irradiation on per cent soluble solids of cantaloupes is not clearly defined; this is probably due to variability between melons and the small sample size. The flesh of the melons is softened immediately by irradiation, but the difference disappears with ripening. The more mature the fruit is at treatment, the less noticeable is this softening effect. The respiratory rate of irradiated melons shows a transitory increase immediately after treatment. Within the doses used, ethylene production is suppressed. The ascorbic-acid content of melons subjected to $100-300 \mathrm{Krad}$ is reduced in a linear fashion with dose.

Gamma irradiation at doses tolerated by cantaloupes appears not to be a beneficial treatment; however, no long-term storage, studies were conducted to determine effects on shelf iife.

\section{SUMMARY}

The effects of gamma irradiation, to 400 Krad, on quality; ripeness, per cent soluble solids, flesh color; and flavor of cantaloupes are minimal. Doses above $400 \mathrm{Krad}$ predisposed the melons to off-aromas, atypical flavors, increased decay, and poorer quality. Storage temperatures, and duration thereof, only slightly influence the responses observed. There is nearly a direct relationship between dose level and softening of the flesh and loss of ascorbic acid. 
The softening effect is obscured by increased ripeness of the fruit. Maturity of the melons at treatment does not affect; the irradiation responses for flesh firmness in the hard-ripe fruits. The rate of evolved carbon dioxide is increased, and ethylene production suppressed, in the range of 100-300 Grad.

- $90-$ 


\section{LITERATURE CITED}

1. Bramlage, W. J. and W. J. Lipton. 1965. Gamma radiation of vegetables to extend market life. U.S.D.A. Mkg. Res. Rpt. No. $703 ; 16 \mathrm{p}$.

2. Claypool, L. L. and R. M. Keefer. 1942. A colorimetric method for $\mathrm{CO}_{2}$ determination in respiration studies. Proc. Amer. Soc. Hort. Sci : 40:177-186.

3. Hughes, R. E. 1956. The use of homocrystine in the estimation of dehydroascorbic acid. Biochem. J. 64:203-208.

4. Loeffler, H. J. and J. D. Ponting. 1942. Ascorbic acid. Rapid determination in fresh, frozen, or dehydrated fruits and vegetables. Ind. and Eng. Chem. 14(11):846-849.

5. Maxie, E. C., I. L. Eaks, N. F. Sommer, Henry L. Rae, and Salah El-Batal. 1965. Effect of ganma radiation on rate of ethylene and carbon dioxide evolution by lemon fruit. Plant Physiol. 40(3):407-409.

6. U. S. Army Quartermaster Corps. 1957. Radiation preservation of Food: U. S. Dept. of. Comm., Office of Tech. Ser., Washington 25, D. C., 286 . 


\section{EFFECTS OF GAMMA IRRADIATION ON \\ POSTHARVEST BEHAVIOR OF HONEYDEW MELONS}

Dale Ravetto, L. L. Morris, and E. C. Maxie

\section{ABSTRACT}

The visual quality, ripeness, per cent soluble solids, skin and flesh color of commercially mature Honeydew melons are not adversely affected by gamma irradiation to $400 \mathrm{Krad}$. The texture of the flesh is softened immediately and persists relative to unirradiated fruits during ripening. Doses above 400 Krad severely softened the melons and predisposed them to bruising.- There were no detectable differences in flavor to $800 \mathrm{Krad}$; however, the flesh of melons at higher doses was dry and mealy. At low doses, dose rate appears not to have significant influence upon the responses observed in irradiated Honeydews.

\section{INTRODUCTION}

The Hnneydew, Cucumis melo L. var. inodouis, is a smooth, round muskmelon with white skin, and firm, greenish flesh. It ranks among the most popular muskmelons grown in California. It was of interest; therefore, to ascertain if postharvest benefits might be derived from gamma irradiation. A series of studies was begun late in the 1966 season to determine: 1) if irradiation has any effect on postharvest decay development and extension of shelf life, and 2) effects of irradiation on physical properties of Honeydew'melons.

\section{MATERIALS AND METHODS}

Honeydew melons, uniform in size and maturity, were obtained from Yolo, California, on October 6, 1966. They were trucked to Davis, 
placed in an air-tight chamber, and treated with 450-500 parts per million (ppm) ethylene gas for approximately 19 hours to stimulate ripening. After this treatment the melons were randomly sorted into 9 lots of 20 melons each and treated as follows:

\begin{tabular}{cc} 
Lot \# & $\frac{\text { Treatment }}{\text { Control }}$ \\
\hline 1 & $25 \mathrm{Krad}-\mathrm{MGI}$ \\
2 & $25 \mathrm{Krad}-\mathrm{Mark} \mathrm{II}$ \\
3 & $50 \mathrm{Krad}-\mathrm{MGI}$ \\
4 & $50 \mathrm{Krad}-\mathrm{Mark} \mathrm{II}$ \\
5 & $100 \mathrm{Krad}-\mathrm{MGI}$ \\
6 & $200 \mathrm{Krad}-\mathrm{MGI}$ \\
7 & $400 \mathrm{Krad}-\mathrm{MGI}$ \\
8 & $800 \mathrm{Krad}-\mathrm{MGI}$ \\
9 &
\end{tabular}

The 25 and 50-Krad lots were irradiated in either the Mobile Gama Irradiator (MGI) or the Mark II Experimental $\mathrm{Co}^{60}$ Food Irradiator to determine if the dose rate influence the responses observed. In the MGI, the melons were irradiated to 25 and $50 \mathrm{Krad}$ in approximately one tenth the time required by the Mark II.

The melons were placed at $68^{\circ} \mathrm{F}$ after irradiation. Five melons from each lot were evaluated at $0,2,4$, and 6 days after treatment; each melon being examined for effects on quality, ripeness, per cent soluble solids, skin and flesh color, and flesh firmess. Quality scores were determined using the scale shown in Table 1. Ripeness was determined using the U.S.D.A. criteria for Honeydews as shown in Table 2 .

Flesh firmness was measured with the Allo-Kramer shear press, model SP-12, equipped with the standard shear compression cell. A 30-second down stroke was used. Skin and flesh color determinations were made with a Gardner Color Difference meter, model AC-3, using the following standards: $R d=61.3, a=-2.3, b=+22.1$; the exposure 
Table 1. Quality parameters and numerical scores used to evaluate Honeydew melons subjected to gamma irradiation.

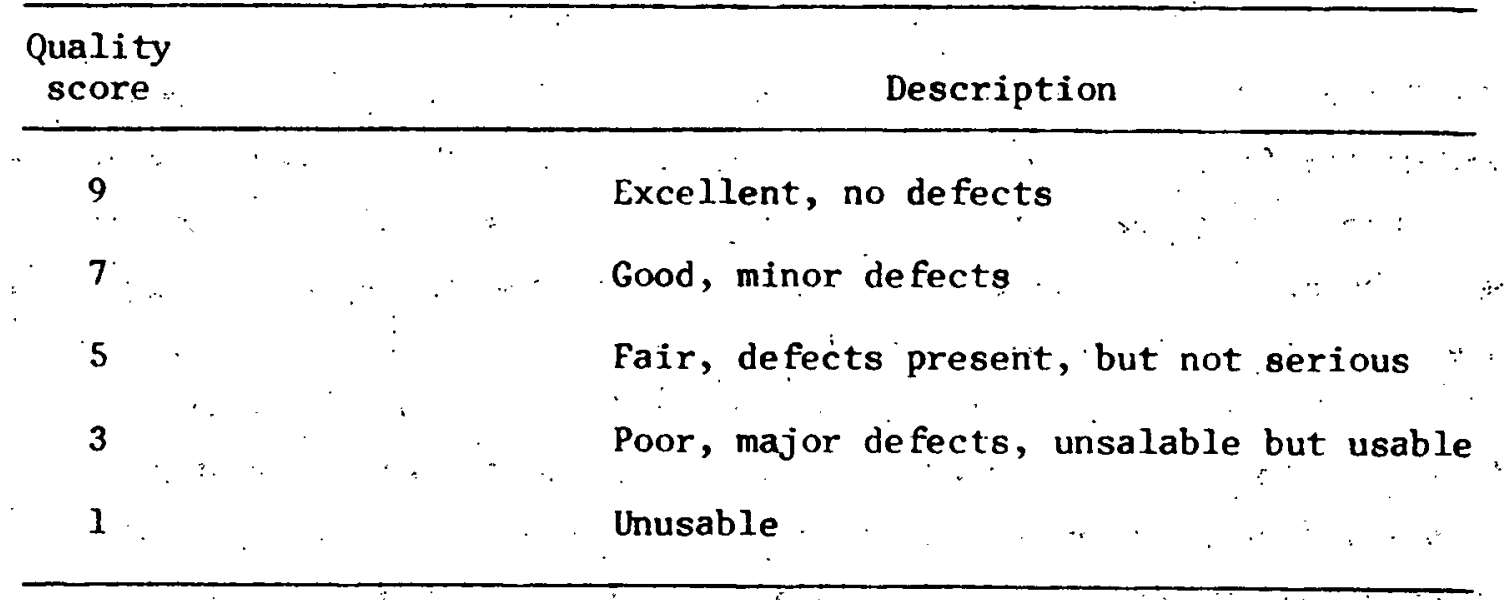


Table 2. Ripeness classes and numerical scores used to evaluate Honeydew melons subjected to gamma irradiation.

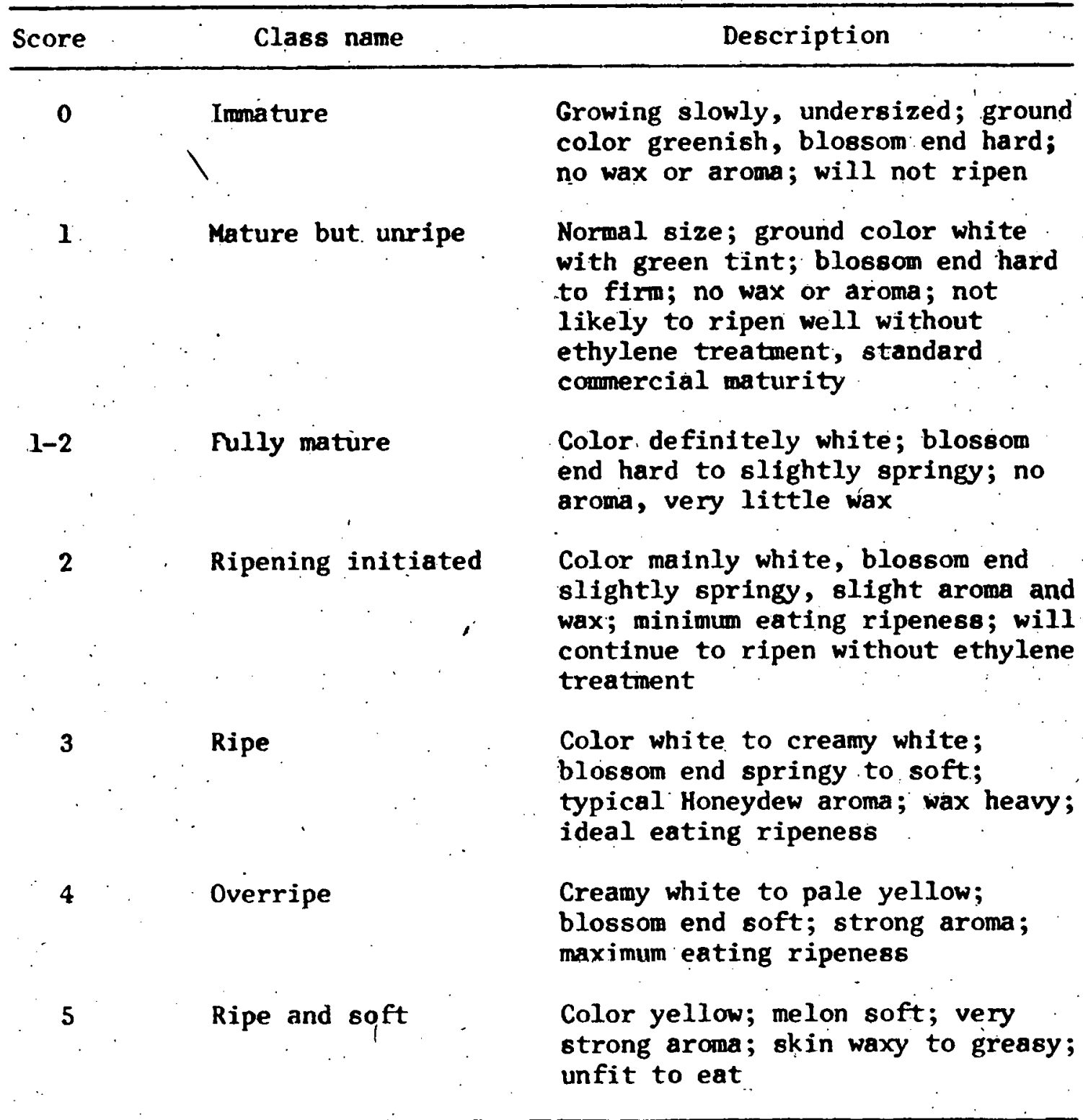


window used was 1.5 inches in diameter. The per cent soluble solids was measured with a Bausch and Lomb Hand Refractometer using juice expressed from the shearing samples. Samples for shearing and color determinations were prepared as reported in the cantaloupe studies.

The ethylene treatment and physical measurements were done at $70-72{ }^{\circ} \mathrm{F}$.

The results reported here are an average of at least 5 melons. for each lot on each evaluation day.

\section{RESULTS}

Figure 1 shows the effect of gamma irradiation on the quality of Honeydew melons held at $68^{\circ} \mathrm{F}$ continuously. Gamma irradiation to $400 \mathrm{Krad}$ does not significantly reduce the quality of the melons. Doses above this level resulted in unmarketable fruit. The effect was noticeable after 2 days at $68^{\circ} \mathrm{F}$ in the fruit subjected to $800 \mathrm{Krad}$. The melons at this dose showed a pale yellow and greenish-white mottling of the skin. Symptoms of bruises were enhanced and appeared as dark green, very soft, water-soaked areas. On the fourth and sixth days after irradiation these melons showed a dark green, water-soaked ring in the flesh immediately under the skin. It was relatively easy to "peel" the skin from the flesh in these melons. There were no discernible effects of gamma irradiation on ripening at doses to $400 \mathrm{Krad}$. As shown in Fig. 2 , the $800-\mathrm{Krad}$ lot appeared to ripen, according to subjective measurements, at a faster rate than melons subjected to lower doses. This, is probably an anomaly since other data indicate that the melons treated to this high dose did not ripen normallty.

The most striking effect of irradiation on Honeydew melons is on Fesh firmness (texture). As shown in Fig. 3, there is nearly a direct relationship between dose level. and amount of softening of the fiesh. This effect did not disappear with time as occurred with 


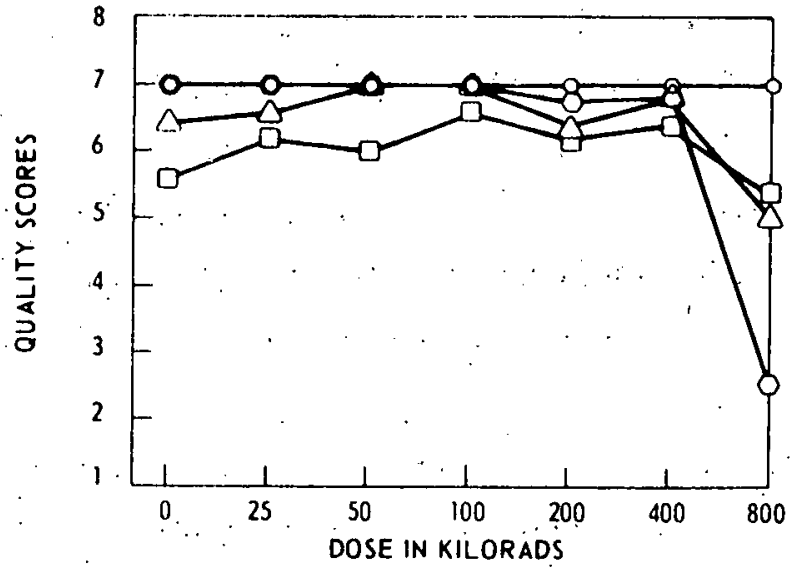

FIG I EFFECT OF GAMMA IRRADIATION ON QUALITY OF HONEY DEW MELONS HELD AT $68^{\circ} \mathrm{F}$

EVALUATION DATES

$\Longrightarrow$ OCTOBER 7

$\square$ OCTOBER 9

$\triangle \triangle$ OCTOBER II

$\curvearrowright$ OCTOBER 13

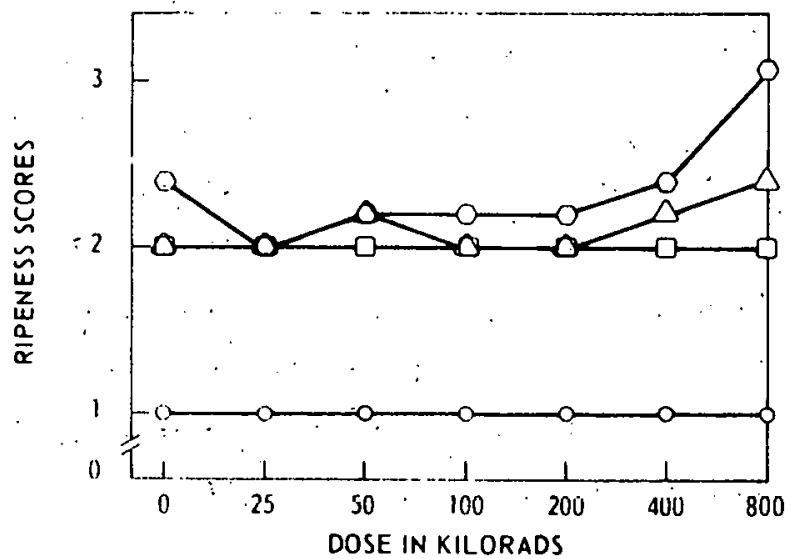

FIC 2 EFFECT OF GAMMA IRRADIATION ON RIPENESS OF HONEY DEW. MELONS HELD AT $68^{\circ} \mathrm{F}$. 
cantaloupes; even after 6 days at $68^{\circ} \mathrm{F}$ the flesh of the irradiated melons was softer than the controls:

The effects of irradiation on per cent soluble solids is shown in Fig. 4. There are slight differences between lots at lower doses, but there are no'significant differences. The melons subjected to: $800 \mathrm{Krad}$ had lower levels of soluble solids, particularly after 6 days of storage. Skin and flesh color differences that occurred with time, and as a result of irradiation, were followed with the color difference meter, but the results were too variable for a valid conclusion.

Table 3 summarizes the analysis of variance and multiple range tests made on data taken for physical measurements of irradiated Honeydews.

Table 4 shows the results for those lots irradiated at different dose rates to 25 and $50 \mathrm{Krad}$. Dose rate was without effect on the parameters measured.

\section{DISCUSSION AND CONCLUSIONS}

The quality, ripeness, per cent soluble solids, skin and flesh color of honeydew melons are not adversely affected in fruits irradiated to $400 \mathrm{Krad}$. At doses above this level, the quality is reduced and ripening is affected. The texture of the flesh is softened immediately after irradiation, and this softening effect persists, at all dose levels, during storage and ripening. The differences seen in ripeness at $800 \mathrm{Krad}$ are probably artifacts since objective measurements of the physical properties of the melons indicated inhibited ripening at this level. Skin color differences were probably influenced by the mottling at the higher doses. There are no detectable effects of irradiation on. flavor, even at $800 \mathrm{Krad}$, as determined by tasting random samples. Many of the melons were bland, and at the higher doses the flesh was dry and mealy. Whether these effects are due to irradiation per se or to abnormal ripening is not known. The melons did not show visual 


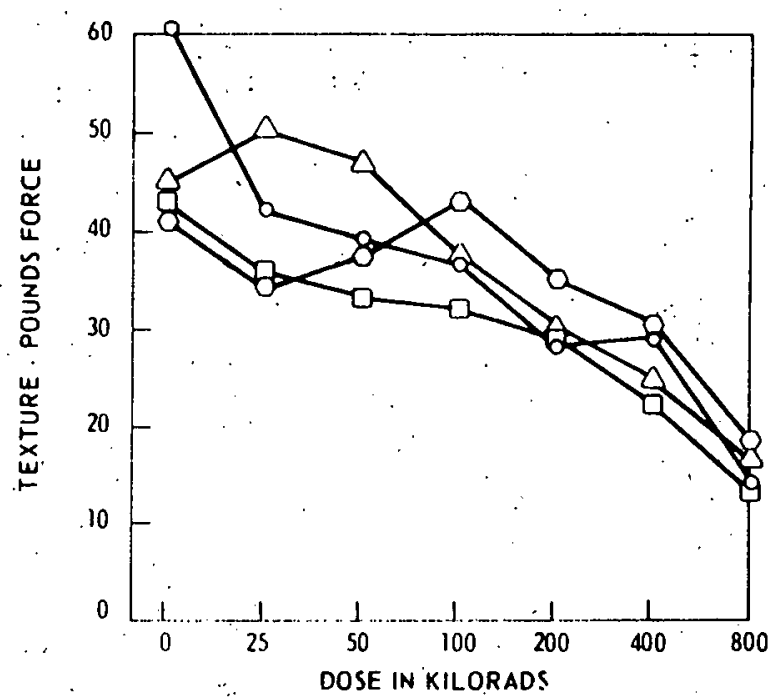

FIG 3 EFFECT OF GAMMA IRRADIATION ON TEXTURE OF HONEY DEW MELONS HELD AT $68^{\circ} \mathrm{F}$

EVALUATION DATES

$\multimap$ OCTOBER 7

$\square$ OCTOBER 9

$\triangle \triangle$, OCTOBER 11

$\longrightarrow$ OCTOBER 13

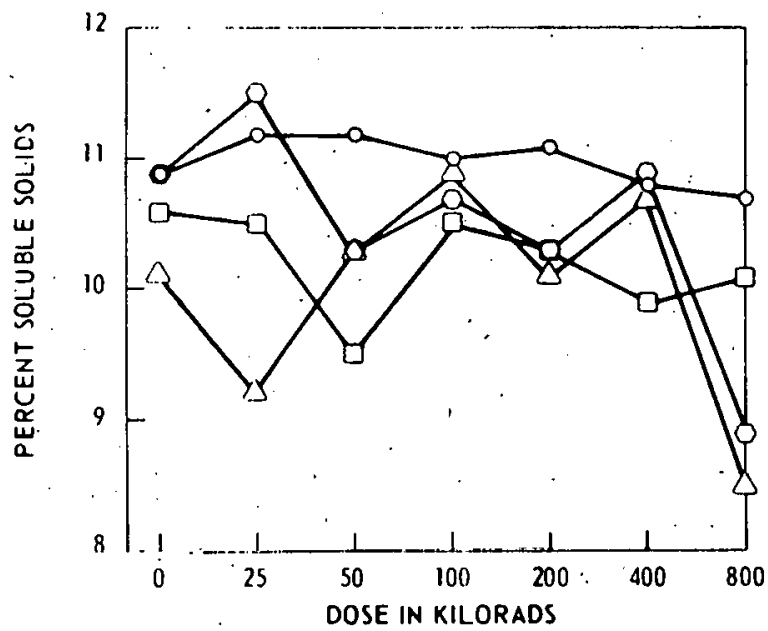

FIG $\triangle$ EFFECT OF GAMMA IRRADIATION ON THE SOLUBLE SOLIDS OF HONEY DEW MELONS HELD AT $68^{\circ} \mathrm{F}$ 
Table 3. Sumary of analysis of variance and multiple range tests on physical measurements of irradiated Honeydew melons.

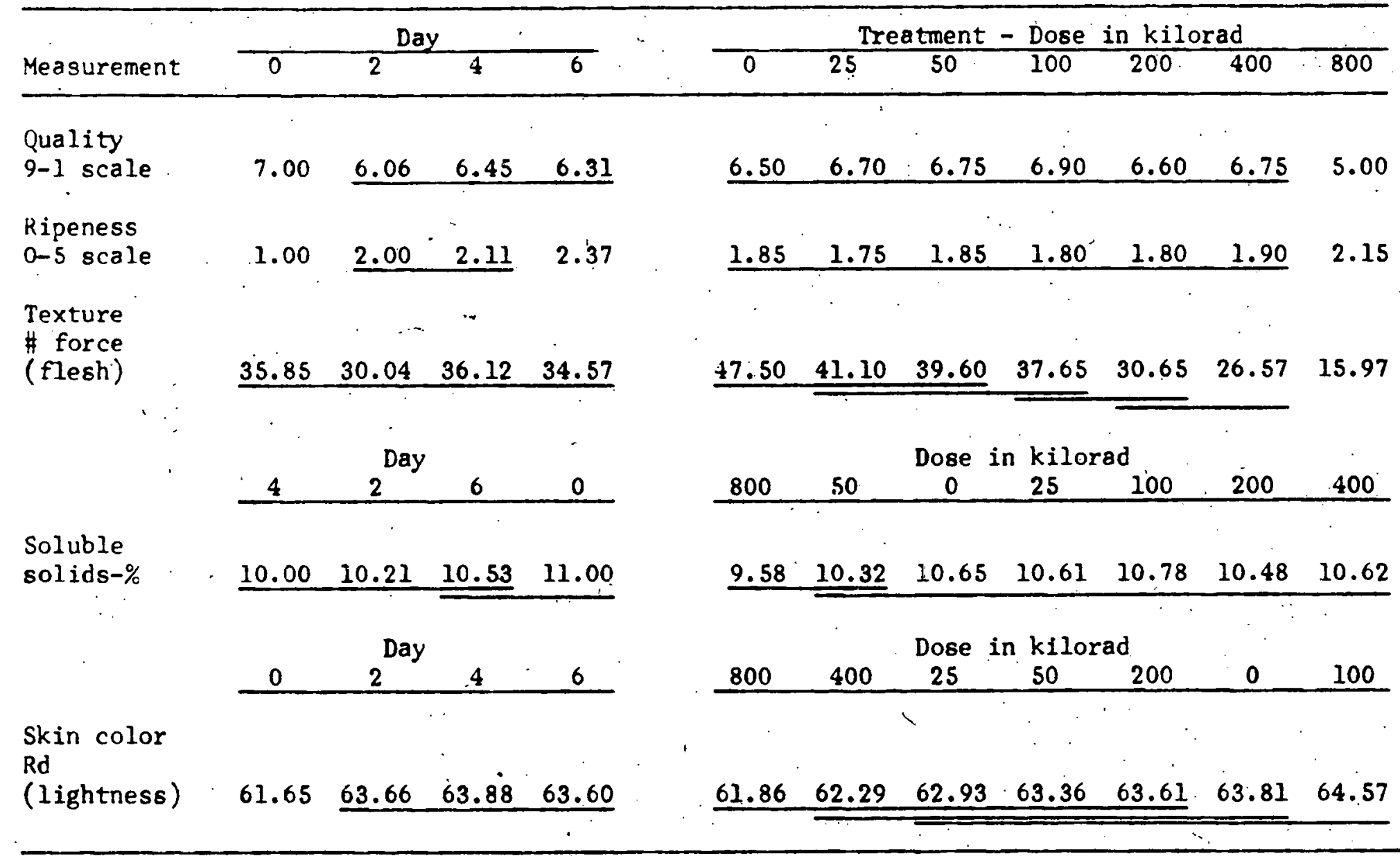

Continued on next page. 
Table 3. (Continued)

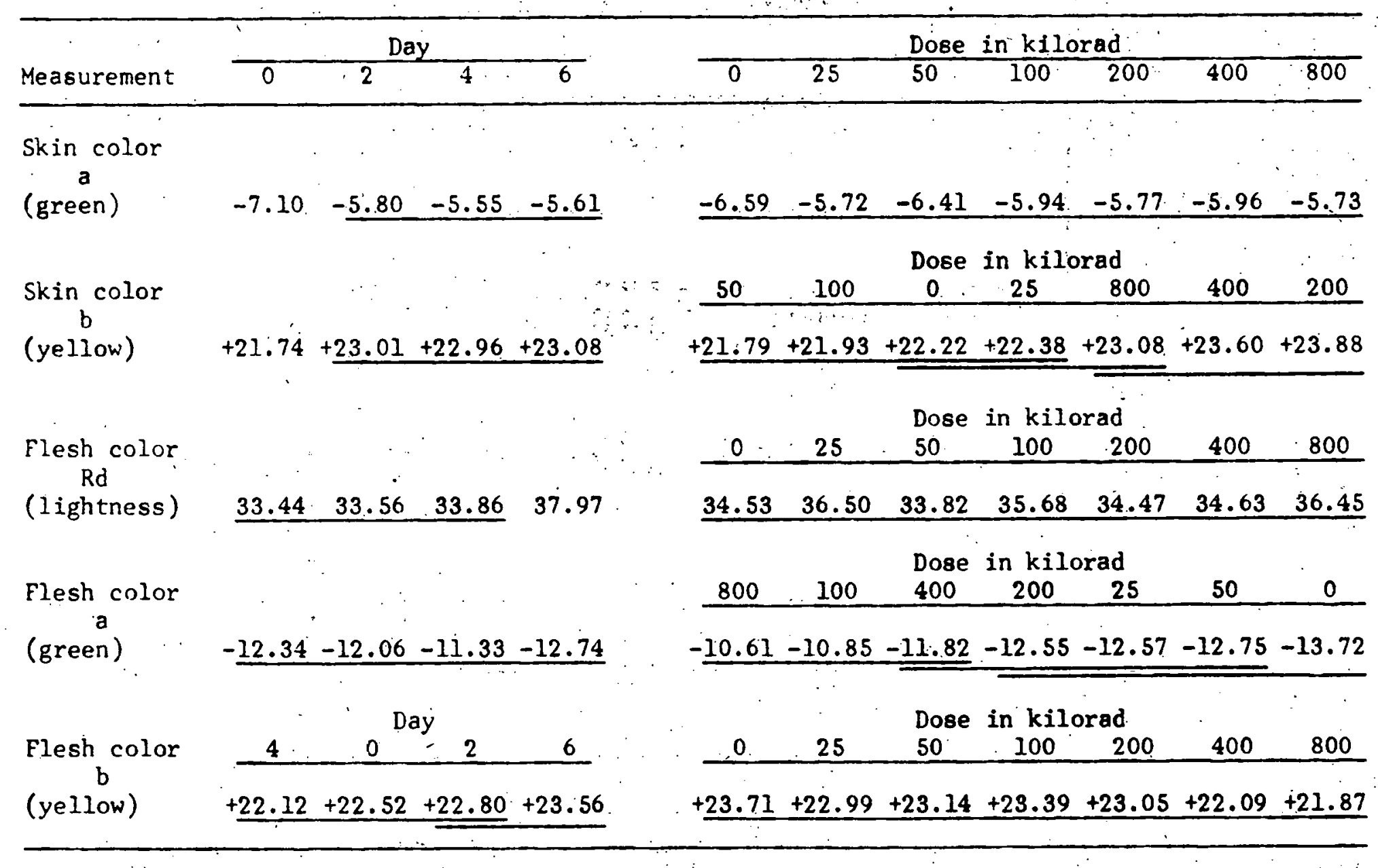

Any figures connected by the same line are not significantly different from each other at $P=0.05$. 
Table 4. Summary of quality, ripeness, flesh firmness, and soluble solids of irradiated Honeydews as influenced by dose rate.

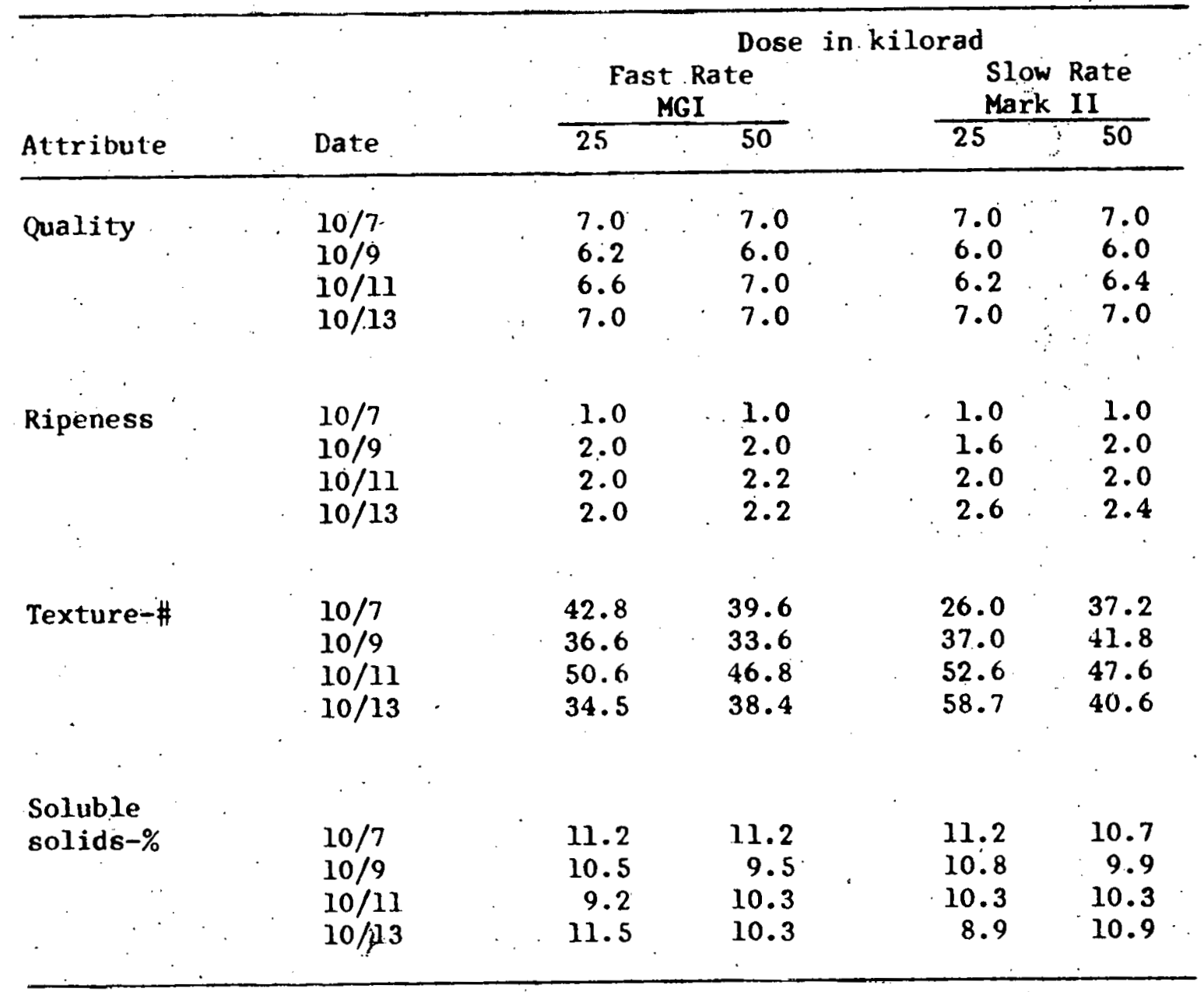

Each figure is an average of readings on five melons. 
signs of decay after 6 days storage at $68^{\circ} \mathrm{F}$, and no tests of longer duration were'conducted. The sample size and dose levels used to study the effects of dose rate were too small to show any significant differences. Higher dose levels and larger samples need to be used. There were some interactions between time and treatment indicating that the melons did not act the same while in storage, but whether this is a consequence of irradiation or just variability between melons is not known.

The results of this experiment might have been influenced by the lack of uniform response by the melons to the ethylene treatment, thus increasing the variability between melons.

It is anticipated that long-term storage studies will be conducted during the 1967 season using -much larger samples.

\section{SUMAARY}

Ganma irradiation to $400 \mathrm{Krad}$ does not significantly affect the quality, ripeness, per cent soluble solids, skin and flesh, color of commercially mature Honeydew melons. Dose levels to $800 \mathrm{Krad}$ predisposed the melions to poor quality. and affected ripeness: There were no detectable flavor differences to $800 \mathrm{Krad}$, although the flesh of many of the irradiated melons was dry and mealy. Flesh firmness is softened immediately at all doses. This greater softening is still evident after 6 days storage at $68^{\circ} \mathrm{F}$. Bruises that involve internal tissues are enhanced because they appear as atypical dark green, water-soaked areas. Intil. long-term storage studies are conducted the possible postharvest benefits to be gained from gamma irradiation with Honeydew melons are not yet clear.

At low doses of 25 and $50 \mathrm{Krad}$, there does not appear to be any significant differences in the responses observed in irradiated Honeydews as influenced by dose rate: 


\title{
EFFECT OF GAMMA IRRADIATION ON THE SUSCEPTIBILITY OF TOMATO FRUITS TO TRANSIT INJURY
}

\author{
Dale Ravetto, L. L. Morris, and E. C. Maxie
}

\begin{abstract}
Gamma irradiation, within the dose limits tolerated by tomato fruits, will not significantly increase the incidence or severity of transit injury if the tomatoes are held tightly in place within a . commercial package. If the irradiated fruit are loosely packed, as. is the current commercial practice, the amount of damage may preclude sale of the fruit.

Adverse effects on ripening and quality may be an additive effect of two stresses, irradiation and transit injury, applied in a short time span. This additive effect might not occur in transcontinental shipments.
\end{abstract}

\section{INTRODUCTION}

The use of gamma irradiation to extend the shelf life of fruits and vegetables has been under investigation for several years. One - of the commodities showing a favorable response is the tomato. Fruits at an advanced stage of ripening can tolerate relatively high doses. . and displays an extension of the shelf life.

Physiological studies of irradiated tomatoes by Abdel-Kader et al. (1) indicated a potential commercial application in the marketing of tomatoes. An important consideration not given adequate attention was the possibility that gamma irradiation may increase the susceptibility of the tomato fruit to transit injury by virtue of its softening of the Cruit tissues. Th ascertain if this softening precluded the use of gamma irradiation, a series of simulated transit tests were conducted 
during the summer and fall of 1966. Care was taken in selecting fruits of the proper stage of ripeness, and in the magnitude of simulated transit injury applied.

\section{MATERIALS AND METHODS}

Three simulated transit tests were conducted during 1966. The experimental plan for each test is given below. Light-pink tomatoes of the 'Ace' variety, obtained from the Merced and Patterson areas of California were used. The fruit was packed in commercial, two-layer flats and had no treatments other than waxing prior to the tests. The fruit was stored at $55^{\circ} \mathrm{F} \pm 1^{\circ} \mathrm{F}$ at a relative humidity of $85-90 \%$ for 4 days, then the fruit was removed to $68^{\circ} \mathrm{F}$. This is considered representative of a transcontinental shipment and retail marketing. Doses of 300 and 400 kilorad (Krad) were used in the first test, and only $300 \mathrm{Krad}$ in Tests 2 and 3. Irradiation was applied at ambient temperature in the Mark II . Co ${ }^{60}$ Experimental Food Irradiator or the Mobile Gamma Irradiator (MGI). Simulated transit injury was applied with the equipment described by Guillou et al. (2). A review of the literature on transit injury of tomatoes indicated that vertical impacts and vibrations caused a major portion of the damage occurring during transit. Thus a sequence of 30 , two-inch vertical impacts, followed by $4,8,16$ minutes vibration at $1.1 \mathrm{G}$. was used to duplicate as closely as possible damage actually received by tomato fruits in transcontinental shipments.

Quality scores for individual fruits from 4 replicates were averaged for each treatment at each evaluation. Evaluations were continued until $50 \%$ of the fruits in the 4 replicates were discarded. Table 3 . shows the quality parameters used and the numerical score assigned to each parameter.

A score for ripeness was obtained in a manner similar to that used for quality scores. Table 2 shows the ripeness classes used and the numerical. score given to each class. 
Table: J. Quality parameters and scores used to evaluate tomato fruits subjected to irradiation and simulated transit injury.

\begin{tabular}{cc}
$\begin{array}{l}\text { Quality } \\
\text { score }\end{array}$ & Parameter description \\
\hline 9 & Excellent, field fresh, no defects \\
7 & Good, minor defects \\
5 & Fair, defects present but not serious \\
3 & Poor, major defects, unsalable, but usable \\
\hline
\end{tabular}


Table 2. Ripeness classes and numerical scores used to evaluate tomato fruits subjected to irradiation and simulated transit injury.

\begin{tabular}{cll}
$\begin{array}{c}\text { Ripeness } \\
\text { scure }\end{array}$ & Cliass & Description \\
\hline 0 & $\begin{array}{l}\text { Mature } \\
\text { green }\end{array}$ & Mature, but entirely green \\
1 & $\begin{array}{l}\text { Breaker } \\
\text { Light } \\
\text { pink } \\
\text { Dark } \\
\text { pink }\end{array}$ & $\begin{array}{l}\text { Approximately equal amounts of green } \\
\text { and pink }\end{array}$ \\
3 & $\begin{array}{l}\text { Table green, entirely pink } \\
\text { ripe }\end{array}$ & $\begin{array}{l}\text { Fully red color, minimum eat ing } \\
\text { ripeness }\end{array}$ \\
\hline
\end{tabular}


To arrive at a satisfactory and objective evaluation of simulated transit injury, the tomatoes were evaluated immediately after treatment or immediately after the simulated transit period. Each fruit was examined for the surface area involved in compression bruising, vibration injury, and softening not due to ripening. Numerical scores were assigned and an average score for the treatment computed for the 4 replicates. Table 3 shows the transit-injury scores used in these tests. Fruits receiving a score of 3 or higher are generally considered unmarketable.

Evaluations for deterioration were made at 2-day intervals and unsalable fruits discarded. Where fruits were decayed, the organisms were identified. Other reasons for discards were shrivel, excessive. softness, and abnormal ripening.

\section{TEST I.}

Fifty, two-layer flats obtained on July 1 were held overnight at $59^{\circ} \mathrm{F}$. On July 2, twelve lots of 4 replicates per treatment (240. fruits) were prepared and treated as follows:

1. Control - no irradiation, no simulated transit injury, fruits moved directly to $68^{\circ} \mathrm{F}$.

2. Control - no irradiation, no simulated transit injury, transit time and temperature.

3. No irradiation, 30 vertical impacts +4 minutes vibratión, transit time, and temperature.

4. No irradiation, 30 vertical impacts +8 minutes vibration, transit time and temperature.

5. No irradiation, 30 vertical impacts +16 minutes vibration, transit time and temperature.

0. No irradiation, 30 vertical impacts only, transit time and temperature: 
Table 3. Injury scores used to evaluate tomato fruits subjected to . irradiation and simulated transit injury.

\begin{tabular}{l}
$\begin{array}{l}\text { Injury } \\
\text { scores }\end{array}$ \\
\hline 0 \\
1 \\
3 \\
5
\end{tabular}$\quad \begin{gathered}\text { None } \\
\text { Moderate - up to } 1 / 2 \text { of the surface damaged } \\
\begin{array}{c}\text { Severe - over } 1 / 2 \text { of the surface damaged; } \\
\text { fruit cracked, etc. }\end{array}\end{gathered}$


7. $\mathrm{N}$ ) irradiation, 8 minutes vibration only, transit time and temperature.

8. Radiation control - $300 \mathrm{Krad}$, no simulated transit injury, transit time and temperature.

9. $300 \mathrm{Krad}+30$ vertical impacts + 8 minutes vibration, transit time and temperature.

10. Radiation control - $400 \mathrm{Krad}$, no simulated transit injury, transit time and temperature:

1.1. $400 \mathrm{Krad}+30$ vertical impacts +8 minutes vibration, transit time and temperature:

12. Check - evaluated upon arrival in Davis, no transit. injury, time, or temperature.

Lot 12 was used to ascertain initial ripeness, quality, and transit injury conditions before the test treatments were applied.

\section{TEST II .}

This test was revised to determine if there were any differences in response when the sequence of simulated transit injury and irradiation was varied. Twenty-four two-layer flats were obtained on Octobér 10, 1966, and treated as per Test I. On the following day the fruit was sorted into 6 lots of 4 flats each and treated as follows:

1. Control - no irradiation, no simulated transit injury, time or temperature, fruit moved directly to $68^{\circ} \mathrm{F}$.

2. Control - no irradiation, no simulated transit injury, transit time and temperature.

3: 300 Krad +30 vertical impacts +8 minutes vibration, transit time and temperature.

4. Kadiation control - 300 Krad, no simulated transit injury, transit time and temperature. 
5. 30 vertical impacts +8 minutes vibration, transit time and temperature then given $300 \mathrm{Krad}$ and placed at $68^{\circ} \mathrm{F}$.

6. 30 vertical impacts +8 minutes vibration, transit time and temperature but no irradiation.

\section{TEST III.}

This test was a repeat of Test II, except for lot 6. For this lot the fruit of each of the 4 flats was place packed in telescoping fiberboard cartons. Two cartons were padded on the bottom, center, and on the top above the fruit with redwood bark pads. The other two cartons were padded on the top and bottom only, but with a chip-board liner placed in the center. The carton lid was placed on each carton, compressed into place and side stapled. All 4 cartons were then treated as per lot 3 : After treatment the fruit was carefully removed from the closed cartons and placed in the commercial package for storage.

Evaluations in all tests were made at a temperature of $70-72^{\circ} \mathrm{F}$ under standard grading lamps.

\section{RESULTS}

TEST I.

The first 7 lots of Test I were concerned with approximating the injury received by tomatoes in actual transit. Thirty vertical impacts in combination with three vibration periods were used. Four minutes vibration was found to be least daniaging and 16 minutes to be too severe a treatment. The 8 -minute vibration period closely approximated the amount of transit injury occurring in commercial load.

Thirty vertical impacts alone did very little damage to the fruit, but did disorganize the pack, especially the top layer of fruit. In every test where simulated transit injury was applied, the top layer of fruit was more adversely affected than the bottom layer. The overall 
effects on ripening and quality were minimal in these first 7 lots, with no significant ditferences in the time required to reach the table-ripe stage. Except for the lot receiving 16 minutes vibration, there were only minor differences in quality between the lots.

The remaining lots, $8,9,10$, and 11 , responded differently when irradiation was introduced. As shown in Fig. 1, there was a significant delay in ripening in the irradiated lots. The effect was especially noticeable when irradiation preceded simulated transit injury. The control lot was table ripe in 12 days; whereas the 300 and 400-Krad lots, without simulated transit injury, required 20 days to reach table ripeness. The 400-Krad lot which received the transit treatment also took 20 days. Fruit subjected to simulated transit did not turn color as uniformly as the control fruit, often appearing blotchy and failing to ripen properly and were usually very soft. Figure 2 shows the effect of combination treatments of irradiation and simulated transit injury on the shelf life of the fruits as the time required for $50 \%$ of the fruit in each lot to reach an unmarketable condition. Irradiation alone increases the shelf $1 \mathrm{ife}$, but when simulated transit treatments were applied, the quality and the shelf life were both decreased. Initially, differences between lots were large but with time they diminished, until at the end of the test they were nil.

Damage was more severe in fruit subjected to 400 Krad than in those receiving $300 \mathrm{Krad}$, reflecting increased softening at the higher dose. Evaluations for simulated transit injury were made at 2-day intervals. As the fruit ripened, injury symptoms were masked by the deepening red color of the fruit. Injured areas that were clearly defined in unripe fruit as water-soaked abrasions and bruises were not easily detected on ripe fruit. Therefore, the only meaningful evaluations are those taken after transit injury and storage treatments. Figure 3 shows the level of simulated transit injury at the, end of the transit period. The amount and severity of injury is higher in the irradiated-vibrated lot.s (compare lots 8 and 9, and 10 and 11); with 


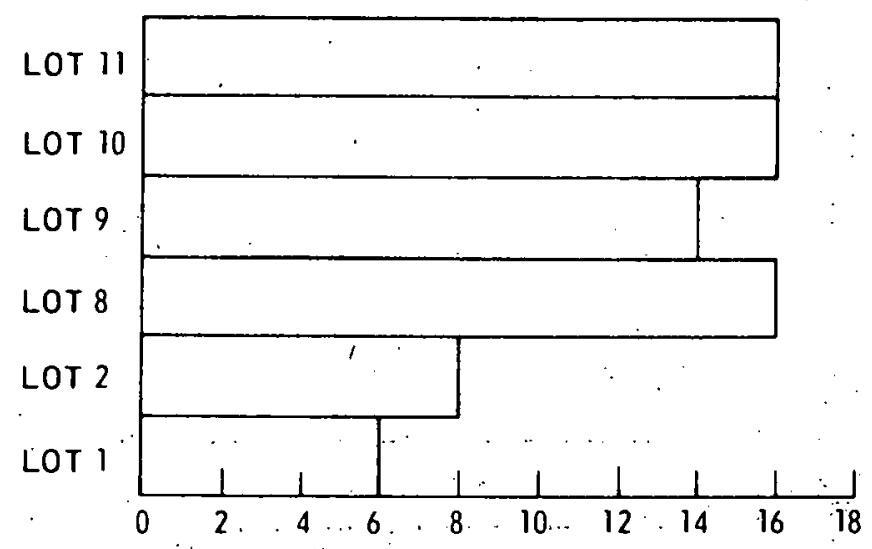

FIG I DAYS TO REÄCH TABLE RIPENESS AT $68^{\circ} \mathrm{F}$ :

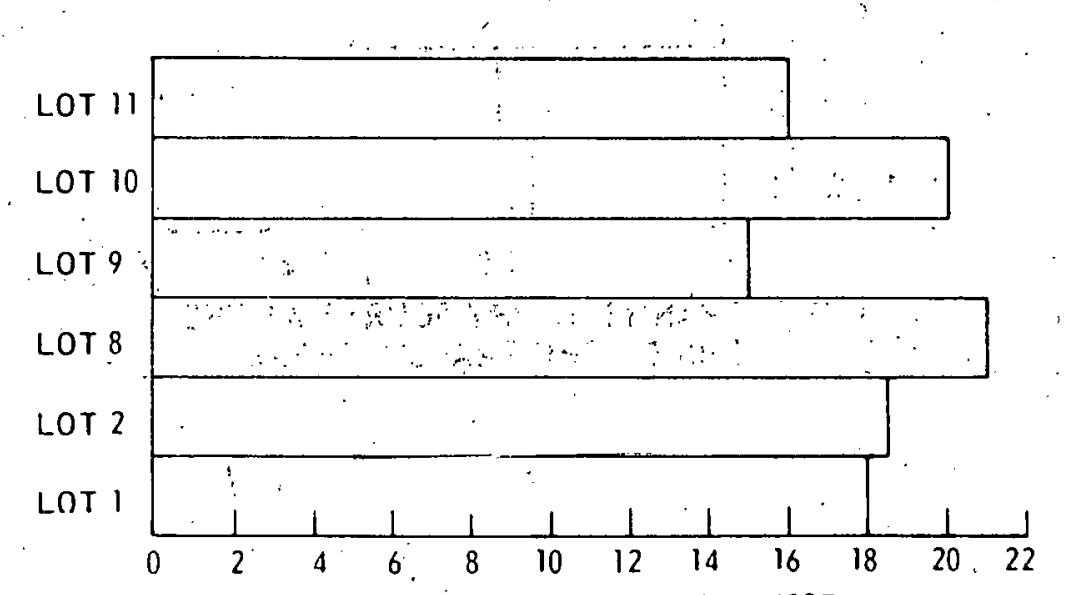

FIG 2 DAYS TO REACH 50, UNMARKETABLE AT $68^{\circ} \mathrm{F}$ 


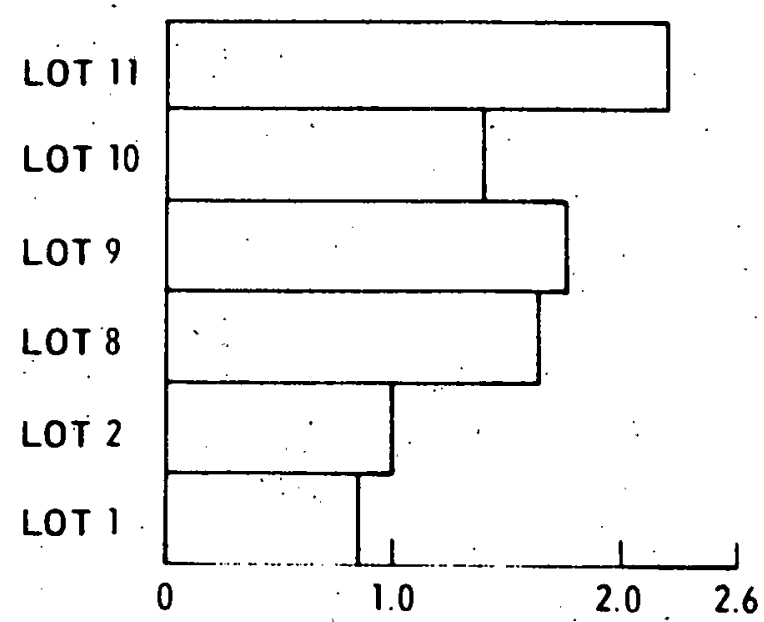

FIG. 3 TRANSIT INJURY SCORES AT THE

END OF THE TRANSIT PERIOD 
the 400-Krad lots showing more injury than the 300-Krad lots. The injury levels are not high enough to preciude sale of the fruit, but would reduce consumer appeal for the fruit. Rot development was the major cause of cullage. The causal organisms in decreasing order of occurrence were: Rhizopus stolonifer (Ehrenb. ex Fr.) Lind., Alternaria tenuis (Nees), Penicillium supp., Fusarium spp., Cladosporium spp., and Botrytis cinerea (Pers. ex Fr.). There did not appear to be a significant fungicidal or fungistatic effect on the incidence of decay even though the irradiated lots had a lower incidence of decay. Other causes of cullage included shrivel, blotichy or abnormal ripening, and excessive softness. The internal condition of the injured fruit included disruption of the locular organization. The seeds were dislodged from the placentae and the gelatinous tissue surrounding the seeds was rediced to a watery fluid. The.injured tomato tissue had a water-soaked appearance but the damage could not be seen externally when the fruit reached table ripeness.

\section{TEST II.}

The effect on ripening was similar to that seen in Test $I$, as is shown in Fig. 4. Irradiation alone increased the time to reach the table-ripe stage by 4 days. Irradiation followed by simulated transit injury delayed ripening 6 days and simulated transit injury alone delayed ripening 2 days. A 2-day delay in reaching the table-ripe stage resulted when irradiation followed the simulated transit injury. In general, these data agree with the results of Test.I. As shown in Figs. 5 and 6 , the shelf life of the fruit was reduced when irradiation either preceded or followed transit injury. Irradiation alone and transit injury alone did not significantly reduce the quality of the fruit, but shelf life was reduced by 2 days in all lots receiving simulated transit injury. As shown in Fig. 7, the irradiated-vibrated lots showed a much higher level of injury at the end of the simulated transit period and 4 days after transfer to marketing conditions. 


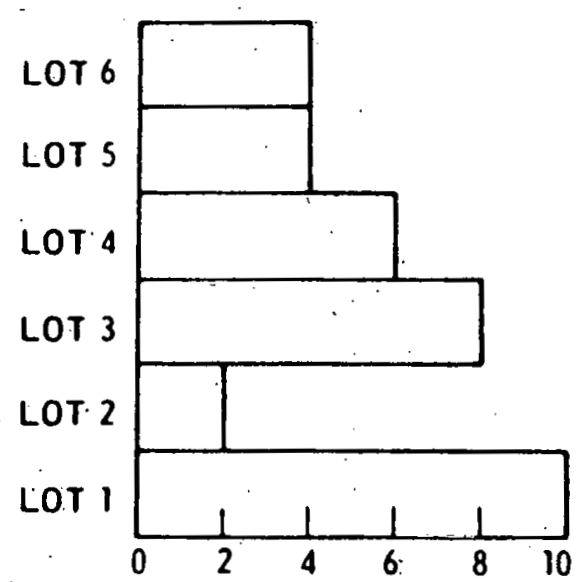

FIG. 4: DAYS TO REACH. TABLE RIPENESS AT $68^{\circ} \mathrm{F}$

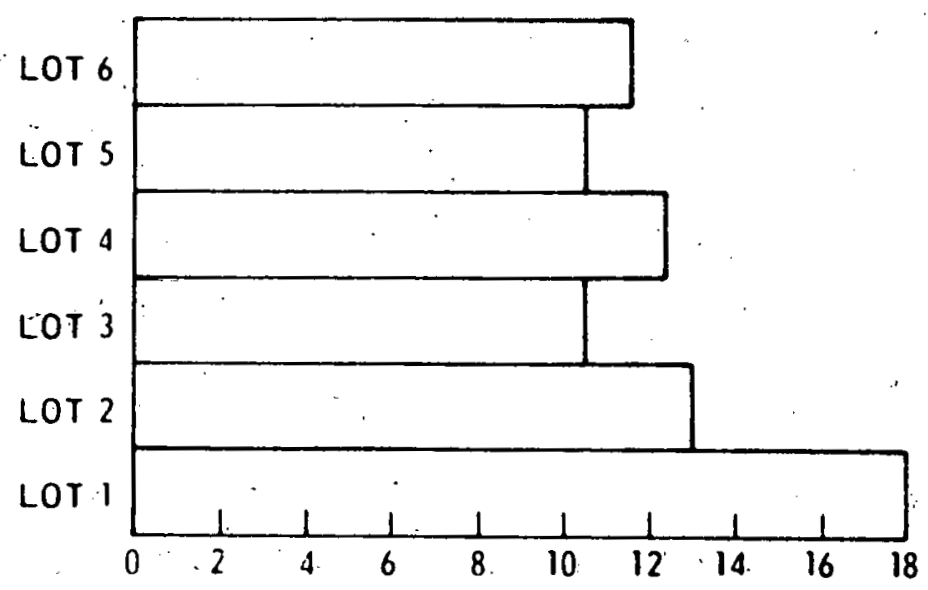

FIG 5 DAYS TO REACH $50^{\circ}$; UNMARKETABLE AT $68^{\circ} \mathrm{F}$ 


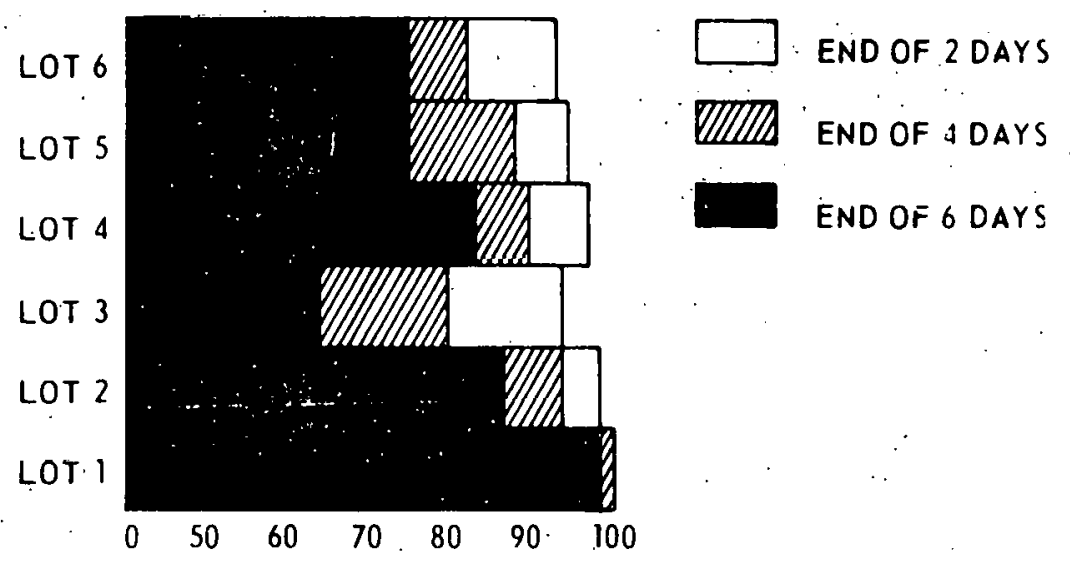

FIG 6 PERCENT MARKETABLE FRUIT AT THE END OF 2, 4, \& 6 DAYS AT $68^{\circ} \mathrm{F}$

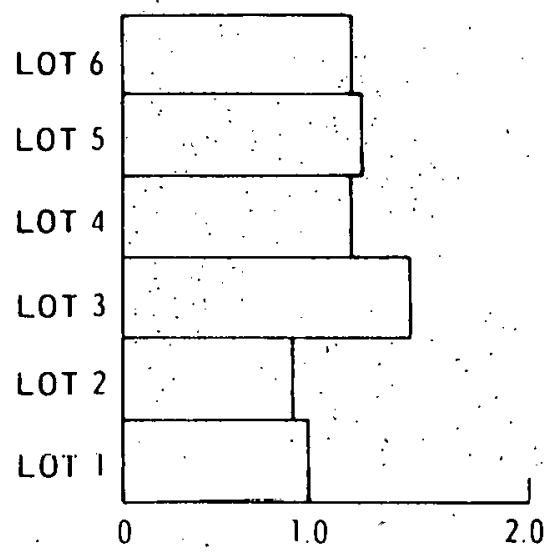

FIG 7 TRANSIT INJURY SCORES AT THE END OF THE TRANSIT PERIOD 
The severity ot injury was consistently higher in all irradiated; and irradiated-vibrated lots. These results are in agreement with the data of Test $I$. With the exception of the vibrated-irradiated lot, all lots receiving $300 \mathrm{Krad}$ had less decay than did the control lot. The major decay organisms, in order of most frequent occurrence were: Rhizopus stolonifer, Alternaria tenuis, Penicillium spp., Fusarium spp., Botrytis cinerea, and Cladosporium spp. Cullage was also due to shriveling, blotchy or abnormal ripening; and excessive softness.

\section{TEST III.}

Figure 8 shows the effect of irradiation and transit injury on ripening. It was similar to that observed in Tests 1 and 2 , but the maximum delay was only 1 day.. As shown in Figs. 9 and 10, there were little differences in quality between lots at the end of the transit period. The non-padded, irradiated-vibrated lots were again consistently lower in quality after 2, 4, and 6 days under marketing conditions. Flats that were padded had a higher percentage of marketable fruit at the end of the test than did the control lot and shelf life for this lot was increased by 2-4 days. Figure 11 shows that the irradiated-vibrated lot had a higher level of injury at the end of: the transit period and after 4 days under marketing conditions. The differences in this test were much greater than those seen in Test II. Padding practically eliminated the damage in the top layer of fruit noted in previous tests. The incidence of decay was similar to that found in Test II, but the effectiveness of irradiation was less pronounced. Rhizopus stolonifer was the most common decay organism, followed by Penicillium spp., Alternaria tenuis, Cladosporium spp., Stemphylium spp., Fusarium spp., and Botrytis cinerea in that order. Shrivel was slightly higher than noted in Test II, but it was not a major cause of cullage. Blotchy ripening occurred in all irradiated and irradiated-vibrated lots except the padded lot. The overall quality of the fruit used in this test was lower than fruit 


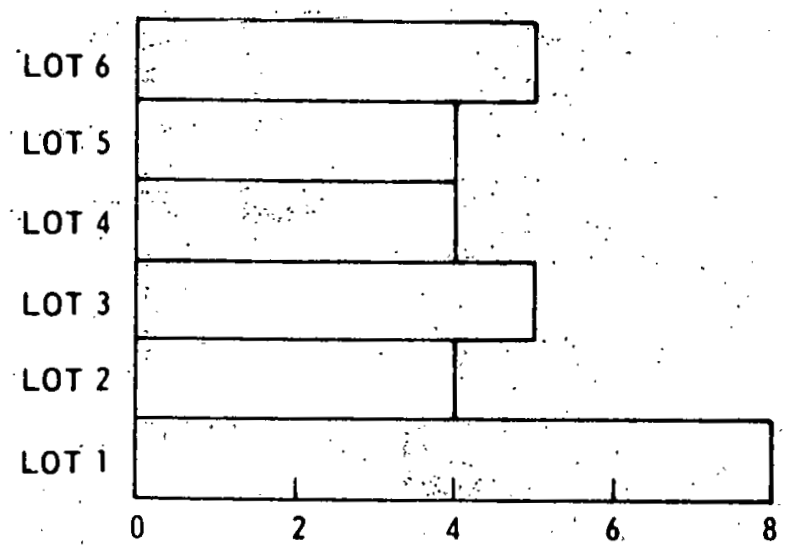

FIG 8 DAYS TO REACH TA'BLE RIPENESS AT $68^{\circ} \mathrm{F}$

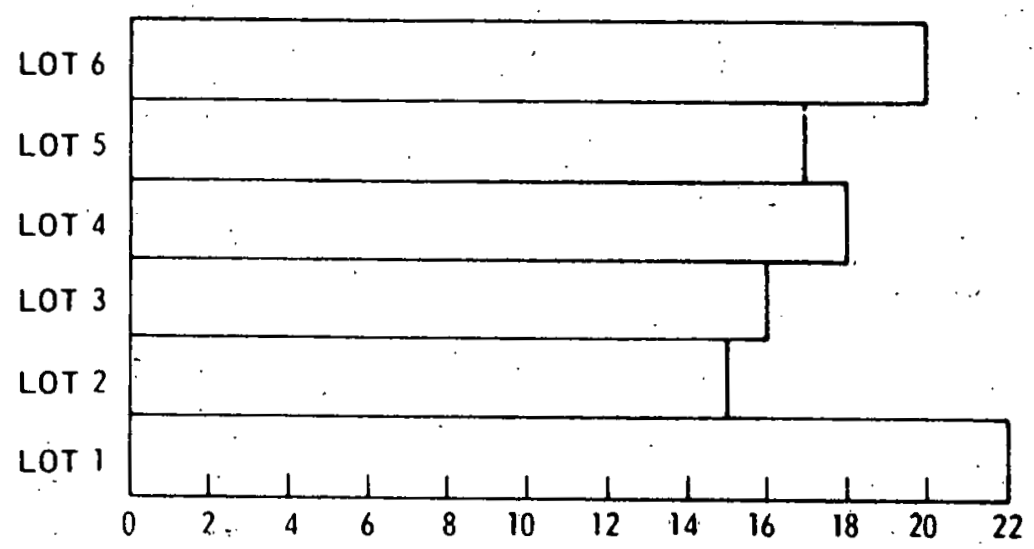

FIG 9 DAYS TO REACH 50. UNMARKETABLE AT $68^{\circ} \mathrm{F}$ 


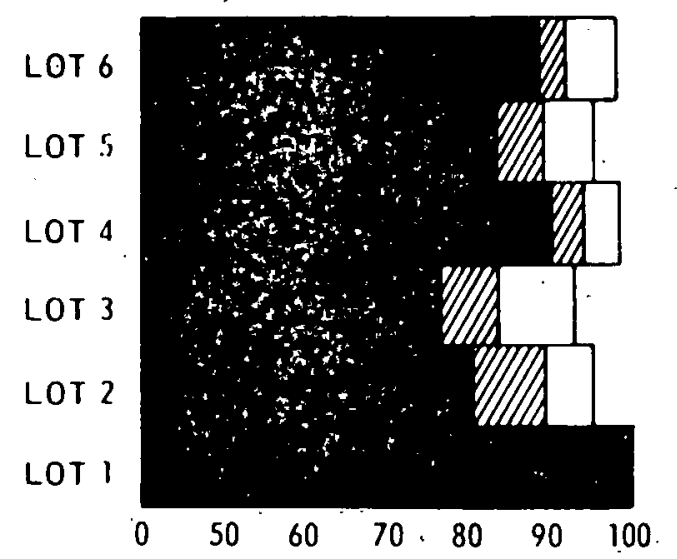

$\square$ END OF 2 DAYS

VIIID END OF 4.DAYS

END OF 6 DAYS

FIG 10 PERCENT MARKETABLE FRUIT

AT THE END OF 2, 4, \& 6 DAYS

AT MARKETING CONDITIONS. $68^{\circ} \mathrm{F}$

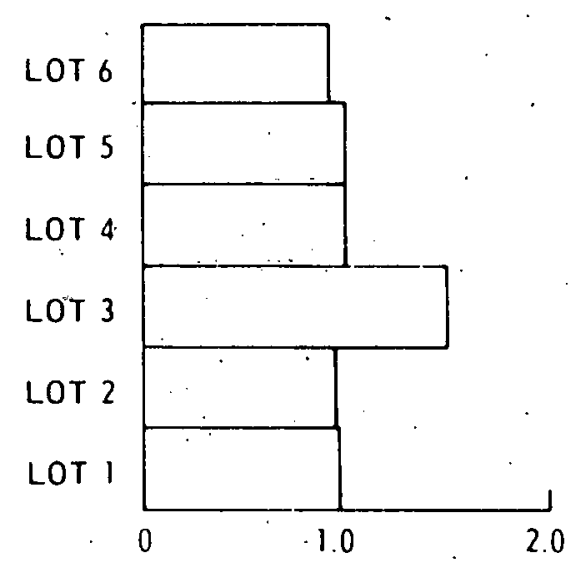

FIG 11 TRANSIT INJURY SCORES AT

THE END OF THE TRANSIT PERIOD 
harvested earlier in the fall season, but field chilling seemed not to be a factor in the responses observed.

\section{DISCUSSION AND CONCLUSIONS}

The results of the three tests reported here indicate that irradiation has a profound influence upon the incidence and severity of 1 ransit injury on tomatoes. Irradiation-induced softenjng plus disruption of the pack organization increase impact and vibration damage to the fruit in simulated transit. However, in lot 6, Test III, the amount and severity of the damage was held to a minimum when padding was used to hold the fruit tightly in place in the package. A need for changing the commercial two-layer pack is indicated. 'This needs further study and evaluation.

The ripening response seen here agrees with results noted by other investigators. That transit injury will delay ripening is not certain, for the simulated transit injury was applied in a single treatment. This does not occur in a transcontinental shipment. Thus, the simulated transit injury in these studies may be excessively severe. This may also be 1 rue for the quality scores; the combined effect of two stresses over a short time period may affect quality more severely than if they were applied over several days as would be the case in commercial shipments.

The incidence of decay was reduced by gamma irradiation in these tests but: to a smaller degree than in earlier work. This again may reflect the eflect of: two stresses applied within a few hours of one another. Irradiation alone delays or prevents lesion growth and development by field infections, but cannot stop reinfection and growth of decay urganisms that contaminate the fruit after treatment. Simulated transit injury provides many infection ports via bruises, cuts, etc., inflicted upon the liuit.

Studies are needed to evaluate $t$ ight packaging as a means of reducing transit injury" on irradiated tomatoes. It is anticipated 
That such studies will be made during 1967 employing the Mobile Gamma Irradiator (MCI).

\section{SUMMARY}

Gamna irradiation of 300 and $400 \mathrm{Krad}$ increased the incidence and severity of simulated transit injury on tomatoes in commercial two-layer packages, but when the fruit was held tightly in place with pads this damage was minimal.

There was a delay in ripening both with.irradiation alone and in combination with simulated tranșit injury. This may be an additive effect of the two stresses applied to the fruit in a span of 2-4 hours. This may also be true for the effects on quality and decay retardation. 


\section{LITFRATIIRE CITED}

1. Abdel-Kader, Adel S., L. L. Mọris, and. E. C. Maxie. 1964. The effect of gamma irradiation on the postharvest behavior of tomato fruits. In: "Radiation Technology in Conjunction with Postharvest Procedures as a Means of Extending the Shelf Life of Fruits and Vegetables," pp. 7-47. U. S. Atomic Energy Commission Research and Development Répt. No. UCD-34P80-2.

2. Guillow, Rene, Noel F: Sommer, and F. Gordon Mitchell. 1962. Simulated Transit Testing for Product Containers. Tappi 45(1): 176A-.179A. 
THE MOBILE GAMA IRRADIATOR (MGI)

F. P. Guerrero, R: F. Stallman, F. Chiero; and E. C. Maxie

\section{INTRODUCTION}

The Mobile Gamina Irradiator was designed by the Vitro Engineering Corporation of New York under contract to the Division of Isotopes Development of the U. S. Atomic Energy Commission. The unit was fabricated at the Georgia-Lockheed Company and delivered to the University of California in June, 1966.

While at Davis, the MGI will be used by the Davis research group in various test shipments of fruits and vegetables to the eastern market. The purpose of these tests will be to evaluate the effects of transit on irradiated fruits and vegetables.

\section{DESIGN CHARACTERISTICS}

The MGI consists of six basic components.

1. The radiation source and cask.

2. The irradiation chamber, and body.

3. The hydraulic system.

4. The conveyor system.

5. The air-conditioning and refrigeration system.

6. The instrument panel.

The components are mounted on a 40-foot heavy-duty trailer-jeep assembly and supported by 4 dual-wheel axles and a landing gear. The total weight of the unit excluding a tractor is 56 tons. Figure 1 shows a side view of the MGI, the input conveyor and the outboard hydraulic unit: 


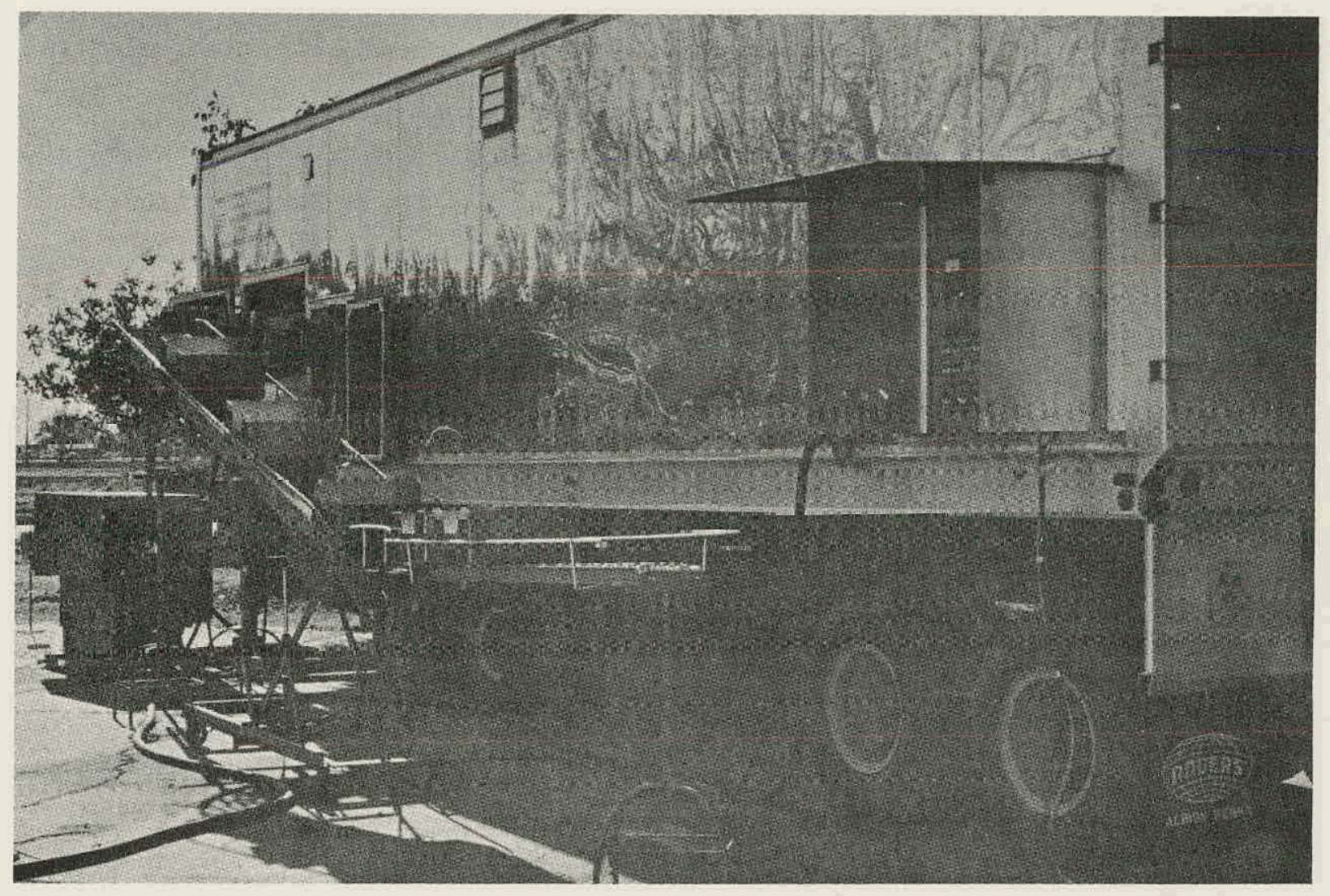

Fig. 1. The Mobile Gama Irradiator. Side view of the MGI includes the outboard hydraulic unit, the input conveyor and the instrument panel. 
The radiation source consists of 19 BNL standard strips of cobalt-60. The strips are 12 "long, $0.64^{\prime \prime}$ wide and $0.06^{\prime \prime}$ thick. The specific activity is $80-90 \mathrm{C} / \mathrm{gm}$ and the total activity is about 80,000 curies (February, 1967). Each strip is doubly encapsulated in stainless steel. This assembly constitutes the cobalt plaque source. The source is welded to an $8^{\prime}$ plaque drive screw which is powered by a small electric motor and supported by a frame located directly behind the cask. The cask is a $4^{8} \times 4^{9} \times 3^{8}$ lead shield in steel weldments weighing 7.65 tons. It consists of $11^{\prime \prime}$ of lead and $1^{\prime \prime}$ of steel and has a large cylindrical lead gate with a slot permitting passage of the plaque upon a $90^{\circ}$ rotation. The cask is mounted on 4 wheels and rests on 2 rails which are mounted to the trailer floor. It is removable and can be shipped separately for repairs or source renewal.

IRRADIATION CHAMBER AND BODY.

This is a large chamber formed by walls of lead 9" thick and lined inside and out with $1 / 2^{\prime \prime}$ steel weldments. The irradiator body is approximately $9-1 / 2^{\prime}$ long, $5^{\prime}$ high and $5^{\prime}$ wide. The total weight of the unit is 28 tons. The chamber has room for 8 carriers which are positioned around the plaque in a rectangular configuration during irradiation. There is also room for the transfer of the carriers at the rear of the chamber.

HYDRAULIC SYSTEM.

This system consists of an inboard and an outboard hydraulic unit. The inboard unit is mounted in the forward part of the trailer and is used for irradiation at doses above $40 \mathrm{Krad}$. The larger outboard unit can maintain the normal operating pressure of $430 \mathrm{psi}$ and can therefore be used at both high and low doses. These units supply the hydraulic pressure to the 12 hydraulic push rods which move the carriers into, through and out of the irradiation chamber. 
THE CONVEYOR SYSTEM.

This system consists of 2 electrically powered belt conveyors, one for the input side and one for the output side. There are also two-90 power turns and about $40^{\circ}$ of roller-skate conveyor. This system moves the carrier up to the input elevator where the hydraulic system can move it into the irradiator. The output conveyor picks the carrier up at the output elevator and conveys it to the loading area at the rear of the MGI.

\section{AIR CONDITIONIAG AND REFRIGERATION SYSTEM.}

The purpose of this system is twofold; first, to provide low. temperature brine ( $40 \%$ methanol, $60 \%$ water) at specific flow rates to coils embedded in the walls and cap of the irradiator body and, secondly, to provide low temperature $\left(4 l^{\circ} \mathrm{F}\right)$ air at $125 \mathrm{cfin}$ through the irradiation chamber. These functions serve to maintain the desired temperature by dissipating the heat generated by the source plaque and that due to ambient temperatures absorbed by the lead body $\cdot$. The flushing of the chamber also eliminates ozone. The system consists of a refrigeration unit mounted on the front end of the trailer, two brine pumps, reservoir and the air-conditioning assembly. The temperature can be monitored and controlled at the instrument panel.

THE INSTRUAENT PANEL.

This unit consists of a panel board mounted at the rear of the trailer and protected by a large aluminum door. The panel has all of the controls and timers for the irradiator. This includes dwell time, defrost interval and defrost duration timers, tempersture control; temperature monitors, and an annunciator panel which indicates malfunctions in some of the units on the MGI. The modules for the product monitor are also mounted on the instrument panel. The product monitor performs periodic examination of the produce in the carriers as checks for leaks in the source. 
OPERATION AND WORK CYCLE.

Figure 2 shows a schematic of the carriers in the dwell positions around the plaque. The lower diagram shows the path taken by the carriers in the irradiation chamber. The hydraulic rods are also shown and identified as follows. The paired rods except $\mathrm{C}-2$ and $\mathrm{C}-8$, the

C-2 and $C-8$ are the forward elevators

C-3 and C-9 are the rear elevators

C-4 and $C-11$ are- the push-rods

C-5 and $\mathrm{C}-10$ are the pull-rods

input (C-6) and the output $(C-7)$ elevators work simultaneously as pairs. The shuttle $(C-1)$ and the cross-over rod $(C-12)$ work independently. The carriers are moved by the sequential action of these 12 hydraulic rods as follows.

The carrier is loaded onto the input elevator which lifts it up into the path of the shuttle. The shuttle is the mechanism, powered by $\mathrm{C}-1$, which introduces a carrier into the chamber when it extends and removes a carrier when it retracts (See Fig. 3 ), the carrier is removed to the output elevator and onto the conveyor. The shuttle is assembled so as to provide shielding in both the extended and retracted position. Once the shuttle is forward the carrier is placed in position 1 by elevator $\mathrm{C}-2$ and the carrier in position 8 is moved up into the shuttle by elevator C-8. The shuttle is then retracted. The push-rods, numbered $\mathrm{C}-4$ and $\mathrm{C}-11$, push the carriers into positions 2 and 6 respectively. The carriers which had occupied these positions are pushed onto elevatars $\mathrm{C}-3$ and $\mathrm{C}-9$ which transfers them from the top level to the bottom level on one side and from the bottom level to the top on the other side. These carriers are pulled into positions 3 and 7 by the pull-rods $\mathrm{C}-5$ and $\mathrm{C}-10$ respectively. The carriers that were in those positions are pushed onto positions 4 and 8 . The cross-over rod $\mathrm{C}-12$, transfers the carriers from position 4 to position 5.

The time required to move a carrier from one position to the next is called the motion time and usually requires 18 seconds. The time 

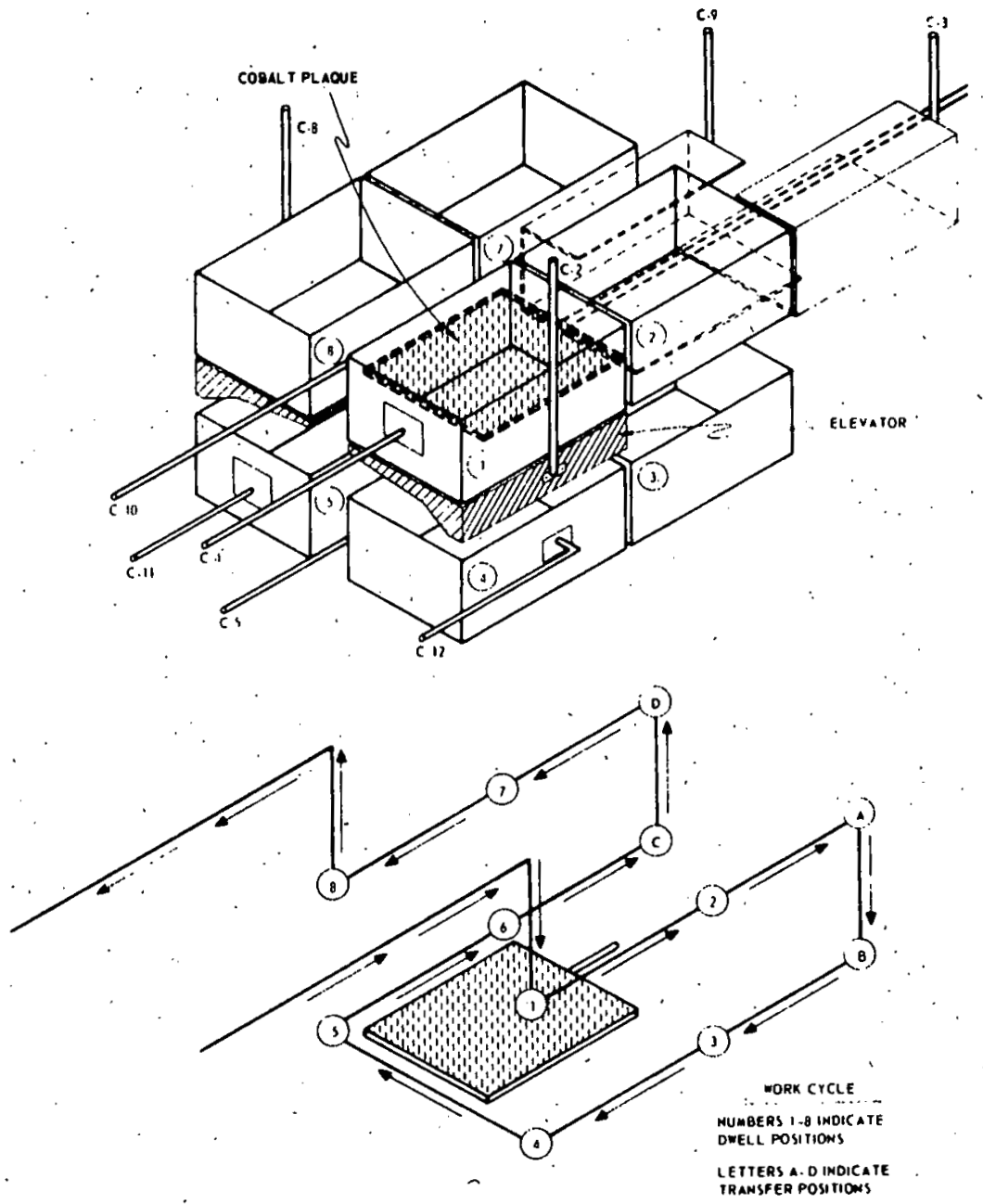

Fig. 2. Schematic of carriers in position around the cobalt plaque and work cycle. Arrows indicate direction of carrier movement during work cycle. 


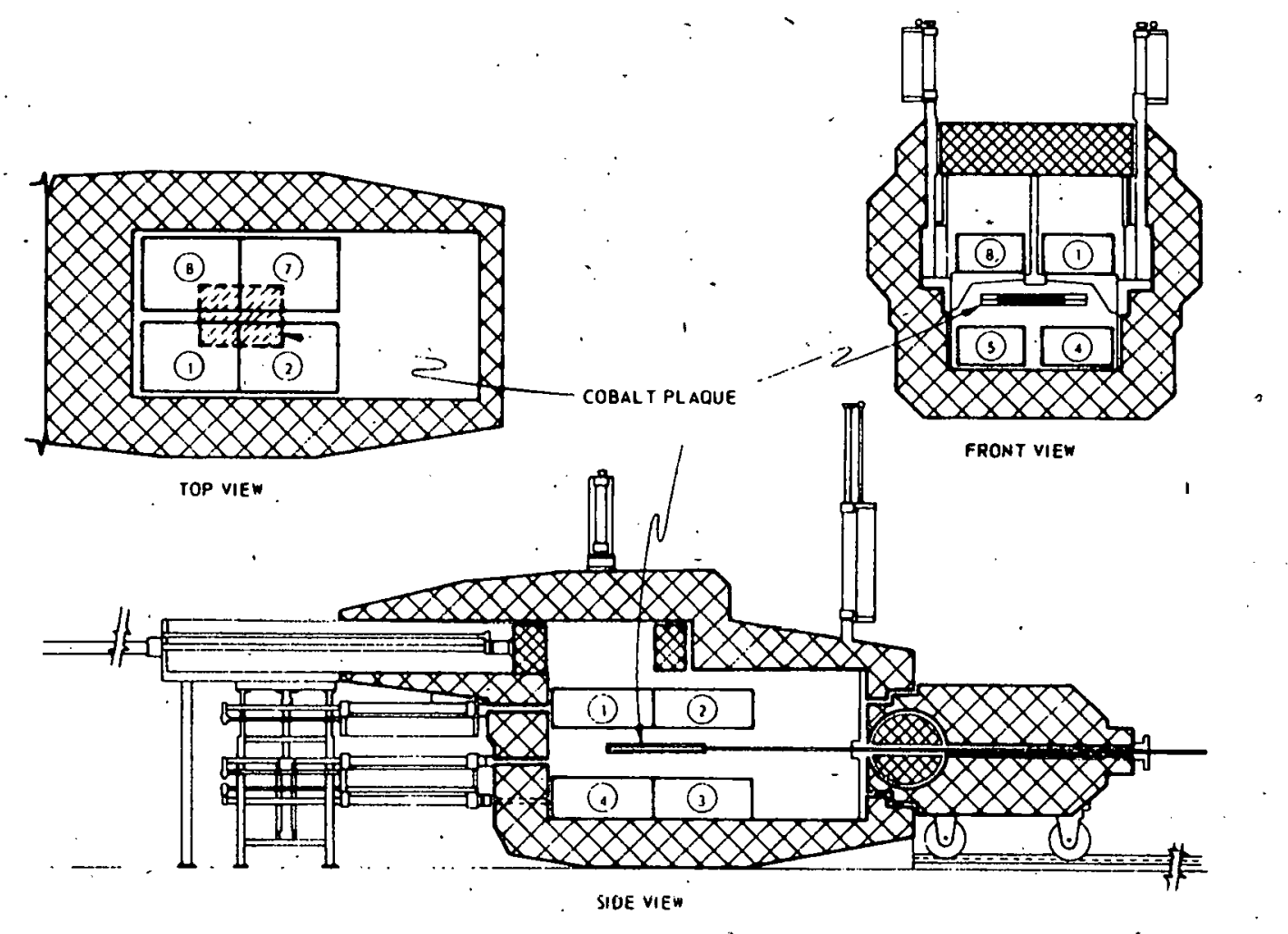

Fig. 3. Schematic of the irradiation chamber and source cask. The numbers indicate the dwell positions of the carriers. 
required for a carrier to complete the entire work cycle is usually about 2.4 minutes. This time can be varied and is dependent upon the operating pressure of the hydraulic system.

\section{SAFETY FEATURES.}

To insure the safe operation of the MGI various electrical and mechanical safety devices have been installed. To monitor the radiation levels around the chamber, three area monitors are located at strategic points. They are connected to the stations at the panel board and activate the alarms if the radiation level exceeds the pre-set level.

A second device is the key interlock system which precludes the opening of the access door to the irradiator chamber it the rotary gate of the cask is not closed and locked. Also it is necessary that the access door be locked before the source plaque can be taken out of the cask. A solenoid attached to the access door prevents the opening of the door if the radiation monitor indicating an open cask gate is activated. Another feature is the audible alarm which is continuous unless the source is in its terminal position either in the irradiator or in the cask. It is impossible to activate the product cycle if the source is not in the terminal positions.

In addition to these safety devices a radiation survey of the MGI was made to deternine any areas of high intensity radiation. Four such areas of pencil-beam thickness were found; one is located at the front end of the irradiator body and measures $5 \mathrm{rad} / \mathrm{hr}$, two were found at. the top of the irradiator near the rear elevators measuring i rad each and one was found at the lett hand side near the brine outlet pipe and measured 2 rads. These have been pointed out to all personnel involved with the irradiator. It has also been established that no one is to go near these areas if the source is out of the cask. During operation a rope barrier at the $2 \mathrm{mr}$ isodose line is set up around the MGI. 
PROGRESS RE.PORT.

Since the arrival of the MGI some modifications have been made. Ore major change was the installation of a new conveyor system which includes a powered conveyor for the output side and 2 power turns. During this period the operators have become familiar with the unit and have prepared a maintenance manual. Another accomplishment was preliminary dosimetry and the establishment of dose rates under both high and low dose conditions (reported in another section of this annual report). Lockheed personnel have visited with the University personnel and a spare parts list has been prejared. At present Lockheed is acquiring the parts which will be stocked with the MGI.

The irradiation work conducted with the unit involved one test shipment of strawherries via air and two other tests to study the effects of irradiation on tomatoes and Honeydew melons.

Future plans include the irradiation of strawberries and bananas for 2-year feeding trials and a series of test shipments of various fruits and vegetables.

THROUGH-PUT CAPACITY.

The amount of fruits or vegetables that the MCI can irradiate depends on two factors, the desired dose and the weight of the fruits or vegetables per carrier.

Based on the following data a table showing through-put capacity was developed.

\begin{tabular}{llc} 
Dose rate & \multicolumn{1}{c}{} \\
\hline High dose & - Krad/hour & 591.7 \\
(w/o steel plates) & Krad/minute & 9.86 \\
Low dose & - Krad/hour & 233.4 \\
(with steel plates) & Krad/minute & 3.89 \\
Motion time & -2.4 minutes &
\end{tabular}


Approximate net weight of fruits and vegetables per carrier:

$\begin{array}{ll}\text { Strawberries } & 26 \mathrm{lbs} \\ \text { Peaches and nectarines } & 25 \mathrm{lbs} \\ \text { Tomatoes } & 30 \mathrm{lbs} \\ \text { Potatoes and onions } & 30 \mathrm{lbs} \\ \text { Bananas } & 20 \mathrm{lbs}\end{array}$

General calculations to establish through-put capacity:

$\frac{\text { Desired dose }}{\text { Dose/minute }}=$ Total time in radiation field

Total time in field - Motion time = Total dwell time

Total dwell time $\div 8=$ Dwell time at each dwell position

Dwell time $+\frac{\text { Motion time }}{8}=\begin{aligned} & \text { Time interval (between } \\ & \text { carriers being ejected) }\end{aligned}$

$60 \div$ Time interval $=$ Carriers per hour

Carriers per hour $x$. Net weight of produce in carriér:= Through-put capacity in Ibs/hr of MGI 
Table 1. Through-put capacity of MGI in 1bs/hr, (November, 1966).

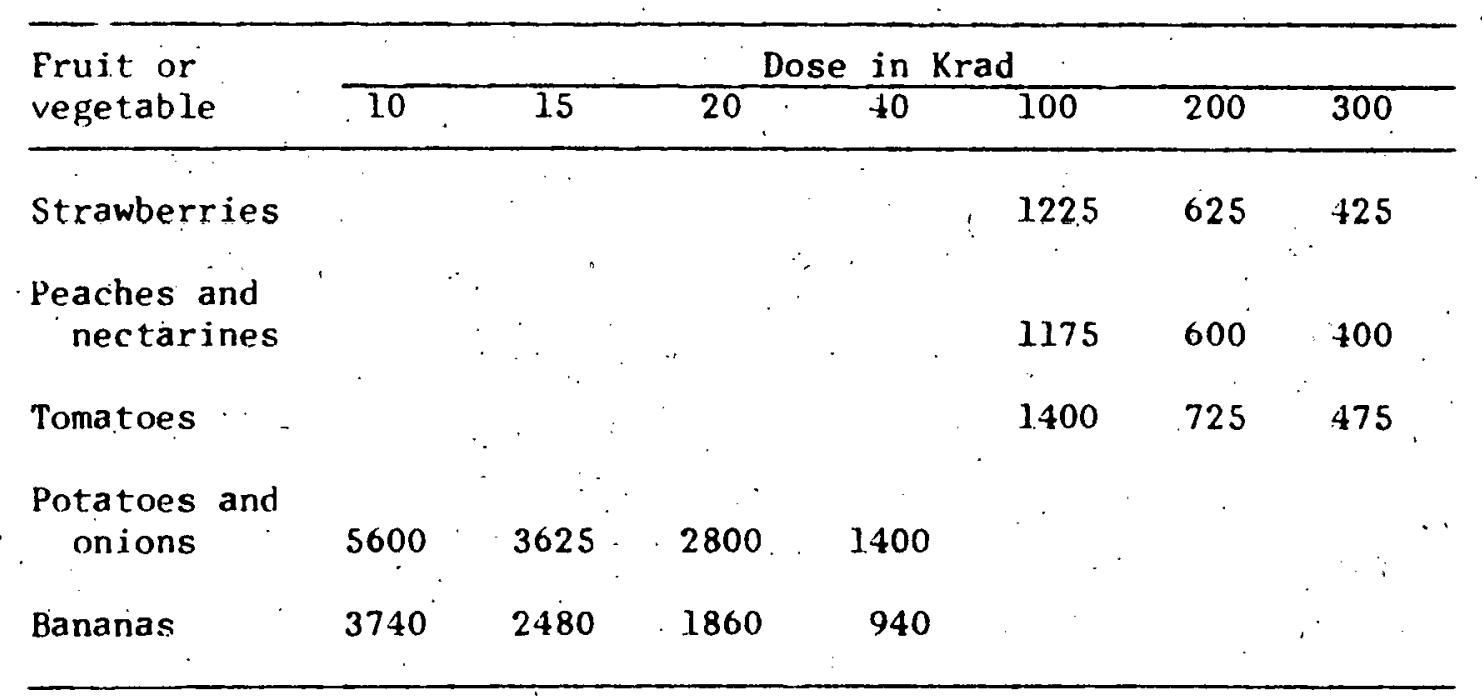




\section{MEASUREMENT OF RADIATION DOSE FOR THE}

MOBILE GAMA IRRADIATOR

F. P. Guerrero, H. L. Rae, Camilla Boyd, and E. C. Maxie

\section{INTRODUCTION}

The Mobile Gamma Irradiator was designed for the irradiation of fruits and vegetables in the 200-Krad range. Installation of steel plates above and below the cobalt plaque permits doses as low as 10 Krad.

The quadrant method irradiation, in which the carriers pass in 4 positions each above and below the source in 8 successive dwell positions, is used in the MGI. At each dwell position approximately $1 / 8$ of the dose is delivered, giving a uniform and efficient absorption of the radiation. The design specification for the maximum/minimum ratio was 1.29 (225/175 $\mathrm{Krad})$.

The objective of the dosimetry was to determine dose distribution under a variety of experimental conditions and to establish dose rates.

\section{MATERIALS AND METHODS}

The dosimetry methods used were Fricke (1), suitable for 4-40 Krad, and Modified Friçke (2), suitable for 40-800 Krad. The solutions for the dosimeters were prepared fresh for each test as follows:

$$
\begin{aligned}
& \text { Fricke - } 0.117 \mathrm{~g}(.001 \mathrm{M}) \mathrm{NaCl} \\
& 1.570 \mathrm{~g}(.004 \mathrm{~N}) \mathrm{FeSO}_{4} \cdot\left(\mathrm{NH}_{4}\right)_{2} \mathrm{SO}_{4} \cdot 6 \mathrm{H}_{2} \mathrm{O} \\
& \text { Salts were dissolved in } 0.8 \mathrm{~N}_{2} \mathrm{SO}_{4} \text { and brought } \\
& \text { to volume of } 1 \text { liter with same } \\
& \text { Modified Fricke }-2.5 \mathrm{~g}(0.01 \mathrm{M}) \mathrm{CuSO}_{4} \cdot \mathrm{SH}_{2} \mathrm{O} \\
& 0.392 \mathrm{~g}(0.001 \mathrm{M}) \mathrm{FeSO}_{4}\left(\mathrm{NH}_{4}\right)_{2} \mathrm{SO}_{4} \cdot 6 \mathrm{H}_{2} \mathrm{O} \\
& \text { Salls were dissolved in } 0.01 \mathrm{M} \mathrm{H}_{2} \mathrm{SO}_{4} \text { and brought } \\
& \text { to volume of l liter }
\end{aligned}
$$


The acid solutions were prepared by using glass or deionized distilled water with 2-20 megaohms conductivity. The dosimetry solutions were placed in glass stoppered bottles and inverted 40 times to insure a good supply ot dissolved oxygen.

The ampoules (supplied by Owens-IIlinois Glass Co.) were: immersed in hot nitric acid for 15 minutes, rinsed thoroughly with deionized distilled water and oven dried. Five ml of the solution were placed in the ampoules and the ampoules sealed with an oxygen-natural gas burner. The ampoules were placed in a plexiglass dosimetry rack (Fig. I), and secured with rubber bands. "The number of ampoules used per test was 10, 15, or 25. The dosimetry rack was placed in an aluminum carrier and run through the irradiator.

Twenty-one teste were conducted over a period of 10 weeks 8 The various experimental conditions for each test are summarized in Table 1. To simulate product density the dosimetrÿ-rack carrier was filled with potatoes. To study the attenuation effects of the carriers preceding and following the dosimetry-rack carrier, dumny loads of potatoes (20 lbs.) or steel plates $(1 / 2 " \times 12 " \times 18 ")$ were used.

The irradiated ampoules were placed in constant temperature bath at $24^{\circ} \mathrm{C}$ for 30 ininutes. The ampoules were opened and the contents poured into a $1 \mathrm{~cm}$ thick quartz cell for optical-density readings in a Beckman DU Spectrophotometer at $304 \mathrm{~m} \mu$. The dose factor is calculated as follows:

$$
\begin{aligned}
& \text { Assumed } G \text { value }=15.6 \mathrm{Fe}^{++t} \text { per } 100 \mathrm{ev}:(\text { Fricke) } \ldots \text { : } \therefore \\
& i \mathrm{rad}=100^{\circ} \mathrm{ergs} / \mathrm{gram} \\
& 1 \mathrm{ev}=1.602 \times 10^{-12} \text { ergs } \\
& 1 \text { mole }=6.02 \times 10^{23} \text { atoms } \\
& \text { Optical density (0.D.) }=459 \text { moles } \mathrm{Fe}^{+++} / 1 \\
& \text { Density of solution }=1.02 \mathrm{~g} / \mathrm{ml} \\
& \mathrm{rad}=\frac{15.6 \mathrm{Fe}}{100 \mathrm{ev}}: \frac{1 \mathrm{ev}}{1.602 \times 10^{-12} \mathrm{ergs}}: \frac{\operatorname{mole}}{6.02 \times 10^{23} \text { atoms }}
\end{aligned}
$$




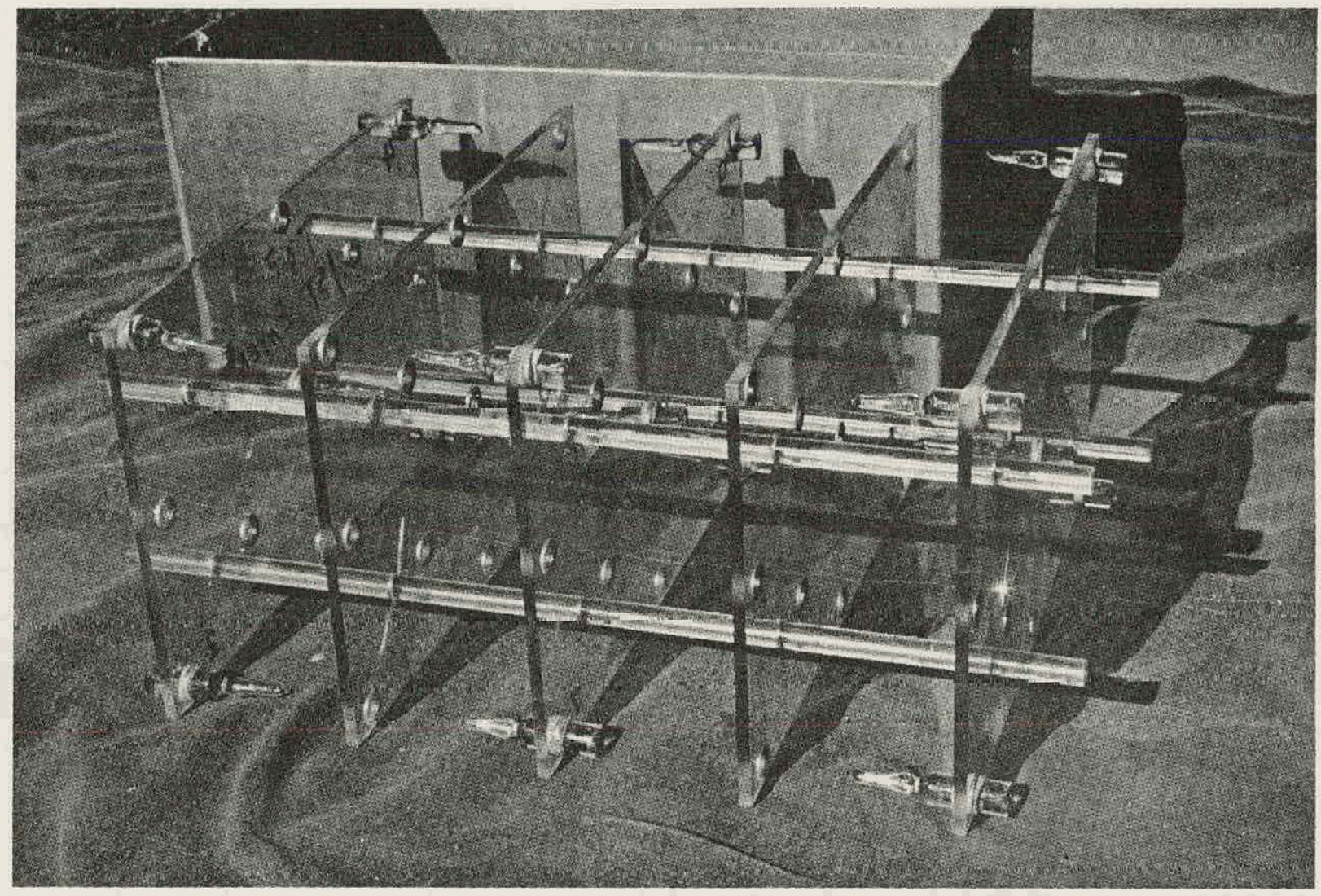

Fig. 1. Dosimetry rack with ampoules in place. Five ampoules per shelf were used. Shelves were numbered 1-5, left to right. Shelf No. 5 was closest to source plaque during transfer. 
Table 1. Code designation and conditions for dosimetry test. ${ }^{1}$

\begin{tabular}{|c|c|c|c|c|c|c|c|c|c|c|c|}
\hline Code & $\begin{array}{l}\text { No. of } \\
\text { ampoules }\end{array}$ & $\begin{array}{l}\text { Dwell } \\
\text { time }\end{array}$ & $\begin{array}{l}\text { Dos } \\
\text { Rack } \\
\text { full }\end{array}$ & $\begin{array}{l}\text { imetry } \\
\text { carrier } \\
\text { empty }\end{array}$ & $\begin{array}{l}\text { Dummy } \\
\text { prece } \\
\text { full }\end{array}$ & $\begin{array}{l}\text { loads } \\
\text { eding } \\
\text { empty }\end{array}$ & $\begin{array}{l}\text { Durnmy } \\
\text { foll } \\
\text { full }\end{array}$ & $\begin{array}{l}\text { loads } \\
\text { owing } \\
\text { empty }\end{array}$ & $\begin{array}{l}\text { Low } \\
\text { dose }\end{array}$ & $\begin{array}{l}\text { High } \\
\text { dose }\end{array}$ & $\begin{array}{c}\text { Date } \\
\text { irradiated }\end{array}$ \\
\hline A & 15 & 4 min. & 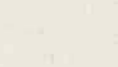 & $\mathrm{x}$ & $x$ & & $x$ & & & $x$ & $10 / 5 / 66$ \\
\hline B & 15 & 2 min. & $x$ & & $x$ & & $x$ & & & $x$ & $10 / 11 / 66$ \\
\hline C & 15 & $4 \mathrm{~min}$ & $x$ & & $x$ & & $x$ & & & $x$ & $10 / 11 / 66$ \\
\hline D & 15 & 4 min. & $x$ & & . & $x$ & $x$ & & & $x$ & $10 / 12 / 66$ \\
\hline$E^{2}$ & 15 & 4 min. & $x$ & 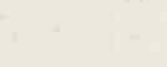 & $x$ & & $x$ & & & $x$ & $10 / 12 / 66$ \\
\hline F & 15 & 2 min. & $x$ & & & $x$ & $x$ & & & $x$ & $10 / 21 / 66$ \\
\hline G & 15 & $4 \mathrm{~min}$ & $x$ & & & $x$ & $x$ & & & $x$ & $10 / 25 / 66$ \\
\hline H & 15 & 3 min. & $x$ & $=-\quad-$ & & $x$ & $x$ & & & $x$ & $10 / 26 / 66$ \\
\hline I & 15 & 2 min. & $x$ & 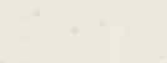 & & $x$ & $x$ & & & $x$ & $11 / 1 / 66$ \\
\hline $\mathrm{J}$ & 15 & 4 min. & $x$ & & & $x$ & $x$ & - & 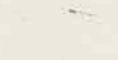 & $x$ & $11 / 1 / 66$ \\
\hline K & 10 & 20 sec. & t & $x$ & $x^{2}$ & $x$ & - & $x$ & $x$ & & $12 / 12 / 66$ \\
\hline L & 10 & 20 sec. & & $x$ & ' & $x$ & & $x$ & $x$ & & $12 / 12 / 66$ \\
\hline M & 25 & $20 \mathrm{sec}$. & $x$ & 'it & & $x$ & & $x$ & $x$ & & $12 / 20 / 66$ \\
\hline$N$ & 25 & 30 sec. & & $x$ & & $x$ & & $x$ & $x$ & & $12 / 13 / 66$ \\
\hline 0 & 25 & 30 sec. & $\mathrm{x}$ & $2 !$ & & $\mathbf{x}$ & & $x$ & $x$ & & $12 / 16 / 66$ \\
\hline $\mathrm{P}$ & 25 & 30 sec. & $x$ & & & $x$ & & $x$ & $x$ & & $12 / 19 / 66$ \\
\hline
\end{tabular}

Continued on next page. 
Table 1. (Continued)

\begin{tabular}{|c|c|c|c|c|c|c|c|c|c|c|c|}
\hline Code & $\begin{array}{c}\text { No. of } \\
\text { ampoules }\end{array}$ & $\begin{array}{l}\text { Dwell } \\
\text { time }\end{array}$ & $\begin{array}{l}\text { Dos } \\
\text { Rack } \\
\text { full }\end{array}$ & $\begin{array}{l}\text { simetry } \\
\text { carrier } \\
\text { empty }\end{array}$ & $\begin{array}{l}\text { Dummy } \\
\text { prece } \\
\text { full }\end{array}$ & $\begin{array}{l}\text { loads } \\
\text { eding. } \\
\text { empty }\end{array}$ & $\begin{array}{l}\text { Dummy } \\
\text { foll } \\
\text { tull }\end{array}$ & $\begin{array}{l}\text { loads } \\
\text { owing } \\
\text { empty }\end{array}$ & $\begin{array}{l}\text { Low } \\
\text { dose }\end{array}$ & $\begin{array}{l}\text { High } \\
\text { dose }\end{array}$ & $\begin{array}{l}\text { Date } \\
\text { irradiated }\end{array}$ \\
\hline$Q$ & .10 & $40 \mathrm{sec}$ & & $x$ & & $x$ & & $x$ & $x$ & & $12 / 12 / 66$ \\
\hline $\mathrm{R}$. & 15. & $2 \mathrm{~min}$. & & $x$ & & $x$ & & $x$ & & $x$ & $12 / 21 / 66$ \\
\hline$S$ & 15 & $4 \mathrm{~min}$. & & $x$ & , & $x$ & & $x$ & & $x$ & $12 / 22 / 66$ \\
\hline$T$ & 15 & $3 \mathrm{~min}$ & . & 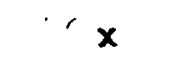 & 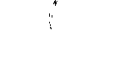 & $x$ & & $x$ & & $x$ & $12 / 22 / 66$ \\
\hline U & 15 & $2 \mathrm{~min}$ & $\dot{x}$ & & & $x$ & & $x$ & & $x$ & $12 / 23 / 66$ \\
\hline
\end{tabular}

1 Check mark $(x)$ indicates condition under column heading.

2 Steel plates 1/2" thick (25 1bs.) were used as dumny loads. 


$$
\begin{aligned}
& \frac{1.02 \mathrm{~g}}{\mathrm{ml}} \cdot \frac{1 \times 10^{6} \mathrm{moles}}{\text { moles }} \cdot \frac{100 \mathrm{ergs}}{\mathrm{g}} \\
& \therefore 1 \mathrm{rad}=0.01649 \mu \mathrm{moles} \mathrm{Fe}^{+++} / 1 \\
& 10 . \mathrm{D} .=459 \mu \mathrm{moles} \mathrm{Fe}^{+++} / 1 \\
& 10^{3} \mathrm{rads}=\frac{459 \mu \mathrm{moles} \mathrm{Fe}^{+++} / 1 / 0 . \mathrm{D} .}{16.49 \mu \mathrm{moles} \mathrm{Fe}^{+++} / 1}=27.82 \cdot 10^{3} \mathrm{rads} / 0 . \mathrm{D} . \\
& \therefore \text { Krad }=27.82 \times 0 . \mathrm{D} .
\end{aligned}
$$

Multiply the 0.D. of the solutions irradiated by the constant 27.82 and the result is the dose absorbed in Krad.

The $G$ value varies in the Modified Fricke dosimetry method; thus it was necessary to standardize the solution against a known source. For this purpose the Mark II Irradiator previously standardized by the Fricke method was used (2).

The $G$ value for the Modified Fricke is about $0.66 \mathrm{Fe}^{+++}$per $100 \mathrm{ev}$. The factor for converting $0 . \mathrm{D}$. to Krad is about $658 \mathrm{Krad} / \mathrm{unit} \mathrm{O.D}$. and is derived as follows:

$$
\begin{aligned}
\text { Modified Fricke Factor } & =\frac{G \text { value of Fricke }}{G \text { value of Modified }} \times \text { Fricke Factor/unit O.D. } \\
& =\frac{15.6}{0.66} \times 27.82 \\
& =658 \mathrm{krad} / \mathrm{unit} \text { 0.D. }
\end{aligned}
$$

In these tests the Modified Fricke Factor was obtained by irradiating 10 ampoules with a predetermined amount of radiation in the Mark II. The optical densities were determined and the average $0 . D$. was divided into the known dose received. This factor was then used to determine the dosimetry of the unknown ampoules irradiated in the MGI.

$$
\begin{aligned}
& \text { CXAMPLE -- } \frac{\text { Known dose in Krad }}{\text { O.D. of Modified Fricke }}=\begin{array}{l}
\text { Factor of } \\
\text { Modified Solution }
\end{array} \\
& \frac{321.5}{0.502}=640.4 \mathrm{Krad} / \text { unit } 0 . \mathrm{D}
\end{aligned}
$$


The optical densities of the unknown solutions were multiplied by the factor obtained to give dose in Krad. The solutions are not completely stable, thus readings were taken on blanks at the time the other ampoules were placed in the radiation field. The average of 3 blanks served as a correction factor to compensate for any ferric ions formed without irradiation.

ANALYSIS OF THE DATA

The data was analyzed and various calculations were made for each test. A summary of the data is presented in Table 2.

The adjusted average dose was calculated by averaging the maximum and minimum doses. Total time in the field was measured using a stop watch. The difference between' total time in the field and total dwell time ( 8 dwell-time intervals) was time in motion. Maximum/minimum ratios were calculated. The standard deviations and coefficients of variation were calculated using standard methods. The per cent error for each test was calculated by subtracting the adjusted average from the maximum dose and dividing by the adjusted average. The per cent attenuation, relationship between dose and time and the amount of error between tests were also calculated as shown in Tables 3, 4, and $\dot{5}$. In calculating these data, only those tests under the same experimental conditions were used.

The pattern of dose distribution within a carrier both in a vertical and horizontal plane was calculated. Vertical distribution for each test was calculated by averaging the doses in each shelf of the dosimetry rack. To determine the effects of radiation on dose absorption during transfer the amount of variation in dose absorption between shelves 3 and 5 was calculated, as shown in Table 6 : Dose distribution on a horizontal plane for each test was calculated by averaiging the doses within each of 5 horizontal axes as shown in Table 7. Other parameters calculated were; average dose per hour and average dose per minute. 
Table 2. Partial summary of the calculations based on the dosimetry data.

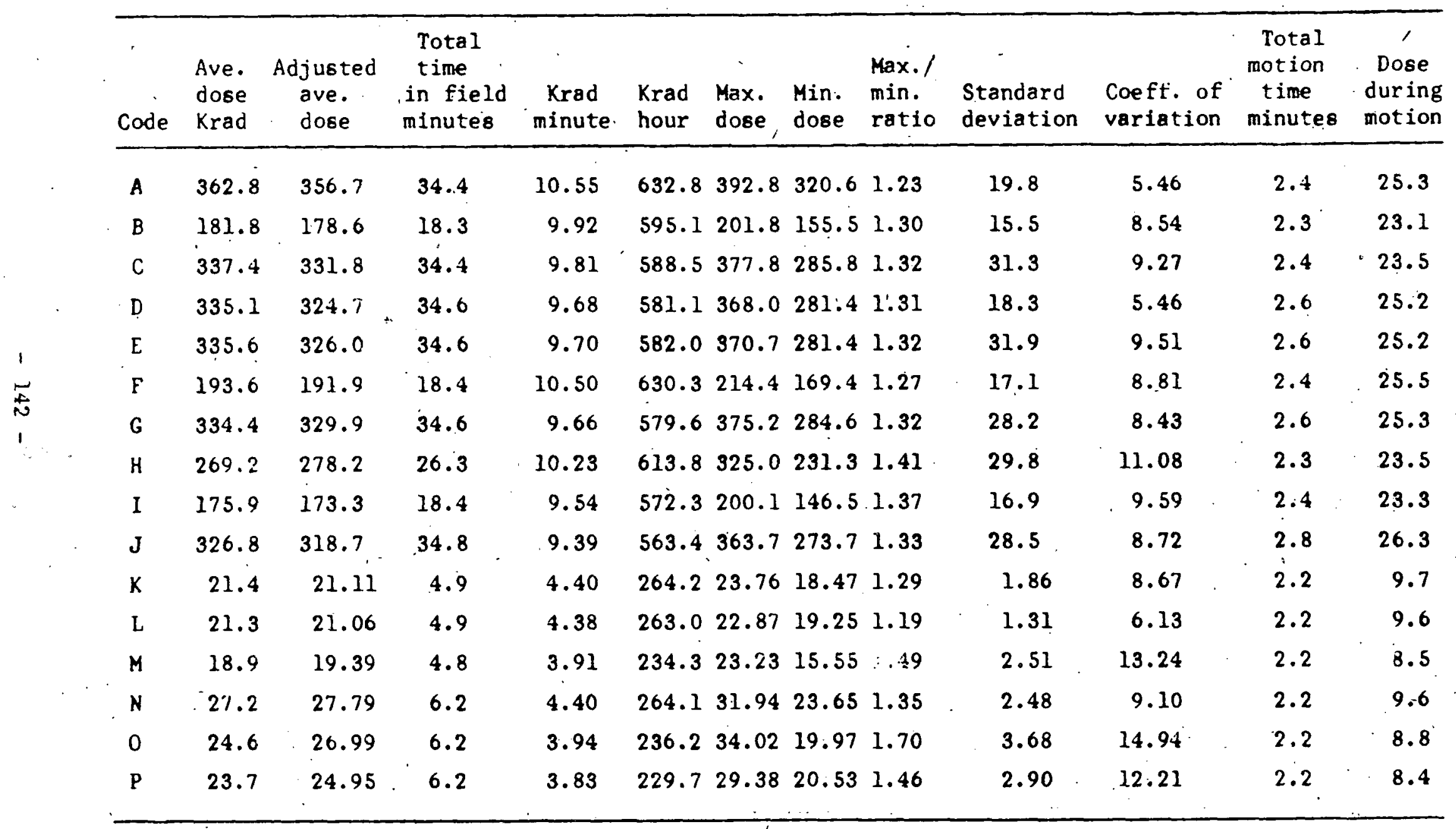

Continued on next page. 
Table 2. (Continued)

\begin{tabular}{|c|c|c|c|c|c|c|c|c|c|c|c|c|}
\hline Code & $\begin{array}{l}\text { Ave. } \\
\text { dose } \\
\text { Krad }\end{array}$ & $\begin{array}{l}\text { Adjusted } \\
\text { ave. } \\
\text { dose }\end{array}$ & $\begin{array}{l}\text { Total } \\
\text { time } \\
\text { in field } \\
\text { minutes }\end{array}$ & $\begin{array}{l}\text { Krad } \\
\text { minute }\end{array}$ & $\begin{array}{l}\text { Krad } \\
\text { hour }\end{array}$ & $\begin{array}{l}\text { Max. } \\
\text { dose }\end{array}$ & $\begin{array}{l}\text { Min. } \\
\text { dose }\end{array}$ & $\begin{array}{l}\text { Max./. } \\
\text { min. } \\
\text { ratio }\end{array}$ & $\begin{array}{l}\text { Standard } \\
\text { deviation }\end{array}$ & $\begin{array}{l}\text { Coeff. of: } \\
\text { variation }\end{array}$ & $\begin{array}{l}\text { Total } \\
\text { motion } \\
\text { time } \\
\text { minutes }\end{array}$ & $\begin{array}{l}\text { Dose } \\
\text { during } \\
\text { motion }\end{array}$ \\
\hline$Q$ & 32.4 & 31.93 & 7.5 & 4.31 & 258.8 & 34.16 & 29.71 & 1.15 & 1.61 & 4.96 & 2.2 & 9.4 \\
\hline$R$ & 193.1 & 193.0 & 18.3 & 10.52 & 632.4. & 206.4 & 179.6 & 1.15 & 9.7 & 5.03 & 2.3 & 24.7 \\
\hline$S$ & 356.1 & 356.8 & 34.5 & 10.31 & 618.8 & 381.3 & 332.3 & 1.15 & 15.0 & 4.21 & 2.5 & 26.1 \\
\hline $\mathrm{T}$ & 269.4 & 272.4 & 26.4 & 10.21 & 612.3 & 291.1 & 253.8 & 1.15 & 13.7 & 5.08 & 2.4 & 24.5 \\
\hline$U$ & 186.5 & 184.0 & 18.3 & 10.17 & 610.1 & 211.6 & 156.4 & 1.35 & 17.6 & 9.41 & 2.3 & 23.8 \\
\hline
\end{tabular}

Ave. motion time 2.37 . 
Table 3. Calculations for averages of; Krad/hour; Krad during motion; max./min. ratio; per cent error; $\mathrm{Krad} / \mathrm{minute,} \mathrm{and} \mathrm{overall}$ attenuation due to potatoes and shielding plates.

\begin{tabular}{|c|c|c|c|c|c|}
\hline Full & Code & $\mathrm{Krad} / \mathrm{hr}$ & $\begin{array}{l}\text { Krad } \\
\text { during } \\
\text { motion }\end{array}$ & $\begin{array}{l}\operatorname{Max} . / \\
\min . \\
\text { ratio. }\end{array}$ & $\begin{array}{l}\therefore \% \\
\text { error }\end{array}$ \\
\hline & B & 595.09 & 23.1 & 1.30 & 12.98 \\
\hline & C & 588.49 & 23.5 & 1.32 & 13.86 \\
\hline & D & 581.10 & 25.2 & $1.3 i$ & 13.33 \\
\hline & $E$ & 582.96 & 25.2 & 1.32 & 113.71 \\
\hline & $\mathbf{F}$ & 630.28 & 25.5 & 1.27 & 11.72 \\
\hline & G & 579.55 & 25.3 & 1.32 & 13.73 \\
\hline & H & 613.80 & 23.5 & 1.11 & 16.82 \\
\hline & I & 572.34 & 23.3 & 1.37 & 15.46 \\
\hline & $J$ & 563.45 & 26.3 & 1.33 & 14.11 \\
\hline & $\mathbf{U}$ & 610.14 & 23.8 & 1.35 & 15.00 \\
\hline & Ave. & 591.72 & 24.5 & 1.33 & 14.07 \\
\hline
\end{tabular}

A. Krad/minute - full

High dose $\frac{591.72}{60}=9.86 \mathrm{Krad}$

Low dose

$\frac{233.40}{60}=3.89 \mathrm{Krad}$

B. Overall attenuation due to potatoes

High dose

$$
\frac{623.81-591.72}{623.81}=5.14 \%
$$

Low dose

$$
\frac{262.52-233.40}{262.52}=11.09 \%
$$

C. Overall attenuation due to shielding plates

Full

$\frac{591.72-233.40}{591.72}=60.55 \%$

Continued on next page. 
Table 3. (Continued)

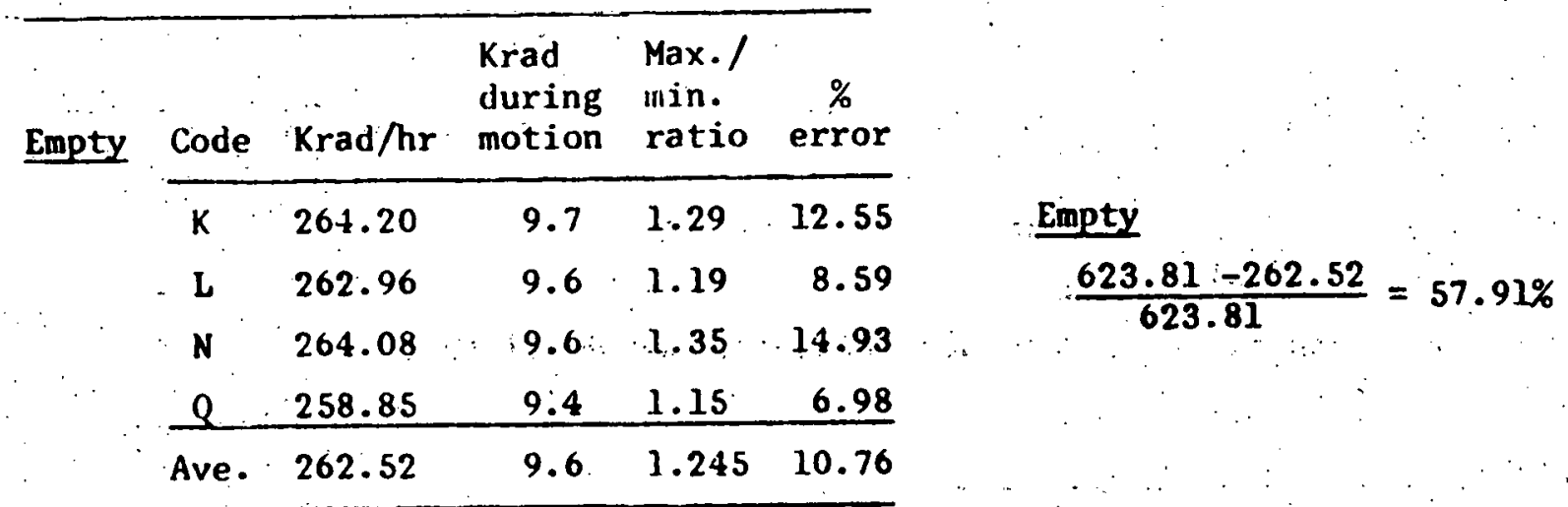


Table 4. Comparison between absorbed dose and dwell time

\begin{tabular}{|c|c|c|c|c|c|}
\hline Code & $\begin{array}{l}\text { Ave. dose } \\
\text { Krad }\end{array}$ & $\begin{array}{l}\text { Dwell } \\
\text { time }\end{array}$ & & $\begin{array}{c}\text { Expected } \\
\text { dose } \\
\end{array}$ & $\begin{array}{c}\text { Actual } \\
\text { dose }\end{array}$ \\
\hline $\mathbf{R}$ & $193: 1$ & $2 \mathrm{~min}$. & $(193.1+356.1) \div 2$ & 274.6 & 269.4 \\
\hline$T$ & 269.4 & $3 \mathrm{~min}$. & & & \\
\hline$s$ & 356.1 & $4 \mathrm{~min}$. & • & & \\
\hline $\mathbf{F}$ & 193.6 & $2 \mathrm{~min}$. & $(193.6+334.4) \div 2$ & $=264.0$ & 269.2 \\
\hline H & 269.2 & 3 min. & & & \\
\hline G & 334.4 & $4 \mathrm{~min}$. & & & \\
\hline $\mathrm{K}$ & 21.4 & $20 \mathrm{sec}$. & $(21.4+32.4) \div 2$ & 26.9 & 27.2 \\
\hline N & 27.2 & 30 sec. & & & . \\
\hline$Q$ & 32.4 & $40 \mathrm{sec}$. & & & \\
\hline
\end{tabular}


Table 5. Per cent error between similar tests.

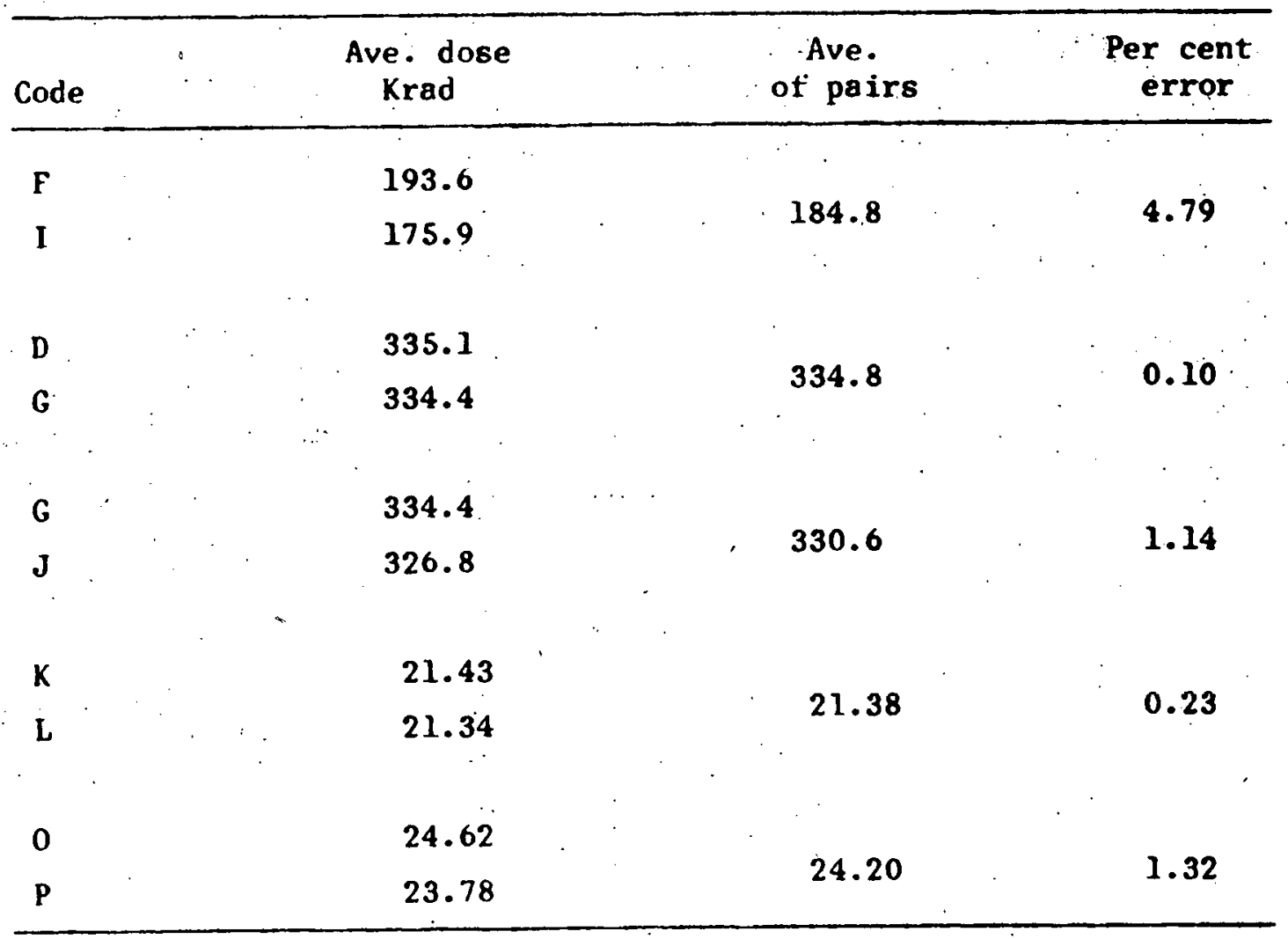


Table 6. Dose distribution on a vertical plane within the dosimetry rack carrier and per cent variation between shelves 3 and 5.

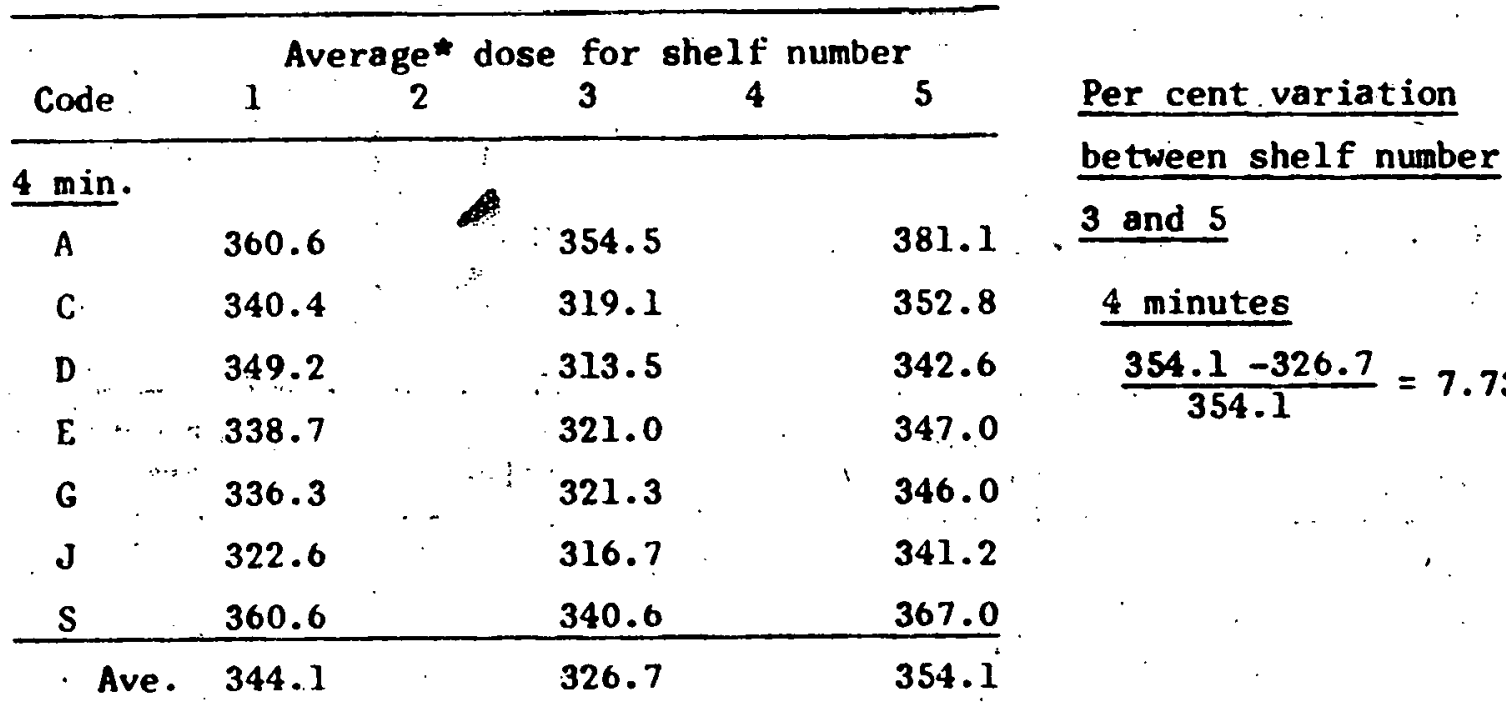

$3 \mathrm{~min}$

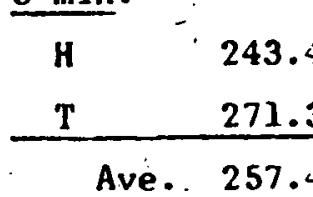

2 min.

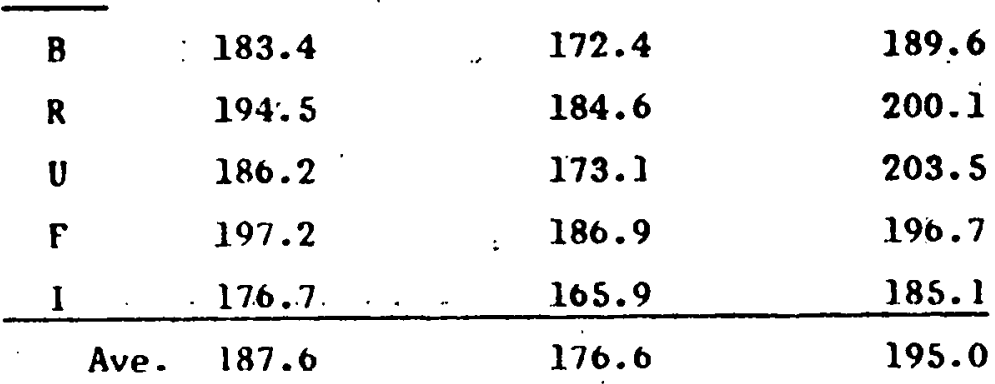

3 minutes

299.7

279.3

$\frac{289.5-263.9}{289.5}=8.84$

\section{2 minutes}

$$
\frac{195.0-176.6}{195.0}=9.43
$$

40 sec.

$\frac{3 \quad 31.10 \quad 33.74}{\text { Ave } \quad 31.10}$

Cont intiod on next page. 
Table 6. (Continued)

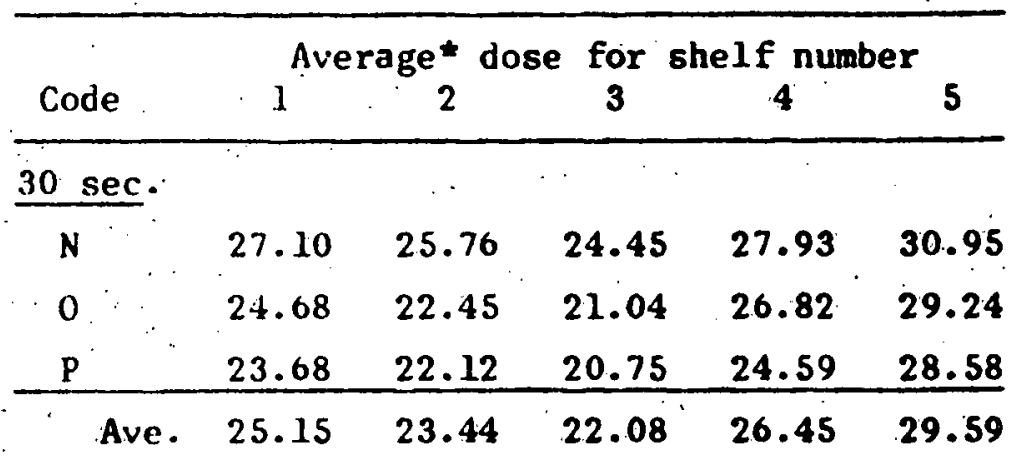

$$
\frac{\frac{30 \text { seconds }}{29.59-22.08}}{29.59}=25.38
$$

\begin{tabular}{llllll}
\hline 20 sec. & & & & & \\
\hline$K$ & & 19.77 & & 23.09 & \\
L & & 20.20 & & 22.49 & \\
M & 19.02 & 17.44 & 16.54 & 19.66 & 22.87 \\
\hline Ave. & 19.02 & 19.14 & 16.54 & 21.75 & 22.87 \\
\hline
\end{tabular}

$\frac{\frac{20 \text { seconds }}{22.87-16.54}}{22.87}=27.67$

* Average of 5 ampoules/shelf or less if any were broken.

$-149=$ 
Table 7. Dose distribution on horizontal plane within the dosimetry rack carrier:

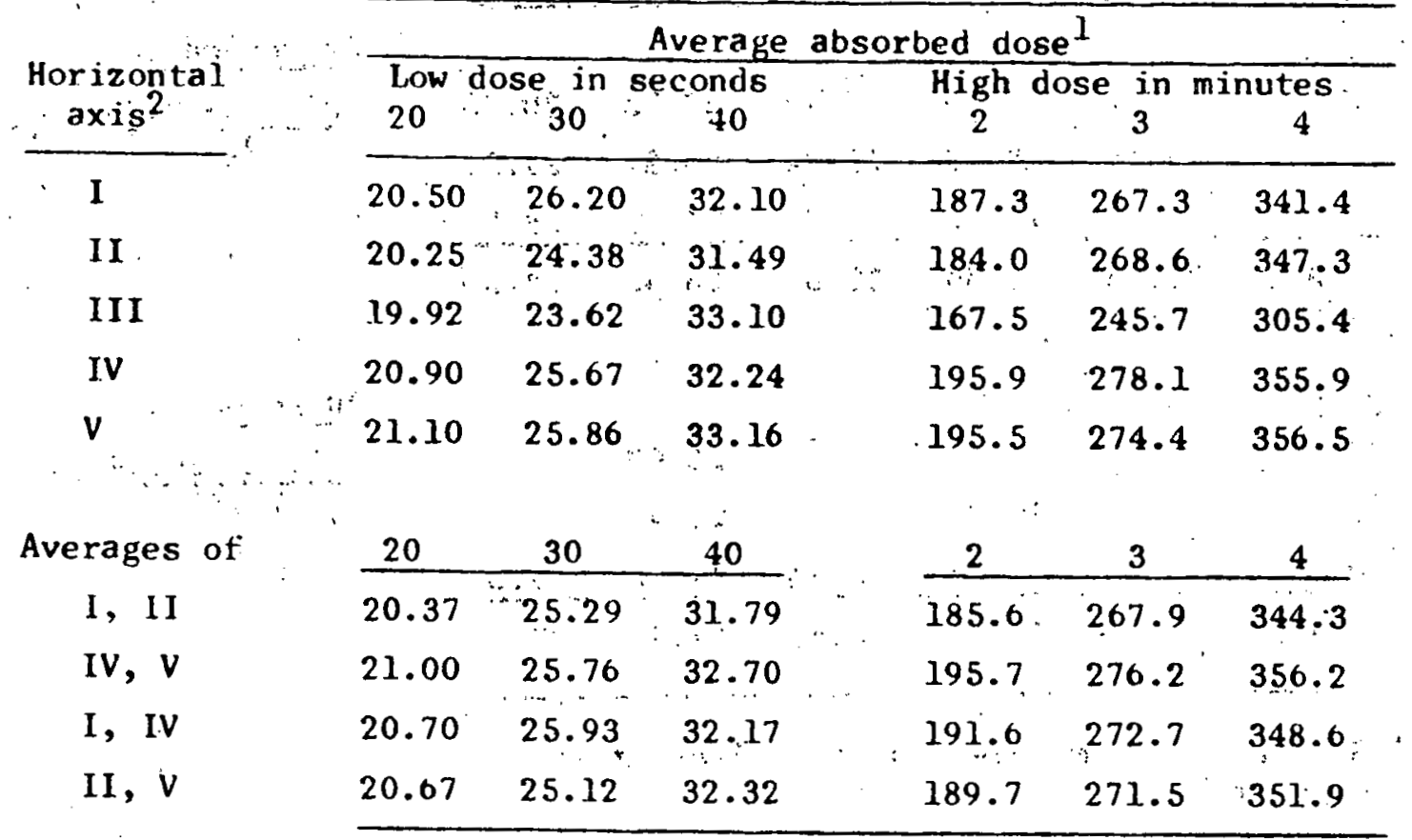

Average of ampoules within a horizontal axis of all tests at a given dwell time.

2 Horizontal axis includes ampoules in positions numbered:

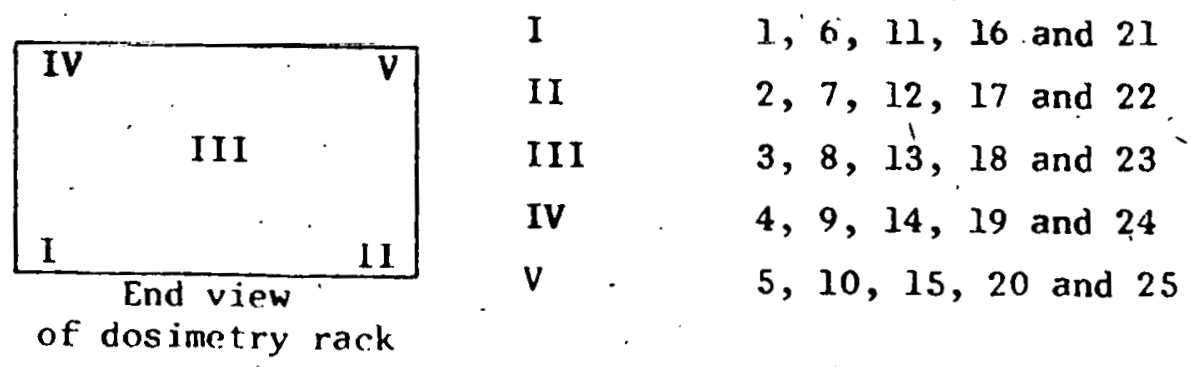




\section{RESULTS}

The adjusted average doses, as shown in Table 2, were slightly lower than the average doses at high dose and slightly higher than the average doses at low dose. Of the maximum/minimum ratios only 5 were out of line when compared to the design ratio of 1.29 ." These were the ratios for tests $H, V, M, 0$, and $P$. In general the coefficients of variation were larger for low-dose tests using a full dosimetry-rack carrier. The average motion time was 2.37 minutes.

Table 3 shows the results of some of the calculations made on the data. The average dose of all the tests using a full dosimetryrack carrier was $591.72 \mathrm{Krad} / \mathrm{hour}$ at high dose and $233.40 \mathrm{Krad} / \mathrm{hour}$ at low dose. When the dosimetry-rack carrier was empty the doses were 623.81 and $262.52 \mathrm{Krad} / \mathrm{hour}$ at high and low dose respectively. The dose per minute was $9.86 \mathrm{Krad}$ at high dose and $3.89 \mathrm{Krad}$ at low dose. The overall attenuation due to potatoes was $5.14 \%$ and $11.09 \%$ at high. and low dose respectively. The attenuation due to the steel shielding plates was $57.91 \%$. It was $60.55 \%$ when potatoes were used in the dosimetry-rack carriers.

During motion of the carrier in the chamber the average dose absorbed was. $24.5 \mathrm{Krad}$ (high dose) and $8.6 \mathrm{Krad}$ (low dose), with the carriex full. When empty the doses were 25.1 and $9.6 \mathrm{Krad}$ at high and low dose respectively. The errors using the maximum/minimum ratios were $14.07 \%$ (ful1) and $7.64 \%$ (empty) at high dose. At low dose they were $21.19 \%$ (full) and $10.76 \%$ (empty). The maximum/minimum ratios were considerably higher in tests using a full dosimetry-rack carrier. The ratios were also slightly higher at low dose.

Table 4 shows that, with the exception of some slight deviation, the relationship between dose and time is linear at both high and low dose. The errors between similar tests as seen on Table 5 were generally below $2 \%$ with the exception of the comparison made between tests $F$ and $I$ in which the error was $4.79 \%$. 
Table 6 shows that the dose distribution on a vertical plane was lowest in the center shelf and increased outward. The shelves nearest the source received more radiation than those furthest from the source. The variation in dose between shelves 3 and 5 was greatest at low dose.

Table 7 shows the dose distribution on a horizontal plane. The top of the carrier received more radiation than the bottom. Dose distribution on either side of the carrier was uniform. The dose on the horizontal axis along the center of the carrier was lowest.

\section{DISCUSSION}

The attenuation effect of the potatoes in the dosimetry-rack carrier resulted in a greater variation in dose distribution within the carrier. This is supported by the larger maximum/minimum ratio, standard deviation, coefficient of variation and per cent error in the tests in which potatoes were used as compared to those tests in which the dosimetry-rack carrier was empty. The maximum/minimum ratios were larger because the range between the maximum and minimum dose was increased.

The steel plates reduced the absorbed dose by about 60\%; however, these plates served to collimate the radiation in a horizontal plane parallel to the source plaque and this resulted in a relatively high dose of radiation to the carriers during transter from the top level to the bottom and vice-versa. The average dose of the ampoules in shelt number 5 was greater than the average of the other shelves because it was closer to the dource during transfer. The per cent variation was greater between the average doses or shelves 3 and 5 . at low dose than at high dose because a higher proportion of the total dose was absorbed during transter under low-dose conditions.

The importance of determining the error in dose distribution is apparent. At high doses the error is $\pm 14 \%$ giving a range of $172-228$ $\mathrm{Krad}$ at $200 \mathrm{Krad}$. At a low dose $(20 \mathrm{Krad})$ an error of $\pm 21 \%$ would 
mean a range of $15.8-24.2 \mathrm{Krad}$. Although the maximum/minimum ratio is indicative of the dose range it does not yield information about dose distribution. It also tends to make the error appear too signiticant. To overcome this and also to get some idea about the dose distribution about, the mean, the coefficient of variation was determined. Since the coefficient is calculated using only 1 standard deviation; it tends to lessen the error; hence it too is limiting in its application.

In calculating the maximum/minimum ratios it was necessary to use the adjusted average since the average of each test was not the average of the maximum and minimum dose. The use of the adjusted average was justified because it approximated the average.

- The aluminum carrier was responsible for some attenuation and this accounts in part for the higher dose at the top of the carrier.

The data accumulated were not sufficient to determine the attenuation effects of the dummy loads. This is not too important because in quadrant irradiation most absorption is via direct radiation when the carrier is in the dwell position. The angular radiation is slight because of the position and size of the carrier in relation to the source plaque.

The linear relationship between dose and time will make it possible to establish dose rates. Based on the average of $9.86 \mathrm{krad} /$ minute the time required to irradiate fruits and vegetables with 200 Krad is calculated using this formula:

$$
\begin{aligned}
\text { Total time in } & =\frac{\text { Desired dose }}{\text { Dose } / \mathrm{minute}} \\
20.28 & =\frac{200 \mathrm{Krad}}{9.86 \mathrm{Krad} / \mathrm{minute}}
\end{aligned}
$$

I'o calculate dwel.l time using the average ot 2.37 minutes for motion time use this formula: 
[We]l. time $=\frac{\text { Total time in radiation field-motion time }}{8 \text { (dwell positions) }}$

2.23 min. $=\frac{20.28-2.37}{8}$

To calculate the minimum dose possible use this formula:

Minimum dose possible $=$ dose/minute (Jow dose) $\times$ motion time

$9.21 \mathrm{Krad}=3.89 \mathrm{Krad} /$ minute $\times 2.37$ minutes 


\section{LITERATURE CITED}

1. Desrosier, N. W. and H. M. Rosenstock: 1960. Radiation technology in food, agriculture and biology. The Avi Publishing Company, Inc., Westport, Connecticut, pp. 401.

2. Personal communication between Mr. H. L. Rae, Pomology Department, University of California, Davis, and Dr. Robert Jarrett, Dosimetry Section, Radiation Laboratory, Quartermaster Research and Engineering Center, Natick; Massachusetts.

3. Romani, R. J., Betty J. Robinson; H. L. Rae, E. C. Maxie, and N. F. Sommer. 1963. Fruit irradiation - physical methods. Rad. Bot. 3:345-350. 


\section{GAMMA RADIATION AND HEAT FOR THERAPEUTIC TREATMENT OF FRUITS AND VEGETABLES FOR POSTHARVEST DISEASES}

N. F. Sommer, E. C. Maxie, Patricia M. Buckley, and F. G. Mitche'll

\section{INTRODUCTION}

Until the world's burgeoning population is stabilized, world food production and distribution must make great technical advances if massive disasters are to be avoided. Unhappily, important quantities of harvested food are lost through spoilage. Even in technically advanced countries, spoilage of harvested fruits and vegetables during distribution and marketing may average $15 \%$ or more $(1,2)$. Marketing losses would undoubtedly be even greater if extreme spoilage hazards were not often anticipated and the commodity diverted to other processing channels, usually less desirable. Impending losses prevent orderly marketing, requiring distress sales and the-transfer of the loss to unwary consumers.

Fresh fruits and vegetables deteriorate from physical, physiological, or pathological causes. Physical damage during harvest, handling, and transit is reduced only through care and protective packaging. Water loss, resulting in wilting or shriveling, is combatted by reducing the vapor pressure deficit by refrigeration, by providing moisture barriers in packaging materials, or by adding moisture to increase the humidity of the surrounding air. Physiological deterioration - tissue ripening or aging - results from natural metabolic processes which can be slowed, though not stopped, by refrigeration. Lowering the temperature by $10^{\circ} \mathrm{C}$ otten slows respiration to half. Ideally, harvested commodities should be maintained at just above their freezing point. Unfortunately, some commodities are injured by holding at: temperatures considerably above that ideal temperature. For example, bananas die and turn black if held at temperatures be low about $14^{\circ} \mathrm{C}$; tomatoes and honeydew melons are 
made susceptihle to rot organisms if stored at $7^{\circ} \mathrm{C}$ or below for more than a few days.

Refrigeration is an all-important factor in the postharvest pathology of most commodities. At the temperatures commonly employed in storage and transit, many postharvest disease organisms stop growth completely. With notable exceptions (3), pathogens are not killed by low temperatures, their growth is only slowed or stopped. If the pathogen is removed from refrigeration, pathogen growth and rotting resume. The effectiveness of refrigeration is limited by: 1 ) the need, in some cases, to remove the commodities from refrigeration to complete ripening; 2) an inability to use the lowest temperatures, because the commodity, is susceptible to chilling injury; and 3 ) the ability of a few important postharvest pathogens to grow at temperatures below the freezing points of fruits and vegetables.

\section{ETIOLOGY OF POSTHARVEST DISEASES}

Choice of the best measures to employ and the degree of control obtained are influenced greatly by the mode, time, and circumstances of infection. Every disease must be considered separately - with regard to how the pathogen gains entrance to the host; at what time infection occurs during growth, maturation, distribution, or marketing; and the relation of disease development to postharvest environmental conditions.

\section{A. TYPES OF INFECTIONS}

Plants and plant parts have a barrier consisting of an epidermis covered with a protective cuticle. This mechanical barrier, along with the biochemical resistance of the host, excludes a.lmost all potential pathogens among bacteria and fungi. Only a few are able to breach the defenses of the plant. 


\section{Direct Infection}

Spores of a few fungus species are capable of penetrating the unbroken host cuticle. Upon germinating on the surface of the host, a fine infection hypha is produced by the germ tube. By physical pressure and enzymatic action, access is gained to : the interior, where colonization occurs. Sometimes penetration is made easier by preferential entrance via stomata or lenticels. If the infection remains quiescent until the fruit starts to. ripen, the extent of the disease problem may be unknown until after harvest.

\section{Contact Infection}

Vegetative mycelium of some pathogens are capable of penetrating the intact surface of the host. Contact infections are common when susceptible plant parts are in contact with soil containing the growing mycelium. In containers after harvest, the hyphae of some fungi are able to grow from rotting to healthy host individuals, causing "nesting."

\section{Insect Inoculation}

The vinegar fly, Drosophila melanogaster Meig., inoculates fruits with spores of postharvest pathogens during the act of ovipositing (4). Presumably, other small animals also spread. disease during feeding or ovipositing. Infection by this means would appear to be greatest when insects are attracted to ripening truit.

4. Wounds

Often the only means of gaining entry into the host is through wounds. During harvesting, vascular elements are broken and severed. Negative pressure may draw cells or spores of pathogens into xylem vessels. The broken or cut surface is 
exposed to contamination. Accidental cuts or punctures may be contaminated at the time of wounding or later. If bruising of tissue is associated with the cuts and punctures, biochemical resistance to invasion may be reduced. On the other hand, wounds may lose their susceptibility to infection as time passes: Natural healing processes (i.e. suberization, periderm formation) or desiccation reduce infectability.

\section{B. DISEASES INITLATED DURING GROWTH AND DEVELOPMENT}

Some of the most troublesome postharvest diseases start in the field or orchard before harvest. Ideally, protective fungicides in the field or orchard would prevent onset of the disease, but even the best preharvest control. measures are often inadequate or of only limited usefulness. For example, Botrytis cinerea Pers., which causes the very important gray mold disease of strawberry fruits; commonly infects at the time of blossoming (5). The nature of flowering in the strawberrý makes control by blossom sprays difficult. From infections established in senescing floral parts, the fungus grows into the base of the receptacle. Growth may be slow until the berry starts to ripen. Since the lesion may be entirely internal, pickers are unable to discriminate at time of harvest. The fungus is capable of growth at temperatures that would freeze the fruit. Consequently, disease development continues, though more slowly; during low-temperature storage and transport. By contact infection and "nesting," a large fraction of the bcrries may be destroyed prior to marketing.

Brown rot disease of the fruits of Prunus species, such as the peach, is an important example of a disease which originates in the orchard. Caused by Monilia sp. (in part Monilinia fructicola (Wint.) Honey), some infrctions occur while fruits are immature. Commonly they remain quiescent until the fruit starts to ripen (Australian work). Additional infections often occur in the orchard near time of harvest. Then, during harvest, wound's become contaminated with conidia 
of the fungus. Whenever temperatures permit, rotting occurs and contact infections result in nesting within containers. Good temperature management during refrigerated transit and storage prevents disease development. Losses may be large, however, when the fruits are removed from refrigeration to allow ripening.

A somewhat similar situation exists with the fungus Sclerotinia sclerotiorum (Lib.) Mass., cause of the watery soft rot disease, particularly common as a postharvest disease of vegetables.. Apothecia appear in the rield during the spring and forcibly eject spores into the air, initiating the disease when the spores land on a susceptible plant. A second means of field infection is sclerotia in the soil: Under humid conditions they germinate, and mycelium may attack commodities in contact with the soil. Control in the field by flooding or chemicals has given only partial control. If lesions are small, diseased commodities cannot be sorted out. Within containers, disease spread by contact proceeds rapidly if temperatures are favorable to disease development. Similarly, species of Pythium and Phytophthora in the soil infect a wide range of hosts, otten by contact infection of the commodity resting on the ground. Spread by contact infection may continue after harvest.

\section{DISEASES INITIATED AT HARVEST}

Many diseases are almost strictly postharvest, with little or no infection occurring during growth and development. Commonly, infections occur almost entirely as a consequence of the contamination of wounds made when the commodity is handled, during and after harvest. These "wound parasites" may, or may not, be capable of contact infections and "nesting" after harvest. Included in this group of pathngens are some responsible for severe losses. For example, Penicillium digitatum Sacc. and $\underline{P}$. italicum Weh. cause the familiar green and blue molds of ritrus fruits. They are evidently strictly "wound parasites," yet they may destroy more fruits than all other organisins. Losses are increased by the ability ot $\underline{P}$. italicum to spread by contact. 
In this class also is the Rhizopus soft rot disease of a wide range of fruit and vegetable hosts. The causal organisms, Rhizopus stolonifer (Ehr. ex Fr.) Lind. and related species, are primarily "wound parasites," but contact infection also readily occurs, with rank mycelial growth readily penetrating the uninjured surface of adjacent hosts. Diseases associated with wounds are commonly incited by species of Alternaria, Aspergillus, Cladosporium, and Stemphilium. In the same category is the very destructive bacterial soft rot disease of vegetables, caused by Erwinia caratovora (Jones) Holland and related species.

\section{POSTHARVEST TREATMENTS}

Postharvest fungicidal treatments may be ajmed: 1) at established infections resulting from inadequate preventive measures in the field or orchard; 2) at contaminated wounds inflicted during and after harvest; or 3 ) at spread by contact after harvest.

\section{A. POSTHARVEST CHEMICAL TREATMENTS}

If disease lesions are present at harvest, known fungicides are inadequate. Such infections are within tissues and cannot be reached by the chemicals. On the other hand, chemicals can often very effectively control diseases associated with wonds if treatment precedes spore germination and penetration of tissue by young hyphae. Even here, however, there may be difficulty in achieving the control desired. It may be impossible to get fungicidal solutions inte deep wounds. Some commodities are difficult to wet, because ol trichomes or a waxy surtace. As a consequence, air bubbles may prevent contact of the spore with the liquid. Anolngous problems of coverage exist with fasenus fungicides. Contact infections and "nesting" have sometimes been effectively prevented by restrict ing the disease to the infected individuals. Tissue-paper wraps impregnated with chemicals 
have been used widely for this purpose. Prolonged fumigation within packages, or chemical residues on the host surface, may restrict. growth of aerial hyphae, preventing contact infection. The status of research on the use of chemicals as postharvest treatments has been reviewed by Eckert (6). At present there is no reason to be encouraged about the possibilities of chemical fungicides as therapeutic treatments.

\section{B. POSTHARVEST PHYSICAL TREATMENTS}

The benefits of an effective postharvest therapeutic treatment would be great with diseases which start in the field or orchard and defy preharvest preventive measures. Needed are fungicidal or bactericidal agents which readily penetrate living tissue and inactivate the pathogen. Thus, the pathogen would have to be severely altered by treatments which do not damage the host. That such selective inactivation is frequently possible is evidently aided by the fact that, at harvest, many fruits and vegetables are no longer growing. Frequently, in fact; the tissue is senescent. The response to insult is frequentily mild in senescent tissues compared to pre-senescing tissue. The pathogen, since it is actively growing, is drastically affected by events affecting growth or division processes. Of cidal agents capable of penetration and exerting their effect within host tissue, two are available: heat and ionizing radiation.

\section{Heat Treatments}

The knowledge that heat could be used to kill micro-organisms developed as a result of discovery of the canning process and pure-culture methods for studying micro-organisms. As a therapeutic fungicidal treatment, heat was used to control loose smut in cereal secl by 1888 (7). In the early 1920's in California, citrus packers started using hot water to improve the effectiveness of a detergent wash used for cleaning fruit. 
Evidently by accident it was discovered that heating could inactivate lesions of the citrus brown rot disease caused by Phytophthora sp. (8). Heat has been used commercialiy to control Colletotrichum gloeosporioides Penz., the cause of anthracnose: of papaya fruits $(9,10)$, and it has been suggested for the same disease of mango fruits $(11,12)$. In the United States, limited commercial use has recently been made of hotwater treatment to cotrol brown rot of peach fruits, caused by Monilinia fructicola (wint.) Honey, as a consequence of the research of Smith (13). Control of gray mold rot of strawberry fruits, caused by Botrytis cinerea, is suggested by results of tests with humidified hot air, reported by Couey (14).

\section{Radiation Treatments}

The bactericidal effects of irradiation have been known since 1898, when Rieder (17) studied the effects of X-rays on bacteria. The possibility of using ionizing radiation for disease control was suggested by studies of the treatment of dermatophytoses $(18,19,20,21)$. Demonstrations that parasites could be killed selectively in host tissues suggested the use of irradiation to eliminate fungi causing seed-borne diseases. After early encouraging reports (22) it was determined that: radiation doses sufficient to kill fungi in seeds would injure embryos (23). Later investigations $(24,25,26,27)$ have confirmed that radiation for disease control is unpromising for therapy of plants or plant parts destined for later growth. Fividently ruled out are seed grains and propagules such as bulbs, lubers, and cuttings. Much more promising subjects for irradiation are plant parts destined for consumption. Although the commodities are still alive, cell division has often virtually ceased. In wher cases, coll division may orcur after harvest but abnormal or reduced grnwth from irradiation may not be objectionable. 
Where growth effects can be ignored, relatively high doses can frequently be tolerated by the host (28). It has become abundantly clear, however, that, despite many early extravagant reports to the contrary, most fruits and vegetables will not tolerate the irradiation doses needed for disease control: One of the most likely exceptions appears to be the strawberry. In California, conditions are especially favorable to the ise: of radiation for postharvest disease control. Because of the climate, plants may bear fruit for about 8 months, thereby providing a resonable period for operation of a radiation source. Fruits are commonly shipped $5,000 \mathrm{kil}$. by rail or $10,000 \mathrm{kil}$. by air, which involves sufficient time for considerable disease development. Important losses can be avoided by a delay in disease development of only a few days. The commodity is of relatively high value. Prevention of even modest losses would likely pay treatment costs. After a dose of $200 \mathrm{Krad}$, disease development and contact infection by $\underline{B}$. cinerea in refrigerated transport is delayed by 5 days or more. The other important pathogen of: strawberries, Rhizopus stolonifer, does not develop at temperatures below about $5^{\circ} \mathrm{C}$.

other commodities showing promise for disease control by irradiation include: sweet cherries, peaches, and nectarines for control of Monilinia fructicola; figs for control of internal. rots caused by Aspergillus niger and Fusarium moniliniaforme; and tomatoes for control of Alternaria tenuis and Rhizopus stolonifer.

In order to increase the utiljty of irradiation as a postharvest fungicidal treatment, considerable research effort has been expended in an attempt to jncrease the effectiveness of irradiation, decrease host damage, or both. Shallow irradiation has been suggesterd as one means of reducing host damage. With diseases in which the lesions are near the surface, a fungicidal 
radiation dose applied to a depth of $2 \mathrm{~mm}$ or so might be nearly as effective as complete penetration. With limited penetration the energy absorbed per fruit would be relatively small and host: injury might be minimized. Such a treatment would be entirely ineffective if lesions were deep within the fruit. Problems of obtaining a uniform dose distribution appear formidable.

The presence of oxygen increases the biological response to irradiation. There appears to be no way, however, that this effect can be used to advantage for improving the fungicidal treatment.

\section{Combined Treatments}

Certain chemicals are known to sensitize micro-organisms to irradiation. With established lesions, however, it is doubtful that the chemical could be brought into contact with the pathogen. It is unlikely, therefore, that chemicals can be used to achieve a synergistic interaction with irradiation.. Even in the unlikely event that effective penetration of the chemical into host tissues could be achieved, many chemical sensitizers could not be used, because of health problems.

Heat has shown promise of greatly improving the effectiveness of irradiation. The possibility of using heat in combination with radiation was suggested by the results of investigations. with bacteria which demonstrated an effect much greater than additive. Whether heat sensitized the bacteria to radiation more than irradiation sensitized the bacteria to heat has evidently depended on the species studied. Morgan and Reed (29) and Kempe (30) found that ionizing radiation sensitized: bacteria to heat while preheating had no effect on inactivation by irradiation. The combined effect of the latter sequence of treatments was strictly additive. Different results were ohtained by Huber et al. (31), Kan et al. (32), and Duggan 
et al. (33), who observed that preheating sensitized bacteria to radiation.

In studies with the yeast Saccharomyces cerevisiae Meyer ex Hansen, Wood (34), showed that inactivation was greatest when heat and radiation were applied simultaneously. With the same species, Stehlik and Kaindl (35) confirmed the advantage of simultaneous treatment in studies of the kinetics of inactivation by heat-radiation treatments.

The effects of heat and radiation on spores of a number of fungus postharvest pathogens have been studied (36). With

R. stolonifer, radiation sensitized to heat more than heat sensitized to radiation. Results were opposite with $\underline{M}$. fructicola, $\underline{P}$. expansum, Botrytis cinerea, and Cladosporium herbarum. 'In tests with Botrytis cinerea (Sommer - Unpublished) the advantage of simultaneous heat and. radiation was small if irradiation was started almost immediately after completion of the heat treatment.

In tests with fungus fruit pathogens, spores that have started to germinate have been shown to be noticeably more sensitive to irradiation even it no germ tubes have yet appeared (Sommer. Unpublished). Possibly this is a consequence of the marked susceptibility to inactivation observed if cells are irradiated at certain stages of nuclear division. Increased hydration and a higher metabolic rate may also contribute to increased susceptibility. A similar increase in susceptibility to heat is noted after the initiation of germination. For example, with $\underline{R}$. stolonifer, $49^{\circ} \mathrm{C}$ for 4 minutes will reduce the population of freshly harvested sporangiospores by about $50 \%$. A temperature of only $39^{\circ} \mathrm{C}$, however, has an equal effect if spores are treated after half of them exhibit the initial stages of germ tube protrusion. 


\section{SUMMARY AND CONCLUSIONS}

The synergistic interaction between heat and radiation has been demonstrated to greatly improve the effectiveness and utility of therapeutic furgicidal treatments." Fungicidal activity can be increased without noticeable added host damage: The likelihood exists, therefore, that commoditjes once considered too sensitive for radiation can tolerate combined treatments since the radiation dose can be reduced. The sensitivity to heat, as to radiation, varies widely among hosts and pathogens. Evidently the best combined treatments must be determined for the various host-pathogen combinations to be treated. 


\section{LITERATURE CITED}

1. Annon. 1965. Losses in Agriculture. Agri. Handbook No. 291. U. S. Dept. Agri., Washington, 120 pp.

2. Wiant, J.S. and C. 0. Bratley. 1948. Spoilage of fresh fruits and vegetables in rail shipments unloaded in New York City 1935-1942. U. S. Dept. Agri., Washington, 62 pp.

3. Matsumoto, T. T. and N. F. Sommer. 1967. Sensitivity of Rhizopus stoloniter to chilling. Phytopath. (In press).

4. Butler, E. E. and C. E. Bracker. 1963. The role of Drosophila melanogaster in the epiphytology of Geotrichum, Rhizopus, and other fruit rots of tomato. Phytopath. 53:1016-1020.

5. Powelson, R. F. 1960. Initiation of strawberry fruit rot caused by Botrytis cinerea.' Phytopath. 50:491.

6. Eckert, J. W. 1967. Application and use of post-harvest fungicides. In Fungicides--An Advanced Treatise. (D. C. Torgeson, Ed.) 1:(In press).

7. Jensen, J. L. 1888. The propagation and prevention of smut in oats and barley. J. Roy. Soc., England, 24:397-415.

8. Fawcett, H. S. 1922. Packinghouse control of brown rot. Calif. Citrog. $\%: 232,254$.

9. Arisumi, T. Test shipments of papayas. Hawaii Agri. Expt. Sta: Tech. Bul. 29, 16 p.p.

10. Akamine, E. K. and T. Arisumi. 1953. Control of postharvest storage of truits and papaya (Carica papaya L.) with special reference to the effect of hot water. Amer. Soc. Hort. Sci. Proc. 01:270-27і.

1.1. Smoot, J. J. and R. H. Segall. 1963. Hot water as a postharvest control of mango anthracnose. P1. Dis. Rptr. 4\%:739-742. 
12. Pennock, W. and G. Maldonaldo. 1962. Hot water treatment of mango fruits to reduce anthracnose decay. J. Agri. Univ. Puertó Rico $46: 272-283$.

13. Smith, J. L., Jr. 1962. Reduction of postharvest brown rot and Rhizopus decay of eastern peaches with họ water. Pl. Dis. Rptr. $46: 861-865$.

14. Couey, H. M. and M. N. Follstad. 1966. Heat pasteurization for control of postharvest decay, in fresh strawberries. Phytopath. $56: 1345-1347$.

15. Smoot, J. J. and C. F. Melvin. 1963. Hot water as a control for decay of oranges. Proc. Fla. Sta. Hort. Soc. 76:322-327.

16. Burchill; R. T. 1964. Hot water as a possible post-harvest control of Gleoesporium rots of stored apples. P1. Path. 13:106-107.

17. Rieder, H. 1898. Wirkung der Röntgen Strahlen aut Bakterịen. Münch. med. Wochsch. 45:101-104. :

18. Jüngling, 0. 1.919. Zur Rontgenbehandlung der Aktinomykose. Bruns' Beitr. klin. Chir. 118:105-125.

19. Levy, R. 1913. Rontgenbestrahlung der Aktinomykose. Centr. Chirur. $40: 12.1-122$.

20. Melchnir, E. 1916. Kinische Erfahrung über kombinierte JodRöntgentherapie der cervico-facialen Aktinomykose. Ber. klin. Wochschr. $53: 586-588$.

2.l. Sardemann, l.. 1914. Ueber die Behandlung der Aktinomykose mit Röntgenstrah]en. Bruns' Beitr: klin. Chir. 90:15\%-167.

22. Pichler, $\Gamma$. and $\Lambda$. Wober. 1922. Brstrahlungsversuche mit: ul traviolettem Licht. Rontigestrahlen und Radium zur Bekampfung von Pflanzenkrankhis jen Centr. Baktérinl. Abt. 2, $57: 319-327$. 
23. Tascher, W. R. 1933. Experiments on the control of seed-borne diseases by X-rays. J. Agr. Res. 46:909-915.

24. Dimond, A: E. 1951. Continuous gamma radiation suppresses crown-gall formation in tomatoes. (Abst.) Phytopath. 11:10-11.

25. Waggoner, P. E. 1956. Altering disesse resistance with ionizing radiation. Phytopath. 46:125-127.

26. Waggoner, P. E. and A. E. Dimond. 1952. Crown gall suppression by ionizing radiation. Amer: J. Bot. 39:679-684.

27. Lo, T. C. 1964. Control of seed borne diseases by radioactive irradiation. Botan. Bull. Acad. Sinica 5:1-16.

28. Sommer, N. F. and R. J. Fortlage. 1967. Ionizing radiation for control of postharvest diseases of fruits and vegetables. Adv. Food Res. $15: 147-184$.

29. Morgan, B. H. and J. H. Reed. 1964. Resistance of bacterial spores to gamma irradiation. Food Res. 19:357-366.

30. Kempe, L. L. 1955. Combined effects of heat and radiation in food sterilization. Appl. Microbiol. 3:346-352.

31. Huber, w., A. Brasch, and A. Waly. 1953. Effects of processing conditions on organoleptic changes in foodstuffs sterilized with high intensity electrons. Food Techn. 7:109-115.

32. Kan, B., S. A. Goldblith, and B. E. Proctor. 1957. Complementary effects of heat and ionizing radiation. Food Res. 22:509-518.

33. Duggan, D. F., A. W. Anderson, and P. R. Elliker. 1963.

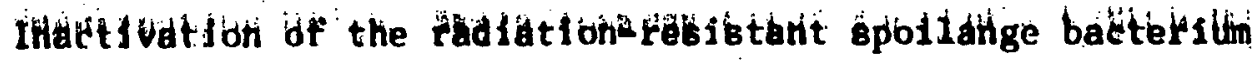
Micrococcus radiodurans. Radiation inactivation rates as influenced by menst ruum temperature, preirradiation heat treatment, and certain reducing agents. Appl. Microbiol. $11: 413-417$. 
34. Wood, T. H. 1954. Intluence of temperature and phase state on $X$-ray sensitivity of yeast. Arch. Biochem. Biophys. 52:157174.

35. Stehlik, G. and K. Kaindl. Food Irradiation." Int. Atomic Energy Agency, Vienna, 229-305 pp.

36. Sommer, N. F., R. J. Fortlage, Patricia Buckley, and E. C. Maxie. 1967. Radiation-heat synèrgism for inactivation of market disease tungi of stone fruits. Phytopath. 57:428-433. 
